\author{
Universidade de São Paulo \\ Faculdade de Odontologia de Bauru \\ Departamento de Fonoaudiologia
}

GRAZIELLA SIMEÃO MUNHOZ

\title{
Proposta de Programa de Prevenção de Perdas Auditivas para Músicos
}

BAURU

2016 
GRAZIELLA SIMEÃO MUNHOZ

\title{
Proposta de programa de prevenção de perdas auditivas para músicos
}

\author{
Dissertação apresentada à Faculdade de \\ Odontologia de Bauru da Universidade de \\ São Paulo para obtenção do título de \\ Mestre em Ciências no Programa de \\ Fonoaudiologia.

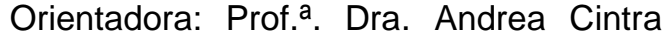 \\ Lopes.
}

Versão corrigida 
Munhoz, Graziella Simeão

M925p Proposta de programa de prevenção de perdas auditivas para músicos / Graziella Simeão Munhoz - Bauru, 2016.

160 p.: il.; $31 \mathrm{~cm}$.

Dissertação (Mestrado) - Faculdade de Odontologia de

Bauru. Universidade de São Paulo

Orientador: Prof. Dra. Andréa Cintra Lopes

Nota: A versão original desta dissertação/tese encontra-se disponível no Serviço de Biblioteca e Documentação da Faculdade de Odontologia de Bauru - FOB/USP.

Autorizo, exclusivamente para fins acadêmicos e científicos, a reprodução total ou parcial desta dissertação/tese, por processos fotocopiadores e outros meios eletrônicos.

Assinatura:

Data:

Comitê de Ética da FOB-USP

Protocolo $\mathrm{n}^{\circ}$ :

30315914.7.0000.5417

Data: 30/04/2014 


\section{DEDICATÓRIA}

Dedico este trabalho primeiramente a Deus e a Nossa Senhora por me darem a oportunidade de ter vivido tantos momentos e por me amarem como me amam; aos meus pais por sempre me apoiarem e incentivarem a perseguir meus objetivos e sonhos, pois são vocês o meu porto seguro e exemplos que desejo seguir; as minhas irmãs que estiveram presentes em todos os momentos da minha via; a minha avó que estimo com tanto amor e carinho; a minha tia Valéria que participa e torce pela minha vitória mesmo que a distância e ao meu namorado que não mediu esforços para caminhar ao meu lado e me envolver em seus braços todas as vezes que precisei e naqueles que não precisei também, pela nossa cumplicidade e amizade que foram essenciais. 


\section{AGRADECIMENTOS}

A minha mãezinha que me protege, ilumina e guia Nossa Senhora, quem eu chamo com tanto carinho e amor, a meu pai e senhor Deus e a Jesus Cristo que me ensinou o que é o amor, a tríade que me deu a vida por duas vezes para que fizesse de mim o seu instrumento.

Aos meus heróis quem chamo de pai e mãe, Ismael e Silvana, às minhas irmãs Lilian e Gabriella, pela paciência, compreensão, amor, respeito e confiança.

Ao meu confidente, amigo e namorado, Cláudio, por todo companheirismo que tivemos. Pelo carinho, paciência, dedicação, compreensão e amor, por me fazer feliz e ser presente em minha vida em todos os momentos.

Às minhas avós Irene, Carolina e ao meu avô, Virgílio (in memoriam) que com todo seu amor, zelo, carinho e sabedoria guiaram meus passos e me fizeram presentes em suas orações, os quais amo tanto.

Às minhas amigas Gabriela Ap. Prearo, Maiara Ap. B. Giacomelli, Mahyara F. Jacob, Camilla Guarnieri, Bruna Antonini, Isabelle Maturana e Luzinete Carvalho por compartilharmos momentos bons e ruins de um relacionamento, mas incluindo os surtos que envolvem época do dissertar. Obrigada pela amizade maravilhosa e por me proporcionarem o prazer da companhia de vocês.

À minha amada tia Valéria, que mesmo distante sempre esteve ao meu lado, me incentivando, preocupando-se, apoiando e orientando. Compartilhamos de tantas histórias, conversas, risos, choros, amizade, compreensão, tolerância e experiências. Obrigada por sempre cuidar de mim e amar como se eu fosse sua filha.

À minha orientadora, professora e amiga Prof. Dra. Andrea, pelo carinho, apoio, paciência, confiança, dedicação, pela oportunidade de me ensinar, pela honra de conhecê-la e por me deixar compartilhar de seus conhecimentos e sabedoria. A pessoa que me ensinou a amar a Audiologia.

À Clínica de Fonoaudiologia da Faculdade de Odontologia de Bauru, ao Órgão de Fomento CAPES, que me auxiliou financeiramente na concessão da bolsa de mestrado proporcionando-me novos ensinamentos acadêmicos. 
Às funcionárias da Clínica de Fonoaudiologia e fonoaudiólogas Dra. Josilene Luciene Duarte e Dra. Raquel Sampaio Agostinho Pesse, pelos ensinamentos, paciência, confiança, respeito e companheirismo.

Agradeço ao Prof. Dr. João Cândido Fernandes, à Profa. Dra. Kelly Cristina Alves Silvério e ao Prof. Dr. Heitor Marques Honório, pela ajuda, carinho e prontidão.

Ao otorrinolaringologista Dr. Eduardo Carvalho de Andrade, pela dedicação e prontidão no atendimento aos sujeitos que apresentaram cerúmen, para que os exames audiológicos fossem realizados com sucesso.

A todos os músicos que participaram do trabalho, minha eterna gratidão, pois sem a colaboração deles nada teria sido possível.

À Profa. Dra. Deborah Viviane Ferrari, Profa. Dra. Kátya Guglielmi Marcondes Freire, Profa. Dra. Valdéia Vieira de Oliveira, Profa. Dra. Ana Cláudia Vieira Cardoso, por aceitarem compor a banca e por toda a contribuição e conhecimento. Agradeço também à Profa. Dra. Natália Barreto Frederigue Lopes, Profa. Dra. Wanderléia Quinhoneiro Blasca, Profa. Dra. Alessandra Giannella Samelli, Profa. Dra. Ana Cláudia Fiorini, Profa. Dra. Silvia Helena Alvarez PiazentinPenna e ao Prof. Dr. Carlos Henrique Ferreira Martins por aceitarem prontamente compor a banca como suplentes caso fosse necessário.

Em especial agradeço a empresa $\mathbf{3} \mathbf{M}$ pela parceria, confiança e credibilidade dedicados ao nosso trabalho, além da doação dos EPIs aos músicos participantes deste trabalho que foram de suma importância para concretização do mesmo. 
A tarefa não é tanto ver aquilo que ninguém viu, mas pensar o que ninguém ainda pensou sobre aquilo que todo mundo vê. 


\section{RESUMO}

INTRODUÇÃO: A audição é um dos sentidos mais importantes para o ser humano, e seu funcionamento está interligado à sua produtividade, o que não é diferente aos músicos, já que ela é de suma importância para a qualidade de seu trabalho e permanência na carreira. $O$ desenvolvimento de um programa de prevenção de perdas auditivas tem por objetivo modificar o comportamento dos músicos em relação à sua audição, uma vez que, constantemente, estão expostos a níveis de pressão sonora elevados e ao surgimento de lesões irreversíveis. Contudo, se medidas preventivas não forem realizadas corretamente, as exposições dos músicos frente à intensidade sonora elevada podem trazer prejuízos à saúde e alguns destes, irreversíveis como, a Perda Auditiva Induzida por Níveis de Pressão Sonora Elevados (PAINPSE) ou Perda Auditiva Induzida por Música (PAIM). OBJETIVO GERAL: submeter os músicos ao programa de prevenção de perdas auditivas (PPPA) e verificar sua eficácia. MATERIAL E MÉTODOS: Participaram componentes de quatro bandas musicais, correspondendo a um total de 16 participantes. Esses membros foram submetidos ao Programa de Prevenção de Perdas Auditivas (PPPA) que engloba as seguintes etapas: (1) medição do nível de pressão sonora no ensaio e show; (2) entrevista específica, Audiometria Tonal Liminar e de Altas Frequências, Logoaudiometria, Imitanciometria e Emissões Otoacústicas por estímulo Transientes e Produto de Distorção; (3) orientação sobre a utilização do Equipamento de Proteção Individual (EPI); e (4) a realização de medidas educativas por meio de workshops. RESULTADOS: O Nível de Pressão Sonora (NPS) durante os ensaios e apresentações/shows, encontram-se elevados, sintomas não auditivos estão presentes em $68,75 \%$ da população total da amostra, presença de zumbido após o show em 100\% da amostra; maiores dificuldades de compreensão de fala no ruído nos músicos que tocam baixo $(75 \%)$. Ao traçar o perfil audiológico do músico foram encontrados: maiores médias dos limiares audiológicos por frequência das bandas estudadas em $500 \mathrm{~Hz}$ e $3 \mathrm{KHz}$ (B1), $3 \mathrm{KHz}$ e $4 \mathrm{KHz}$ (B2), $3 \mathrm{KHz}, 4 \mathrm{KHz}$ e $6 \mathrm{KHz}$ (B3) e em $3 \mathrm{KHz}$ (B4); as maiores médias dos limiares audiológicos por frequência dos instrumentos estudados foram em $3 \mathrm{KHz}, 4 \mathrm{KHz}$ e $6 \mathrm{KHz}$ (voz), $3 \mathrm{KHz}$ e $4 \mathrm{KHz}$ (guitarra), $3 \mathrm{KHz}, 4 \mathrm{KHz}$ e $6 \mathrm{KHz}$ (baixo) e $3 \mathrm{KHz}, 4 \mathrm{KHz}$ (bateria); presença de entalhe nas frequências de $2 \mathrm{KHz}, 4 \mathrm{KHz}, 6 \mathrm{KHz}$ e $8 \mathrm{KHz}$ na audiometria tonal liminar; já na audiometria de altas frequências em todas as 
frequências apareceram ao menos um caso, reflexos ausentes em $4 \mathrm{KHz}$ (ipsilateral e contralateral); ausência de resposta em $4 \mathrm{KHz}$ para todos os baixistas bilateralmente (100\%) quando pesquisado EOE por estímulo transiente e na produto de distorção foram encontradas ausência de respostas em $50 \%$ da amostra na frequência de $6 \mathrm{KHz}$, sendo assim pesquisada a curva de crescimento ( $d p$ growth rate) aparecendo resposta em $75 \mathrm{~dB}$ em quase $100 \%$ dos casos em que houve necessidade de sua realização. Quanto aos achados obtidos da avaliação realizada pelos participantes (músicos) referente ao website, os resultados mostraram que o mesmo atende às necessidades propostas, ou seja, a promoção da saúde auditiva em músicos. CONCLUSÃO: Existe a necessidade de serem tomadas medidas preventivas e a inserção dos músicos em um Programa de Prevenção de Perdas Auditivas (PPPA) a fim de proporcioná-los maiores condições de qualidade de vida e em seu trabalho, já que necessitam da sua audição para desempenhar com eficácia suas atividades e se manter no mercado de trabalho atuando como músico.

Palavras-chave: perda auditiva; perda auditiva provocada por ruído; ruído ocupacional; música. 


\begin{abstract}
INTRODUCTION: Hearing is one of the most important senses for the human being, and its operation is interconnected to its productivity, which is no different to the musicians, since it is of the utmost importance for the quality of their work The development of a hearing loss prevention program, aims to modify the musicians behavior in relation to their hearing, once, constantly, are exposed to high sound pressure levels and the emergence of permanent injury. However, if preventives measures are not performed correctly, the exposures of the musicians facing the high sound intensity can bring losses to health and some of these, irreversible such as, Hearing Loss Induced by High Sound Pressure Levels (HLIHSPL) or Musicinduced hearing loss (MIHL) - Noise-Induced Hearing Loss (NIHL). GENERAL
\end{abstract} OBJECTIVE: submit the musicians to the Hearing Loss Prevention Program (HLPP) and verify its effectiveness. MATERIAL AND METHODS: participated components from four musical bands, corresponding to a total of 16 participants. These members were submitted to the Hearing Loss Prevention Program (PPPA) that include the following steps: (1) measurement of the sound pressure level at the rehearsal and concert; (2) specific interview, Pure Tone Audiometry and High Frequencies, Logoaudiometry, Imitanciometry and Distortion Product Evoked Otoacoustic Emissions (DPEOE); (3) guidance on the use of Personal Protective Equipment (PPE); and (4) the achievement of educational measures through workshops. RESULTS: The Sound Pressure Level (SPL) during the rehearsals and performances/shows are elevated, symptoms not auditory are presents in $68,75 \%$ of the total sample population, presence of tinnitus after the show in $100 \%$ of the sample; major difficulties of speech comprehension in the noise of the musicians who playing bass (75\%). When plotting the audiological profile of the musician were found: highest averages of audiological thresholds by frequency from the studied bands in $500 \mathrm{~Hz}$ and $3 \mathrm{KHz}(\mathrm{B} 1), 3 \mathrm{KHz}$ and $4 \mathrm{KHz}(\mathrm{B} 2), 3 \mathrm{KHz}, 4 \mathrm{KHz}$ and $6 \mathrm{KHz}(\mathrm{B} 3)$ and in $3 \mathrm{KHz}$ (B4); the major averages of audiological frequency thresholds of the studied instruments were in $3 \mathrm{KHz}, 4 \mathrm{KHz}$ and $6 \mathrm{KHz}$ (voice), $3 \mathrm{KHz}$ and $4 \mathrm{KHz}$ (electric guitar), $3 \mathrm{KHz}, 4 \mathrm{KHz}$ and $6 \mathrm{KHz}$ (bass) and $3 \mathrm{KHz}, 4 \mathrm{KHz}$ (drums); presence of notch in the frequencies of $2 \mathrm{KHz}, 4 \mathrm{KHz}, 6 \mathrm{KHz}$ and $8 \mathrm{kHz}$ in the pure tone audiometry; but in the high audiometry frequencies, in all frequencies appeared at least one case, missing reflexes in $4 \mathrm{KHz}$ (ipsilateral and contralateral); missing reply in $4 \mathrm{KHz}$ for all 
bassists bilaterally (100\%) when researched EOE by transient stimulus and in the distortion product were found missing responses in $50 \%$ of the frequency sample of $6 \mathrm{KHz}$, so researched the growth curve (dp growth rate) showing response in $75 \mathrm{~dB}$ at almost $100 \%$ of cases which there was need for its achievement. CONCLUSION: there is a need to take preventive measures and the insertion of the musicians in the Hearing Loss Prevention Program (HLPP) in order to provide them greater conditions of quality of life and in their work, since they need their hearing to play effectively their activities and stay in the labor market working as a musician.

Keywords: hearing loss; hearing loss caused by noise; noise occupational; music. 


\section{LISTA DE FIGURAS}

\begin{tabular}{|c|c|c|c|c|c|c|c|}
\hline $\begin{array}{l}\text { Figura } \\
\text { ensaio. }\end{array}$ & $1-$ & Disposição & dos & músicos & $\mathrm{da}$ & B1 & $\begin{array}{r}\text { durante } \\
\ldots \ldots . .75\end{array}$ \\
\hline $\begin{array}{l}\text { Figura } \\
\text { ensaio. }\end{array}$ & $2-$ & Disposição & dos & músicos & da & B2 & $\begin{array}{r}\text { durante } \\
\ldots \ldots . .75\end{array}$ \\
\hline $\begin{array}{l}\text { Figura } \\
\text { ensaio.. }\end{array}$ & $3-$ & Disposição & dos & músicos & $\mathrm{da}$ & B3 & $\begin{array}{r}\text { durante } \\
\ldots \ldots . .76\end{array}$ \\
\hline Figura & 4- & Disposição & dos & músicos & $\mathrm{da}$ & B4 & durante \\
\hline
\end{tabular}

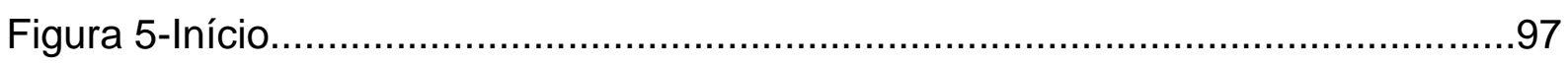

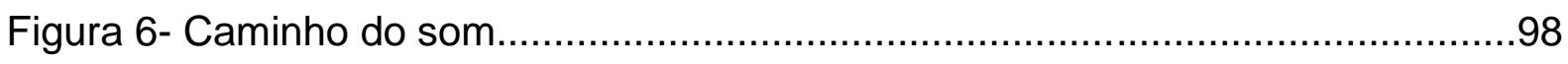

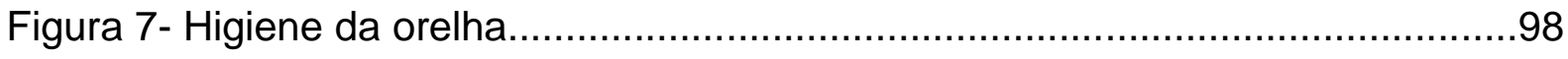

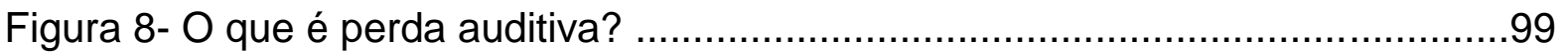

Figura 9- Perda Auditiva Induzida por Ruído (PAIR) .....................................100

Figura 10- Como prevenir.............................................................................

Figura 11- Tempo de exposição $x$ intensidade, segundo NR15 ..........................102

Figura 12- Atuação Fonoaudiológica............................................................103

Figura 13- Resultados obtidos na pesquisa...............................................104

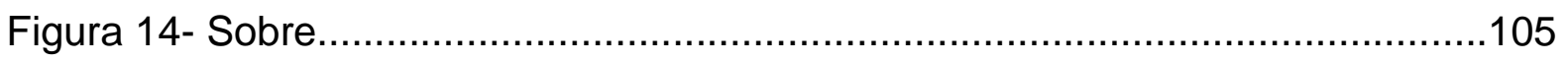

Figura 15- Formulário utilizado para decisão da data e período para o

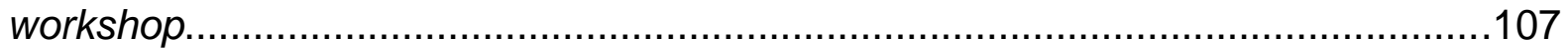

Figura 16- Planilha de resultados gerados pelo excel após envio de resposta do

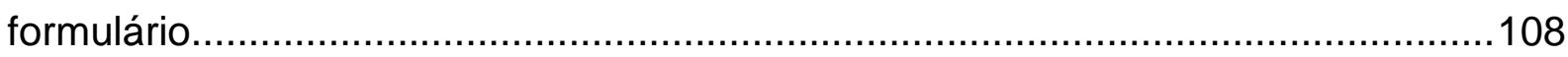

Figura 17- Questionário on line, referente a avaliação da efetividade do web site.125 


\section{LISTA DE TABELAS}

Quadro 1- Programas de conservação auditiva para

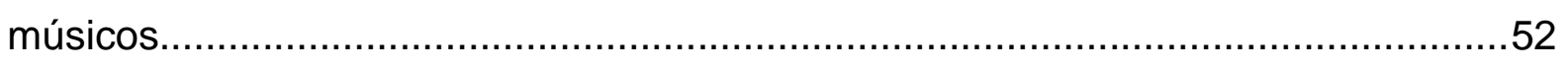

Tabela 1- Valores de corte para normalidade na audiometria de altas frequências em dB NA, por faixa etária, segundo Burguetti, Peloggia e Carvallo (2004)

Tabela 2- NR.15 Limites de tolerância x Tempo de exposição para ruídos contínuos ou intermitentes..

Tabela 3- NPS produzido pela banda durante ensaio e show.

Tabela 4- Lateralidade das orelhas a iniciarem a Audiometria tonal Liminar Convencional e de Alta Frequência. .83

Tabela 5- Lateralidade das orelhas a iniciarem a Logoaudiometria (SRT) .83

Tabela 6- Lateralidade das orelhas a iniciarem a Logoaudiometria (IRF) 84

Tabela 7- Média dos limiares por frequência de acordo com B1.... .85

Tabela 8- Média dos limiares por frequência de acordo com B2. .85

Tabela 9- Média dos limiares por frequência de acordo com B3. .85

Tabela 10- Média dos limiares por frequência de acordo com B4. .85

Tabela 11- Média dos limiares por frequência de acordo com o instrumento voz.

Tabela 12- Média dos limiares por frequência de acordo com o instrumento guitarra.

Tabela 13- Média dos limiares por frequência de acordo com o instrumento baixo.

Tabela 14- Média dos limiares por frequência de acordo com o instrumento bateria. .86

Tabela 15- Porcentagem de presença de entalhe por frequência de acordo com as bandas.

Tabela 16- Porcentagem de presença de entalhe por frequência de acordo com os instrumentos.

Tabela 17- Média dos limiares por frequência de acordo com B1 .87

Tabela 18- Média dos limiares por frequência de acordo com B2.

Tabela 19- Média dos limiares por frequência de acordo com B3.

Tabela 20- Média dos limiares por frequência de acordo com B4. 
Tabela 21- Média dos limiares por frequência de acordo com o instrumento voz.....88 Tabela 22- Média dos limiares por frequência de acordo com o instrumento guitarra...... .88

Tabela 23- Média dos limiares por frequência de acordo com o instrumento baixo. .88

Tabela 24- Média dos limiares por frequência de acordo com o instrumento bateria. 88

Tabela 25- Porcentagem de presença de entalhe por frequência de acordo com as bandas.

Tabela 26- Porcentagem de presença de entalhe por frequência de acordo com os instrumentos.

Tabela 27- Participantes e limiar de obtido do LRF e a porcentagem de acertos do IPRF

Tabela 28- Presença de resposta em porcentagem das Frequências das Emissões Otoacústicas Evocadas por estímulo transiente de acordo com cada banda analisada

Tabela 29- Presença de resposta em porcentagem das Frequências das Emissões Otoacústicas Evocadas por produto de distorção de acordo com cada banda analisada

Tabela 30- Presença em porcentagem das Frequências das Emissões Otoacústicas Evocadas por estímulo transiente de acordo com cada instrumento analisado .93

Tabela 31- Presença em porcentagem das Frequências das Emissões Otoacústicas Evocadas por estímulo transiente de acordo com cada instrumento analisado. .93

Tabela 32- Valores obtidos - Índice de Leitura Flesch 106 


\section{LISTA DE GRÁFICOS}

Gráfico 1- Lateralidade do zumbido x presença de zumbido nos componentes da banda .78

Gráfico 2- Caracterização da presença do zumbido por banda. .79

Gráfico 3- Tempo em horas de ensaio x presença de zumbido a toda hora. 80

Gráfico 4- Relação do instrumento voz (cantores) x presença de zumbido. 81

Gráfico 5- Comparação entre o músico que utiliza o instrumento baixo e a presença de dificuldades em entender a fala no ruído.

Gráfico 6- Comparação entre as bandas e ausência de reflexo (ipsi e/ ou contralateral)

Gráfico 7- Comparação entre os instrumentos, ausência e presença de reflexo (ipsi e/ ou contralateral) na frequência de $4 \mathrm{KHz}$

Gráfico 8- Comparação entre lateralidade e as frequências que foram pesquisadas a curva de crescimento (dp growth rate)

Gráfico 9- Relação entre as bandas e as frequências da curva de crescimento (dp growth rate)

Gráfico 10-Relação entre os instrumentos e as frequências da curva de crescimento (dp growth rate)

Gráfico 11- Distribuição da necessidade de ter realizado acompanhamento Fonoaudiológico por banda. 


\section{LISTA DE ABREVEATURAS E SIGLAS}

A.B.N.T.- Associação Brasileira de Normas Técnicas.

ABA- Academia Brasileira de Audiologia.

ABA- Academia Brasileira de Audiologia.

AT-AC - Audiometria tonal liminar convencional.

AT-AF - Audiometria tonal de altas frequências.

CBO- Classificação Brasileira de Ocupações.

CLT- Consolidação das Leis Trabalhistas.

CLT- Consolidação das Leis Trabalhistas.

dB (A)- Decibel nível de audição.

$\mathrm{dB}-$ Decibels.

EOA- Emissões Otoacústicas.

EOE- Emissões Otoacústicas Evocadas.

EOEpd- Emissões Otoacústicas Evocadas por Produto de Distorção.

EOEt- Emissões Otoacústicas Evocadas por estímulo transiente.

EPA- Environmental ProtectionAgency

EPI- Equipamento de Proteção Individual.

FUNDACENTRO- Fundação Jorge Duprat Figueiredo de Segurança e Medicina do

Trabalho.

Hz- Hertz.

IBGE - Instituto Brasileiro de Geografia e Estatística.

IPRF- Índice percentual de reconhecimento de fala.

LRT - Limiar de reconhecimento de fala.

MAE- Meato Acústico Externo.

MT- Ministério do Trabalho.

MUS002-n ${ }^{\circ}$ do RG fornecido para o participante da pesquisa.

MUS003- ${ }^{\circ}$ do RG fornecido para o participante da pesquisa.

MUS004- ${ }^{\circ}$ do RG fornecido para o participante da pesquisa.

MUS005- $n^{\circ}$ do RG fornecido para o participante da pesquisa.

MUS006- $n^{\circ}$ do RG fornecido para o participante da pesquisa.

MUS007-n ${ }^{\circ}$ do RG fornecido para o participante da pesquisa.

MUS010-n ${ }^{\circ}$ do RG fornecido para o participante da pesquisa.

MUS011-n ${ }^{\circ}$ do RG fornecido para o participante da pesquisa.

MUS012-n ${ }^{\circ}$ do RG fornecido para o participante da pesquisa.

MUS015- ${ }^{\circ}$ do RG fornecido para o participante da pesquisa.

MUS017- ${ }^{\circ}$ do RG fornecido para o participante da pesquisa.

MUS018- $n^{\circ}$ do RG fornecido para o participante da pesquisa.

MUS020-n ${ }^{\circ}$ do RG fornecido para o participante da pesquisa.

MUS021- ${ }^{\circ}$ do RG fornecido para o participante da pesquisa.

MUS022- ${ }^{\circ}$ do RG fornecido para o participante da pesquisa.

MUS023- ${ }^{\circ}$ do RG fornecido para o participante da pesquisa.

$\mathrm{NHO}$ - Norma de Higiene Ocupacional.

NIOSH- Instituto Nacional para Saúde e Segurança Ocupacional.

NPS - Nível de pressão sonora.

NPS- Nível de Pressão Sonora.

NR15- Norma regulamentadora 15.

OD- Orelha direita.

OE- Orelha esquerda. 
OMB- Ordem dos Músicos do Brasil.

OMS - Organização mundial da saúde.

ONU- Organização das Nações Unidas.

OSHA- OcupationalSafaty\& Health Administration.

PAIM- Perda auditiva induzida por música.

PAINPSE - Perda auditiva induzida por nível de pressão sonora elevado.

PAIR- Perda auditiva induzida por ruído.

PAIRO-Perda auditiva induzida por ruído ocupacional.

PAO-Perda auditiva ocupacional.

PART-Perda auditiva relacionada ao trabalho.

PCA- Programa de Conservação Auditiva.

PPPA- Programa de Prevenção de Perdas Auditivas.

TCLE- Termo de Consentimento Livre e Esclarecido.

TTS- TemporaryThreshold Shift. 


\section{SUMÁRIO}

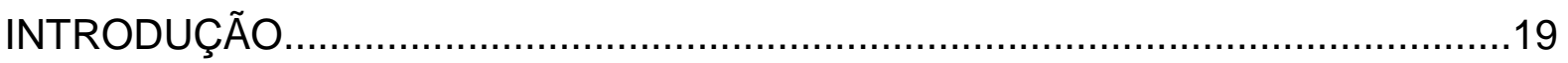

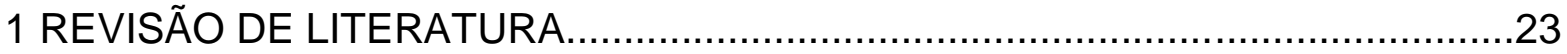

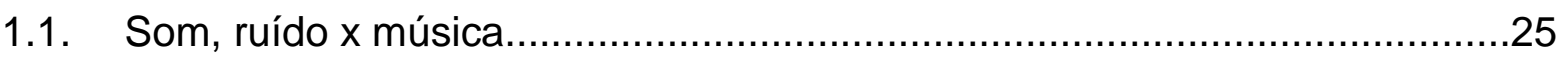

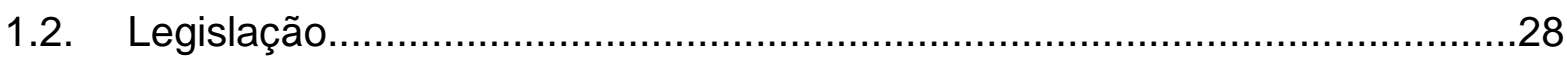

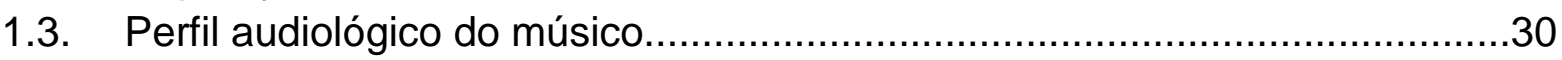

1.4. Uso do Equipamento de Proteção Individual (EPI) .................................46

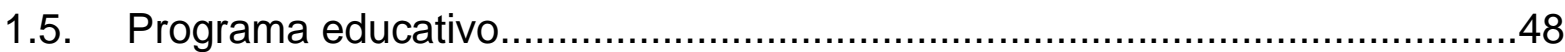

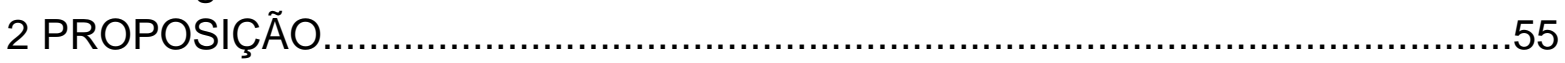

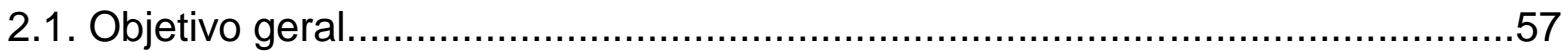

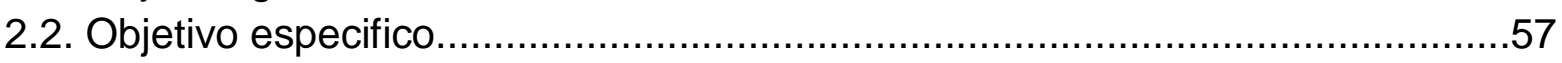

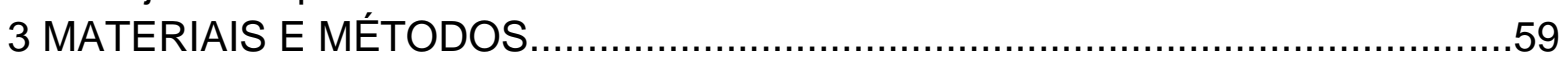

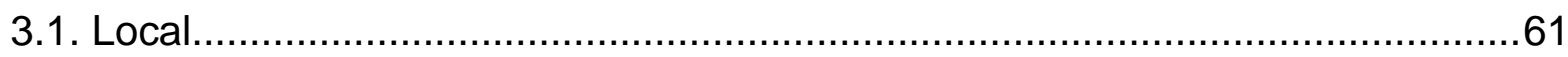

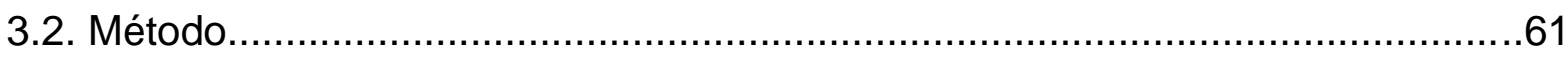

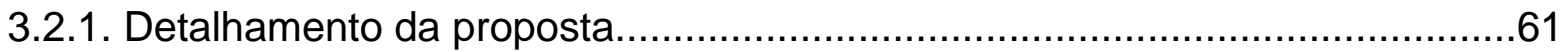

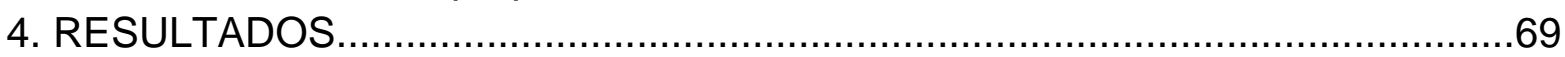

4.1. Caracterização da amostra.................................................................... 71

4.1.0. Submeter os músicos, componentes das bandas ao Programa de Prevenção

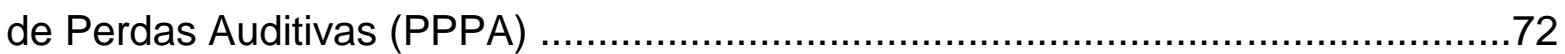

4.1.1 Medição do Nível de Pressão Sonora (NPS) nos ensaios e shows.................72

4.1.2. Entrevista específica e avaliação audiológica........................................76

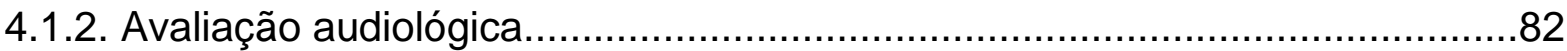

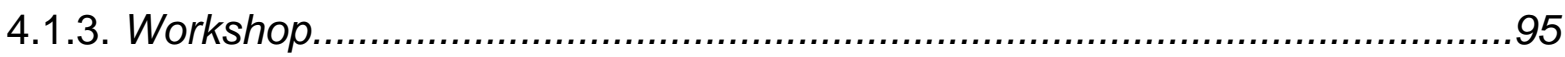

4.2.0. Verificar a eficácia do PPPA/ workshop.................................................106

4.2. Resumo dos achados encontrados no tópico: Resultados.............................112

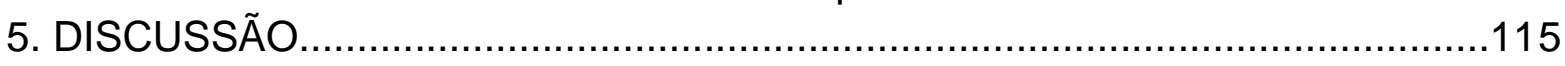

5.1.0. Submeter os músicos, componentes das bandas ao Programa de Prevenção de Perdas Auditivas (PPPA) .....................................................................117

5.1.1 Medição do Nível de Pressão Sonora (NPS) nos ensaios e shows...............118

5.1.2. Avaliação audiológica....................................................................120

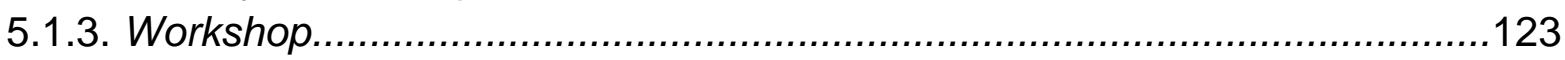

5.2. Verificar a eficácia do PPPA/ workshop..................................................124

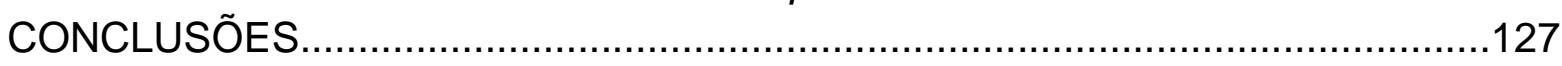

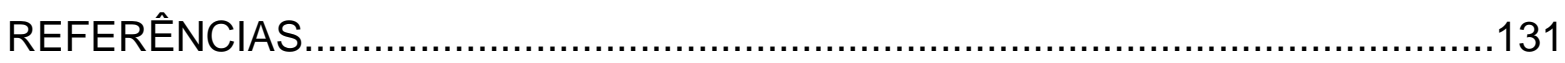

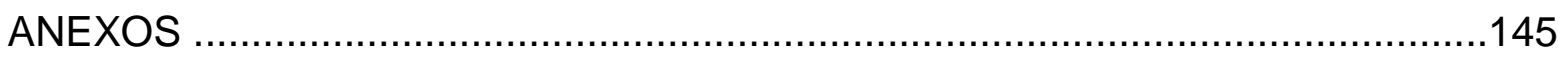


Introdução 


\section{INTRODUÇÃO}

A audição é um dos sentidos mais importantes para o ser humano e seu funcionamento está interligado à sua produtividade, o que não é diferente aos músicos, já que este sentido é de suma importância para a qualidade de seu trabalho e sua permanência na carreira. O desenvolvimento de um programa de prevenção de perdas auditivas tem por objetivo modificar o comportamento dos músicos em relação à sua audição, uma vez que, constantemente, estão expostos a sons elevados e ao surgimento de lesões irreversíveis. Contudo, se medidas preventivas não forem realizadas corretamente, as exposições dos músicos frente à intensidade sonora elevada podem trazer prejuízos à saúde de alguns destes, irreversíveis como a Perda Auditiva Induzida por Níveis Elevados de Pressão Sonora (PAINPSE) ou Perda Auditiva Induzida por Música (PAIM).

Os músicos estão expostos frequentemente a elevados níveis de pressão sonora devido às várias horas de ensaios e à frequência de apresentações, podendo assim desenvolver a Perda Auditiva Relacionada ao Trabalho (PART). Além de déficits de audição, a perda auditiva traz prejuízos principalmente à qualidade de vida.

No Brasil, a Norma Regulamentadora 15 (NR 15) do Ministério do Trabalho (MT) aplica-se somente a trabalhadores expostos a níveis de pressão sonora elevados que desempenhem suas funções em empresas regidas pela Consolidação das Leis do Trabalho (CLT), de forma que ainda não existe na sua legislação trabalhista uma resolução específica que proteja os músicos dos efeitos referentes à exposição à musica amplificada, considerando a intensidade, a duração e a frequência às quais estão expostos.

Muitos destes profissionais desconhecem os efeitos causados pela exposição a níveis elevados de pressão sonora, sejam eles auditivos ou não auditivos, interferindo diretamente em sua qualidade de vida. $\mathrm{O}$ uso de protetores auditivos desenvolvidos especialmente para atendê-los acaba não sendo levado em conta por falta de conhecimento ou custo elevado. Estes protetores são desenvolvidos especialmente para este público, já que trabalham de forma que precisam escutar os instrumentos, mas sem perder a audibilidade de algumas frequências, podendo ser universais ou personalizados. Os modelos universais possuem filtro que reduz o ruído, não abafa os sons da fala e os sons ambientais, tem design confortável e 
leve. Já os modelos personalizados que também contêm características dos universais são confeccionados de acordo com a anatomia da orelha de cada pessoa, promovendo maior conforto para o uso constante e prolongado.

Mais do que apenas informá-los sobre sua audição ou sobre o uso do protetor, é importante criar e implementar o Programa de Prevenção de Perdas Auditivas (PPPA) especialmente para este público, para o qual deve ser verdadeiramente efetivo a fim de provocar mudanças de comportamento. Considerando que a habilidade auditiva é um dos sentidos fundamentais para a vida do ser humano, bem como importante recurso para as atividades profissionais, como a música, e para a melhoria de sua qualidade de vida, esta pesquisa tem por objetivo principal submeter os componentes das bandas (músicos) ao Programa de Prevenção de Perdas Auditivas (PPPA) e verificar sua efetividade. 


\section{$\underline{\text { Revisão de literatura }}$}




\section{REVISÃO DE LITERATURA}

\subsection{SOM, RUÍDO X MÚSICA}

Segundo Russo e Santos (1993), som é uma modificação da pressão que ocorre em meios elásticos, propagando-se em forma de ondas ou oscilações mecânicas, longitudinais e tridimensionais. Resultante de um movimento vibratório de partículas materiais, muitos corpos podem servir como fonte sonora, porém devem ter uma característica vibrátil. Pode também ser definido como a sensação produzida quando as vibrações longitudinais de moléculas no ambiente externo atingem a membrana timpânica.

O som apresenta três características fundamentais: a frequência, a amplitude e o timbre, que é uma característica da fonte sonora (MEDEIROS, 1999).

Frequência: refere-se ao número de ciclos que as partículas materiais realizam em um segundo ou o número de vibrações por unidade de tempo; é medida pela unidade chamada Hertz $(\mathrm{Hz})$, que se refere à altura do som e permite classificálo em uma escala que varia de grave a agudo (MEDEIROS, 1999).

Amplitude: é a energia que atravessa uma área num intervalo de tempo ou a força exercida pelas partículas materiais sobre a superfície na qual incidem. A amplitude relaciona-se à intensidade sonora, sendo um dos processos físicos utilizados na medida desta juntamente com a pressão efetiva e a energia transportada pelo som; permite classificar o som em uma escala de fraco a forte (MEDEIROS, 1999).

Timbre: é uma qualidade da fonte sonora, que nos permite diferenciar, por exemplo, a mesma nota musical emitida por instrumentos diferentes, através de diversas frequências harmônicas de que se compõem um determinado som complexo (MEDEIROS, 1999).

Ruído: refere-se às vibrações aperiódicas, que não mantém relações matemáticas entre as frequências, ou seja, são dissonantes. É um tipo de som de natureza esparsa, cujo espectro não exibe componentes de frequências distintos. É difícil definir com precisão o ruído, pois qualquer som pode molestar, ser desagradável ou irritante quando o ouvinte encontra- se mal preparado, física ou mentalmente (MEDEIROS, 1999). 
De acordo com a Norma ISO 2204/1973 (International Standard Organization), os ruídos podem ser classificados, segundo a variação do seu nível de intensidade com o tempo, nos seguintes tipos: ruído contínuo (com variações de níveis desprezíveis); ruído intermitente (cujo nível varia continuamente de um valor apreciável); ruído de impacto e de impulso (apresenta-se em picos de energia acústica de duração inferior a um segundo) (FELDMAN; GRIMES,1985).

O ruído é um som sem harmonia e negativo, mas, em determinado contexto, pode nos passar informações úteis, por exemplo, alerta sonoro indicando velocidade de direção (em automóveis) entre outros (BISTAFA, 2006). Porém, não costumamos ver a música como um ruído, mas como um som agradável. Quando usada de forma incorreta (forte intensidade, períodos longos e frequentemente), ela se torna uma ameaça ao sistema auditivo (MENDES; MORATA, 2007).

De acordo com um artigo publicado pela revistada da Academia Brasileira de Audiologia (ABA) em 2010, o ruído é a terceira maior causa de poluição no mundo, perdendo apenas para o ar e a água. A preocupação com o ruído ambiental é bastante antiga. Atualmente é considerado um problema crescente na sociedade ocidental e exerce papel importante nas alterações da saúde auditiva em geral (FIORINI, 1997; OLSEN, 2004).

O ruído é o principal agente físico presente em diferentes categorias profissionais. A exposição a níveis de pressão sonora elevados em função de sua duração, frequência, intensidade e suscetibilidade individual, além de acarretar múltiplas consequências ao organismo humano, constitui um dos principais riscos à audição, podendo causar a PAINPSE (GONÇALVES, 2009).

A música sempre representou um papel importante na vida do ser humano, expressando sua cultura e suas origens. O som agradável instrumental requer dos músicos várias horas de estudos individuais e coletivas. Esta exposição sistemática a níveis elevados de pressão sonora pode causar prejuízo auditivo permanente (NAMUUR, 1999).

Segundo Oliveira (2010), "definir música é uma das tarefas mais árduas que se pode imaginar dentro do escopo da musicologia e da filosofia da música; há quem diga mesmo que é uma tarefa impossível se não for completamente inútil". Nesse sentido, o autor destaca que talvez o melhor seja não defini-la, uma vez que o conceito de música é suficientemente entendido por qualquer pessoa. É possível 
então falar de música em seus diversos prismas, sem a necessidade de dizer o que o conceito significa (OLIVEIRA,2010).

Para Requião (2008) e Requião e Rodrigues (2011), a música é associada por muitas pessoas ao lazer e ao ócio, a uma atividade não produtiva ou não rentável, o que a distância de uma atividade de trabalho. São comuns os relatos de músicos sobre o fato de como sua atividade é vista. Às vezes, tal atividade é encarada com certa desconfiança pela sociedade como se a música não fosse um trabalho e uma forma de sobrevivência. Por outro lado, dizer que o músico toca por inspiração divina, um talento ou dom, é desmerecer todo o processo de trabalho realizado, horas de estudo e dedicação até chegar à performance final, apresentada ao público como se esse resultado não fosse às custas de grande esforço (LÜDERS; GONÇALVES, 2013).

A música então é concebida como um som agradável. Ao ouvi-la, associamola a fatos importantes ou a acontecimentos de nossa vida no passado; ou ainda quando usada de forma intensa, pode transformar-se em transtorno na vida das pessoas. A exposição a níveis de ruído de 100 dB NPS somente é permitida durante uma hora por dia. Ficar exposto à música durante duas horas e meia, por exemplo, excede os limites seguros para a audição humana (GOVERNO DO BRASIL, 1978).

Vários estudos têm demonstrado o potencial risco de perda auditiva induzida pela música; entre músicos de bandas de rock, trios elétricos, orquestras sinfônicas, bandas de baile ou até mesmo em treinos instrumentais individuais (MENDES; MORATA, 2007).

A música é um som prazeroso ao ouvido humano, porém este som possui potencial de ser descrito como ruído. Pode até mesmo transformar-se em um transtorno à saúde das pessoas (ANDRADE et al., 2002).

Além disso, constatou-se que o aumento da exposição pode vir a trazer prejuízos à integridade física do músico, pois alguns músicos reclamaram de outros efeitos físicos, como a insônia após o trabalho, além da perda auditiva e do zumbido, concordando com o que foi afirmado por Ferraz,1996.

No entanto, a música, sempre tão ligada à história de vida das pessoas marcando bons e maus momentos, vem a cada dia tornando-se foco de atenção de profissionais de diversas áreas, principalmente os especialistas em saúde do trabalhador, audição e acústica (LÜDERS; GONÇALVES, 2013). 


\subsection{LEGISLAÇÃO}

O Instituto Nacional para Saúde e Segurança Ocupacional (National Institute for Occupational Safetyand Health - NIOSH) é mais rígido em seus padrões, recomendando a exposição máxima de 8 horas a $85 \mathrm{~dB}(\mathrm{~A})$. Soma-se a isso a recomendação do decréscimo de exposição pelo acréscimo dos níveis de pressão que é baseada em $3 \mathrm{~dB}(\mathrm{~A})$, e não em $5 \mathrm{~dB}(\mathrm{~A})$ como no OSHA. Assim para cada acréscimo de $3 \mathrm{~dB}(\mathrm{~A})$, a NIOSH recomenda metade do tempo de exposição (GLENVIEW, 2007).

Segundo Isleb et al. (2010), alguns países como Austrália, Suíça, Itália e Finlândia preocupam-se com os limites de exposição sonora ocupacional em atividades musicais ou na indústria do entretenimento, tanto para os músicos como para o público. Embora não se percebam muitas diferenças nas recomendações para a exposição à música e ao ruído intenso, pelo menos há sinalização de que os músicos podem perder a audição e, portanto, devem tomar medidas de prevenção da perda auditiva. Já na Suécia, as recomendações são bem mais específicas. Para os músicos, a intensidade Leq (A) para 8 horas diárias de exposição não deve ultrapassar $115 \mathrm{~dB}(\mathrm{~A})$ e picos de mais de $140 \mathrm{~dB}(\mathrm{C})$. Para ouvintes, a intensidade Leq (A) máxima é de $115 \mathrm{~dB}(\mathrm{~A})$. Os valores máximos foram assim definidos partindo do pressuposto de que a música não é tão prejudicial para a audição quanto o ruído industrial.

$\mathrm{Na}$ Suécia, existem duas recomendações de limites de segurança ocupacional, no que diz respeito ao ruído no trabalho e atividades musicais, tanto para músicos quanto para ouvintes (KÃHÃRl et al., 2003).

Para os músicos, a Administração Sueca de Saúde e Segurança Ocupacional tem regulamentado para cálculo de risco de perda auditiva, $85 \mathrm{~dB}$ Laeq/ 8h com 115 dB (A) e $140 \mathrm{~dB}$ (C) de pico como nível máximo (KAHARIT, 2003). Para os ouvintes, a recomendação da Diretoria Nacional de Saúde e Bem Estar Social da Suécia, é estabelecida em $100 \mathrm{~dB}$ Laeq, sendo que o valor máximo durante uma apresentação musical é de $115 \mathrm{~dB}$ (A) (KAHARIT, 2003).

No Brasil, ainda não há legislação específica que trate do risco de perda auditiva entre os músicos (MENDES; MORATA, 2007). Não consta nas normas da Associação Brasileira de Normas Técnicas (ABNT) nenhuma diretriz legislando sobre o controle do ruído em atividades de lazer (ANDRADE et al., 2002). 
Enfatiza-se ainda ser necessário que se discriminem em normas de segurança, além do número de dias de trabalho permitidos semanalmente, o número de horas diárias e os níveis de pressão sonora emitidos durante cada apresentação (ANDRADE et al., 2002).

A falta de padronização legal para exposição sonora específica para músicos pode criar a falsa suposição de que este tipo de ambiente de trabalho está livre de riscos auditivos, uma vez que todos os músicos seriam beneficiados por um padrão específico de proteção auditiva (OWENS, 2004).

Segundo Wade (2010), órgãos do governo americano estão cientes do problema da perda de audição em músicos, o que inclui o Departamento do Trabalho dos Estados Unidos e o Departamento de Saúde e Serviços Humanos com suas organizações OSHA e NIOSH, além da Environmental Protection Agency (EPA). Todos esses órgãos reconhecem que os músicos correm o risco de se exporem a intensidades sonoras que podem danificar a audição assim como em outras ocupações perigosas tais como as funções de bombeiros, militares, trabalhadores da construção civil, mineiros e operários.

Segundo a lei americana, assim como em outros países, como o Brasil, a exposição a níveis sonoros acima de $85 \mathrm{~dB}(\mathrm{~A})$, ao longo de um dia de trabalho de oito horas, é considerada perigosa para a audição, fazendo com que os órgãos acima citados venham a promulgar regulamentos de segurança para trabalhadores expostos a ruído, mas que costumam ser ignoradas na área da música.

No Brasil, a Fundação Jorge Duprat Figueiredo de Segurança e Medicina do Trabalho (FUNDACENTRO, 2001), publicou uma série de Normas de Higiene Ocupacional (NHO), para orientar os profissionais da saúde que atuam na área da saúde ocupacional. A NHO 1, que trata dos critérios para avaliação da exposição ocupacional ao ruído, mostra um grande avanço na prevenção de perda auditiva ocupacional, uma vez que utiliza o fator de dobra de $3 \mathrm{~dB}$, a exemplo do que ocorre em diversos países. Faz-se, portanto, necessária uma legislação que ampare os músicos, não somente determinando níveis seguros de exposição sonora e medidas preventivas eficazes, mas que possam gerar também recursos financeiros para este fim (MENDES; MORATA; MARQUES, 2007; SANTONI, 2008). 
Na Classificação Brasileira de Ocupações (CBO), disponível na página de acesso virtual do Ministério do Trabalho e do Emprego ${ }^{1}$, os compositores, os músicos e os cantores estão catalogados como um grupo ocupacional de base (SOUZA; BORGES, 2010).

Lüders e Gonçalves (2013) questionam o porquê de o músico ainda não contar com o devido amparo legal no que tange a sua saúde e segurança no trabalho, enquanto trabalhador já que eles têm seu lugar na Classificação Brasileira de Ocupações (CBO) e pertencem a uma instituição - Ordem dos Músicos do Brasil (OMB) - que regula, defende e fiscaliza o exercício da profissão (ou pelo menos, assim o deveria fazer). Ele ainda vem dar como uma possível resposta que talvez isso, mais uma vez, nos remeta àquela falsa ideia de que ser músico não é um trabalho, uma forma de sobrevivência; ou então, que o fato de a música ser agradável aos ouvidos não os colocaria em risco.

A falta de padronização legal para exposição sonora específica para músicos pode criar a falsa suposição de que este tipo de ambiente de trabalho está livre de riscos auditivos, uma vez que todos os músicos seriam beneficiados por um padrão específico de proteção auditiva (OWENS, 2004).

Para Chesky (2011), em função de falta de conhecimentos e habilidades para lidar com estas questões, os profissionais da música não estão preparados para reconhecer situações de risco, falar sobre segurança, alertar os colegas quando a esta preocupação ou se engajar em ações preventivas, adotando comportamentos de proteção.

\subsection{PERFIL AUDIOLÓGICO DO MÚSICO}

A audição é um dos sentidos mais importantes para o desenvolvimento psicossocial do indivíduo e tem fundamental importância na integração do homem à sociedade (GUIDA, 2007).

No ambiente de trabalho a maioria dos sons contém um número infinito de componentes de frequência. No entanto, somente a faixa de frequência compreendida entre 20 e $20.000 \mathrm{~Hz}$ (ou ciclos por segundo) é capaz de sensibilizar a orelha humana. Acima de $20.000 \mathrm{~Hz}$ encontram-se osultra-sons e, abaixo de $20 \mathrm{~Hz}$,

\footnotetext{
${ }^{1}$ Disponível em: <http://www.mtecbo.gov.br/>.
} 
os infra- sons, não sendo apreendidos pela orelha humana (SILVA, 2003). Qualquer frequência acima de $20.000 \mathrm{~Hz}$, o ouvido humano não consegue captar, ouvir ou entender (ARAÚJO; FEDICZKO, 2011), sendo que nosso sistema auditivo suporta sons entre 0 a 90 dB NPS, acima disto tornam-se desagradáveis e até dolorosos, podendo ser lesivos e destrutivos (PFEIFFER et al., 2007).

Todavia, alguns elementos de nosso ambiente podem interferir nessa habilidade. Exposição excessiva ou repetida a sons muito fortes em qualquer idade pode danificar o aparelho auditivo, resultando em perda de acuidade auditiva. Músicos estão sob risco considerável de dano, em boa parte, pois estão regularmente expostos a sons musicais fortes, sendo que a fonte destes sons está muito próxima de suas orelhas (GLENVIEW; ILLINOIS, 2007).

A literatura apresenta diversas nomenclaturas para a perda auditiva, podendo ser denominadas Perda Auditiva Induzida por Níveis de Pressão Sonora Elevada (PAINPSE) ou Perda Auditiva Induzida por Música (PAIM), além daquelas relacionadas ao trabalho em indústrias ou empresas em que o ruído é o agente insalubre, como a Perda Auditiva Induzida por Ruído (PAIR), Perda Auditiva Induzida por Ruído Ocupacional (PAIRO), Perda Auditiva Ocupacional (PAO) ou Perda Auditiva Relacionada ao Trabalho (PART) (BRASIL, 1997; LOPES, GENOVESE, 1991).

A PAINPSE é considerada uma das doenças ocupacionais mais prevalentes em todo o mundo (DIAS et al., 2006). Segundo esses autores:

\begin{abstract}
Caracteriza-se pela perda auditiva provocada em função da exposição por tempo prolongado ao ruído, configurando-se como uma perda auditiva do tipo neurossensorial, geralmente bilateral, irreversível e progressiva com o tempo de exposição ao ruído (CID 10 - H83.3). A perda tem seu início e predomínio nas frequências de $3.000,4.000$ ou $6.000 \mathrm{~Hz}$, progredindo, posteriormente, para 8.000, $2.000,1.000,500$ e $250 \mathrm{~Hz}$. Em condições estáveis de exposição, as perdas em $3.000,4.000$ ou $6.000 \mathrm{~Hz}$, geralmente atingirão um nível máximo, em cerca de 10 a 15 anos. Uma vez cessada a exposição ao ruído intenso não haverá progressão da perda. (MINISTÉRIO DA SAÚDE, 2006)
\end{abstract}

Diante da importância que a audição representa para os músicos, estudos evidenciaram que, mesmo apresentando audição normal, esses profissionais estão sujeitos ao acometimento de perda auditiva induzida por níveis elevados de pressão sonora (PAINPSE) (MENDES, MORATA, MAIA et al., 2007; AMORIM et al., 2008). 
Além disso, os músicos também acabam sendo submetidos a elevados níveis de pressão sonora em ambientes de apresentação ou mesmo em seus ensaios (MARTINS et al., 2008). Qualquer indivíduo atuante na esfera da sociedade moderna, como profissionais de diversas áreas, tais como trabalhadores de indústrias, militares e dentistas (MINISTÉRIO DA SAÚDE, 2006), também estão expostos a consideráveis níveis de pressão sonora.

Segundo o Ministério da Saúde (2006), é importante diferenciar a PAINPSE de outros agravos auditivos que, apesar de terem o mesmo agente etiológico, possuem características distintas, como trauma acústico, mudança temporária de limiar e mudança permanente do limiar. O trauma acústico é uma alteração auditiva provocada pela exposição a ruído abrupto e muito intenso, como por exemplo, tiros e explosões. Normalmente é unilateral e acompanhada de zumbido. A mudança temporária de limiar ocorre devido à exposição prolongada a sons intensos, causando uma redução na sensação auditiva, mas que cessada a exposição retorna ao normal. Ela ocorre em função das exposições prolongadas e repetidas a sons de intensidade elevada, não havendo tempo de repouso de uma exposição à outra, caracterizando a PAINPSE (PINTO et al., 2002). A PAINPSE também é influenciada por alguns fatores, dentre eles características físicas do ruído (tipo, espectro e nível de pressão sonora), tempo de exposição (frequência e horas) e suscetibilidade individual (determina a influência das perdas auditivas, esclarecendo o fato de alguns músicos apresentarem perdas auditivas mais graves do que outros, num tempo de exposição semelhante e tocando o mesmo tipo de música (HARGER; BARBOSA, 2004; SAMELLI; SCHOCHAT, 2000).

Alguns estudos têm demonstrado a presença de perda auditiva em músicos, podendo ser precedida ou acompanhada de outros distúrbios auditivos, tais como zumbido, hiperacusia, distorção ou diplacusia (KAHARIT, 2003) e diminuição da inteligibilidade da fala (NEVES, 2007). Essa dificuldade para compreensão da fala ocorre especialmente na presença de ambientes ruidosos (BELTRAMI, 1992). Santoni (2008) completa dizendo que são frequentes os casos de hipertensão arterial, estresse, depressão, ansiedade, aumento da tensão muscular, alteração do sono, gastrite e dificuldade de concentração. Além desses já citados também podem estar presentes, irritação, tontura e cefaléia (BELTRAMI, 1992).

Segundo estudos realizados por Pereira et al. (2010), observou-se um grande número da baixa qualidade do sono quando comparada a outras categorias 
profissionais, como enfermeiros e motoristas. Além disso, baixos índices de qualidade do sono mostraram associação com baixa capacidade para desempenhar as atividades do dia-a-dia e do trabalho. A percepção de dor e desconforto também apresentou forte associação com a qualidade do sono, confirmando ser esse um aspecto ergonômico importante da profissão de músicos.

$\mathrm{Na}$ literatura, podemos encontrar ainda estudos que comprovam a perda auditiva como consequência da exposição à música em intensidades elevadas, acompanhada além dos sintomas como zumbido, sensação de plenitude auricular, cefaleia e tontura (RUSSO et. al., 1995; NAMUR et al., 1999; ANDRADE et al., 2002; MENDES; MORATA; MARQUES, 2007; AMORIM et al., 2008; SANTONI, 2008; GONÇALVES et al., 2009; GONÇALVES et al., 2013;). Segundo Mitre (2003), estes sintomas, somados às manifestações não auditivas, como irritabilidade e fadiga, podem ser os primeiros sinais de lesão do órgão auditivo.

Os efeitos sobre a audição são o zumbido e a surdez propriamente dita, pois nem toda perda auditiva leva à surdez profunda. O tempo de exposição e a intensidade a que o indivíduo está exposto estão diretamente relacionados com a perda auditiva. O zumbido é uma sensação auditiva percebida pelo indivíduo na ausência de uma fonte sonora externa. Pode ser considerada uma sequela de agressão sofrida pelo sistema auditivo, sendo considerado um sintoma sem cura estabelecida. Ele apenas sinaliza que algumas células do aparelho auditivo estão sobrecarregadas. Na verdade, o zumbido não é causa, mas a consequência da perda auditiva (SANCHEZ, 2007).

Existem inúmeras causas do zumbido, como a sua associação a incidência de Perda Auditiva Induzida por Níveis de Pressão Sonora Elevados (PAINPSE). Sendo várias causas possíveis para o zumbido, como a origem no sistema auditivo, alterações metabólicas, hormonais, cardiovasculares, odontológicas, musculares da região de cabeça e pescoço, psicológicas, neurológicas e distúrbios psiquiátricos (SANCHEZ, 2007). Estes sons estão associados a apito, barulho de cachoeira, motor, grilo, chuva, panela de pressão, chiado, rádio fora do sistema, cigarra, dentre outros (FREIRE, 2014).

Segundo Einhorn (2009), músicos de rock têm admitido que sofrem de zumbido e relatam ter seus desempenhos musicais limitados ou mesmo terem se aposentado da profissão de músico por causa desse problema. 
Já a surdez é um defeito invisível, mas que provoca sérios danos na relação de comunicação humana com o mundo. A diminuição da audição produz uma redução na percepção de sons e dificulta a compreensão das palavras. A sua evolução depende da causa e da gravidade da lesão, sendo que se a exposição for repetitiva, a lesão causada na orelha interna poderá ser definitiva e a surdez, portanto, será irreversível (PALÁCIOS; MARQUEZE, 2006).

Estudos realizados por Maia et. al. (2007), Amorim et al. (2008), Martins et. al. (2008) e Otubo et al. (2013) indicaram que o perfil audiológico encontrado em músicos de diversos estilos musicais e orquestra segue o padrão de evolução da PAINPSE, com início de comprometimento nas frequências agudas (3, 4 e $6 \mathrm{kHz}$ ) mesmo na ausência de queixa auditiva. Segundo o Ministério da Saúde (2006), não existe, até o momento, tratamento para PAINPSE, sendo recomendada a adoção de medidas de prevenção, tais como tratamento acústico de salas de ensaio, uso de protetores auditivos especiais de atenuação uniforme e acompanhamento audiológico por meio da audiometria tonal e emissões otoacústicas (MENDES; MORATA, 2007; SANTONI, 2008).

A perda auditiva ocasionada tanto pela música quanto pelo ruído é caracterizada por um entalhe na região de frequências entre 4 e $6 \mathrm{KHz}$ e progride proporcionalmente as condições da exposição (MORATA, 2007).

A avaliação dos limiares tonais de altas frequências de forma periódica pode ser útil na detecção precoce da deficiência auditiva sensorioneurais, presentes em músicos (LÜRDES et al., 2013; OUTUBO, 2015).

A audiometria de altas frequências avalia os limiares audiométricos a partir de $9 \mathrm{KHz}$ a $20 \mathrm{KHz}$, tornando- se uma prática importante no monitoramento auditivo de sujeitos expostos a níveis elevados de pressão sonora. Além disso, possibilita a percepção do desgaste auditivo causado pelo fator idade antes mesmo de apresentar alteração na audiometria convencional.

Segundo o Ministério do Trabalho e Emprego do Brasil, através da NR7, estabelece que o exame audiométrico deve ser realizado pela via aérea nas frequências de $500 \mathrm{~Hz}$ a $8 \mathrm{KHz}$. Assim, ainda não existe uma padronização para audiometria de alta frequência.

De acordo com Freire (2014), o fonoaudiólogo dever saber da importância dos resultados obtidos na avaliação audiológica dos profissionais da música, em especial nos limiares de audiometria de alta frequência (até $20 \mathrm{KHz}$ ), pois são dados 
fundamentais que devem ser considerados como a base da mixagem dos retornos de som, sejam esses monitores in- ears (fones de ouvido) ou de chão (caixa de som).

A avaliação audiológica é importante também para todos os profissionais da música, incluindo engenheiros e técnicos de som, já que precisam ter consciência do quadro audiológico do artista para qual faz mixagem e também de sua própria audição (FREIRE, 2014).

A Organização Mundial da Saúde (OMS) (2011) aponta que 28 milhões de brasileiros possuem algum tipo de problema auditivo, o que revela um quadro no qual $14,8 \%$ do total de 190 milhões de brasileiros possuem problemas relacionados à audição. Em âmbito mundial, 16\% da população é afetada pela perda da audição, de acordo com Organização Mundial da Saúde (OMS, 2013); contudo, em março de 2015, a OMS vem alertar que 1,1 bilhão de jovens, em todo o mundo, corre risco de sofrer perda auditiva devido à exposição ao barulho causada por seus hábitos diários. Nos países desenvolvidos, a situação é tão grave que, de acordo com estimativas, mais de 43 milhões de pessoas, entre 12 e 35 anos, já sofrem de surdez incapacitante, sendo que dessa faixa etária $50 \%$ está exposta a riscos pelo uso excessivo de tocadores de mp3 e smartphones, e $40 \%$ pelos níveis de ruído prejudiciais de discotecas e bares (OMS, 2015).

A música intensa pode afetar a audição principalmente dos jovens. $O$ ideal seria a realização de campanhas de prevenção verdadeiramente efetivas, voltadas para crianças e adolescentes, alertando sobre o perigo da música alta, exposição do tempo do uso do fone de ouvido e a potência adequada para se ouvir música.

Mais de cinco milhões de jovens norte-americanos apresentam alguma perda de audição causada principalmente por shows de rock, fogos de artifício, cortadores de grama ou walkman. De acordo com o manual de alguns desses equipamentos, 0 walkman atinge $90 \mathrm{~dB}$ e alguns eletrônicos mais modernos podem chegar a $110 \mathrm{~dB}$, sendo que o sistema auditivo humano suporta sons entre 85 e 100 dB. A exposição continuada a sons entre 100 e 120 dB podem levar à perda auditiva e, acima de 120 $\mathrm{dB}$, pode provocar trauma acústico (CRUZ, 2008).

Em estudo realizado por Sumera (2015), cujo objetivo foi caracterizar e comparar o perfil audiológico de indivíduos usuários ou não de estéreos pessoais, com e sem queixa de zumbido, ela observou que os sintomas mais prevalentes relatados pelos jovens foram plenitude auricular e hipersensibilidade auditiva, e a 
exposição não ocupacional relacionada ao ruído foi, por exemplo, frequentar cinema, discoteca, danceterias e/ou bailes, shows de música pop e rock.

Sant'Ana e Lopes (2009) realizaram estudo em duas escolas públicas e duas privadas, nas quais aplicaram 100 questionários a adolescentes entre 11 e 18 anos de idade, de ambos os sexos, ouvintes ou não de música amplificada. Evidenciaram que os mesmos fazem uso indiscriminado dos dispositivos sonoros portáteis individuais, desconhecendo os riscos de perda auditiva, bem como suas formas de tratamento.

Considera -se que o volume de dispositivos de áudio pessoais, tais como tocadores de mp3, podem variar seu volume entre $75 \mathrm{~dB}$ e $136 \mathrm{~dB}$. Recomenda se contudo, que as pessoas usem esses aparelhos não mais do que uma hora por dia e a um volume baixo. Já em discotecas e bares, os níveis de ruído podem variar entre 104 dB e 112 dB ((OMS, 2015). De acordo com os parâmetros determinados pelo Órgão das Nações Unidas (ONU), permanecer mais de 15 minutos nesses locais não é seguro. $O$ mesmo se aplica em instalações esportivas, onde o nível de ruído oscila entre $80 \mathrm{~dB}$ e $117 \mathrm{~dB}$ (OMS, 2015).

Além dos níveis de pressão sonora e o tempo de exposição, a ocorrência de perda auditiva depende também de fatores ligados ao ser humano, como a susceptibilidade individual, uso de medicamentos, patologias relacionadas ao aparelho auditivo, entre outros fatores (MIRANDA; DIAS, 2008).

Fernandes et al. (1996) verificaram a intensidade do ruído presente em casas noturnas, utilizando um medidor do nível de pressão sonora ETB-142-A, e concluíram que há possibilidade de desenvolver perda auditiva, visto que a intensidade do ruído presente variou entre $78 \mathrm{~dB}$ a $111 \mathrm{~dB}$. No mesmo ano, Regazzi (1996) realizou medições no interior de três estabelecimentos noturnos com música amplificada e o nível de ruído médio verificado também foi elevado e considerado prejudicial, variando de $96 \mathrm{~dB}$ a $103 \mathrm{~dB}$.

Dentre as inúmeras profissões e funções exercidas pelo homem em seu trabalho, estão os músicos (FERNANDES et al., 2004) que em geral gostam de sua profissão, sendo a música seu primeiro interesse. Muitas vezes sacrificam as vantagens de outras profissões mais estáveis, com horas de trabalho regular e melhores salários, a fim de exercer o que mais gostam. No entanto, a profissão de musicista, apesar de agradável e criativa, pode oferecer riscos à saúde do músico, e em especial à sua audição (MENDES; MORATA, 2007), pois sofrem com os efeitos 
da exposição aos altos níveis de intensidade sonora. Embora o som gerado por seus instrumentos não se caracterize como ruído, a exposição a ele causa a perda auditiva e outras alterações importantes que interferem na sua qualidade de vida (FERNANDES et al, 2004).

A incapacidade auditiva se refere aos problemas auditivos sentidos pelo indivíduo com relação à percepção da fala em ambientes ruidosos, e as outras alterações relacionam-se às consequências não auditivas da perda, influenciada por fatores psicossociais e ambientais, tais como estresse e ansiedade (FERNANDES et al., 2004).

De acordo com Palin (1994), Kahariet et al. (2001) e Mendes et al. (2002), a posição que o músico toca em relação ao grupo também é um fator importante, contribuindo para o aumento do nível de pressão sonora de exposição, devido às características sonoras de outros instrumentos tocados na proximidade do músico, e dos aspectos físicos do ambiente.

Todos os músicos de uma banda ou orquestra compartilham o risco de níveis sonoros excessivos, contudo não no mesmo grau. Por exemplo, os músicos das palhetas duplas da orquestra estão sentados à frente dos trompetes, trombones e/ou percussão e recebem altos níveis de pressão sonora e intensidade frequentemente produzidos por esses instrumentos (GLENVIEW; ILLINOIS, 2007).

Alguns instrumentos são capazes de produzir sons potencialmente perigosos. Flautistas podem gerar níveis que excedem $105 \mathrm{~dB}(\mathrm{~A})$, picos $120 \mathrm{~dB}(\mathrm{~A})$ e trompetistas $95 \mathrm{~dB}(\mathrm{~A})$. Bandas e orquestras completas podem produzir sons que excedem 99-105 dB (A). Outros estudos têm encontrado níveis sonoros igualmente altos, ou mesmo maiores em bandas de marcha e bandas de jazz durante ensaios ou apresentações (GLENVIEW; ILLINOIS, 2007).

Músicos ou qualquer profissional que trabalha com música estão expostos a altos níveis de pressão sonora, o que, em longo prazo, poderá trazer grandes consequências para a audição, podendo até mesmo desenvolverem PAINPSE (GLENVIEW; ILLINOIS, 2007). A susceptibilidade individual tem influência na determinação das perdas auditivas. Esse fato explica o porquê de alguns músicos apresentarem perdas auditivas mais graves do que outros, num tempo de exposição semelhante e tocando o mesmo tipo de música (SANELLI; SCHOCHAT, 2000). 
Acredita-se que a melanina possa proteger a orelha interna contra o ruído através de um mecanismo envolvendo a geração e a neutralização de radicais livres (HUMES, 1984; QUARANTA et al., 2001; THOMAS et al., 1981; WARD, 1979).

A orelha interna é dos importantes locais onde os melanócitos estão localizados. Alguns autores têm informado que as células que contêm melanina na orelha interna protegem a cóclea contra vários agentes estressantes, particularmente, contra o nível elevado de ruído. Mostraram ainda que animais albinos têm capacidade de audição normal, mas são mais suscetíveis à perda auditiva induzida por ruído (CONLEE et al., 1896).

Royster et al. (1980) estudaram os diferentes grupos étnicos, em relação à audição, e concluíram que a as pessoas que apresentavam pigmentação da pele branca é mais vulnerável a adquirir perda auditiva induzida por ruído, do que os que apresentavam mais pigmentações, mostrando que a melanina da orelha interna pode proteger a audição contra o ruído elevado.

A literatura relata que a melanina tem maior concentração na região basal do órgão espiral, o qual corresponde à audição em altas frequências (BARRENAS, 1997; ARDIC et al., 1998).

A melanina presente na orelha interna tem um importante papel para um desempenho adequado, e a sua ausência acarreta em danos evidenciados por exames específicos, como o uso das emissões otoacústicas por produto de distorção (EOAPD) (BARRENAS, 1997; CONLEE et al., 1986).

Segundo o Ministério da Saúde (2006), não existe até o momento tratamento para PAINPSE, sendo recomendada a adoção de medidas de prevenção, tais como tratamento acústico de salas de ensaio, uso de protetores auditivos especiais de atenuação uniforme e acompanhamento audiológico por meio da audiometria tonal e emissões otoacústicas evocadas (EOE) (MENDES; MORATA, 2007; SANTONI, 2008).

O estudo das Emissões Otoacústicas Evocadas (EOE) tem sido descrito como útil na detecção precoce de perdas auditivas, auxiliando no monitoramento do status auditivo na região da cóclea (MAIA et. al, 2007) e evidenciando a redução de suas amplitudes ou mesmo a ausência de suas respostas, conforme a duração e a intensidade da exposição ao ruído (GATTAZ, WAZEN, 2001). Além disso, alterações na amplitude das EOE por Produto de Distorção (EOEPD) podem preceder alterações audiométricas mais graves, sendo um exame recomendado para 
diagnóstico de perdas auditivas progressivas a fim de que se implementem programas de prevenção das perdas auditivas de origem ocupacional (LOPES FILHO; CARLOS; REDONDO, 1995; GATTAZ; WAZEN, 2001). No entanto, pouco se conhece acerca da variação dos níveis de resposta dessas emissões, além da grande variabilidade e susceptibilidade individuais (MAIA et. al, 2007).

Estudos realizados por Coelho et al. (2010) mostraram que tanto as EOEat quanto as EOEpd são úteis no diagnóstico da PAIR, sendo que as EOEat se revelam mais sensíveis às mudanças temporárias de limiar que as EOEpd, e as EOEpd se destacam mais eficazes no diagnóstico precoce da PAIR em indivíduos com audição aparentemente normal, pelo fato de captar as respostas nas frequências mais altas, que são as primeiras a serem atingidas pela PAIR, enquanto que a audiometria tonal revela a PAIR quando esta já se instalou.

As EOE vêm sendo utilizadas de forma eficaz na detecção de alterações cocleares e diagnóstico precoce da PAIR (ALCARÁS, 2012). Segundo Oliveira (1997), a lesão coclear por ruído pode ser descrita em três fases de acordo com o tempo de exposição:

1) Inicial: morte das células ciliadas com formação de escaras não perceptível ao exame audiométrico convencional;

2) Após poucos anos de exposição: danos no primeiro terço da cóclea ou a 10 $\mathrm{mm}$ da base coclear, por ser uma área mais sensível devido a fatores metabólicos, anatômicos e vasculares, havendo detecção de alteração audiométrica nos limiares tonais de 3 a $6 \mathrm{kHz}$;

3) Após décadas de exposição: há lesões de uma faixa mais extensa da cóclea comprometendo as frequências médias e baixas.

Se o dano não for muito sério, as células se recuperam num período máximo de 48 horas. No entanto, se a exposição for muito longa ou intensa, a lesão pode se tornar permanente. É nesse ponto que os MP3 players diferenciam-se do walkman e dos concertos de rock. A fita cassete não armazenava mais de duas horas de música e as pilhas de um walkman também não duravam muito. Já os MP3 players permitem ouvir música em altíssimo volume durante um dia inteiro. Com períodos diários mais longos de audição, as células da cóclea não têm tempo para se recuperar e ficam irreversivelmente danificadas (GREGO, 2006).

A evolução da eletrônica e o consequente aumento da potência dos amplificadores, acoplados aos instrumentos musicais modernos, levaram à elevação 
da intensidade da música e do risco de perda auditiva entre os músicos (MENDES; MORATA, 2007).

De acordo com a OMS (2015), o volume máximo de exposição ao som considerado seguro é de $105 \mathrm{~dB}$ por no máximo quatro minutos quando se trata de tocador de mp3 no volume máximo.

Lacerda, Morata e Fiorini (2001), em seus estudos sobre Nível de Pressão Sonora (NPS), constataram que dependendo do NPS, eles podem levar não só a lesões auditivas, como também a fadiga, mal-estar, irritação, intolerância, insônia e fadiga vocal.

A avaliação do nível de pressão sonora de exposição dos músicos é complexa devido à grande variância de acordo com o local do concerto ou show e música sendo tocada, idealmente a exposição deve ser medida por meio de um dosímetro, para o alcance de uma avaliação média de exposição em tempo real, em cada ambiente, durante os ensaios e apresentações (SANTUCCI, 1990).

Toppila e Laitinen (2004) afirmam que a diferença entre trabalhadores industriais e músicos está no número de fatores de risco. Assim, este estudo sugere que a baixa perda auditiva observada nos músicos é devido ao menor número de fatores de risco e não pelo fato de a música ser menos perigosa para o ouvido que o barulho nas indústrias.

Apesar de apresentarem, na maioria das vezes, resposta normal nas audiometrias, não pode ser afastada a possibilidade de uma futura perda auditiva, pois, antecedendo a ocorrência da mudança permanente de limiar, tem-se observado sempre uma mudança temporária, atingindo o seu máximo, logo após o término da exposição (SILVA, 2002). Esta mudança temporária também dominada de TemporaryThreshold Shift (TTS) se manifesta devido a discretas alterações intracelulares, edema das terminações nervosas junto às células ciliadas alterações vasculares, químicas e exaustão metabólica, além da diminuição da rigidez dos estereocílios, que ocasionam uma redução na capacidade das células em perceberem a energia sonora que as atingem (SOUZA, 2002).

Essas alterações podem ser reversíveis, mas dependendo da intensidade do ruído (música) e duração da exposição do indivíduo a ela (HAUSLER, 2004) tendo como característica básica uma alteração primária nos limiares entre 3000 e 6000 Hz (PIZARRO, 2000). 
Dependendo do estímulo (intensidade, duração, frequência, horário), o ruído pode causar danos às células ciliadas que podem ser, de forma mais leve, lesões em algumas de suas estruturas e, de forma mais severa, sua destruição total (UGALDE et al., 2000). Em alguns casos, as células de sustentação também podem ser afetadas (PFEIFFER et al., 2007).

Além dos sintomas auditivos, como o zumbido e a dificuldade para discriminar os sons da fala, a exposição ao ruído também pode causar alterações cardiovasculares, neuroendócrinas, imunológicas, gastrointestinais, cefaleias entre outros (PFEIFFER et al., 2007).

Segundo Panelli (2014), a perda auditiva induzida por ruído em trabalhadores, sempre foi muito estudada e discutida. No entanto, a perda auditiva induzida por música apresenta poucos e contraditórios estudos, em sua maior parte, realizados com músicos e profissionais relacionados à música amplificada.

É possível afirmar que a audiologia está voltando os seus esforços para a proteção da audição dos funcionários industriais, mas deixando de lado a importância do trabalho preventivo com os músicos, contudo não se pode esquecer que a perda auditiva ocupacional também sofrida pela categoria dos músicos é irreversível, mas possível de ser evitada (KWITK, 1996).

Estudos realizados por Pfeiffer (2007), tiveram por objetivo verificar a mudança temporária do limiar de audição em músicos expostos a níveis de pressão sonora elevados em um show de rock, sendo realizados os seguintes procedimentos: anamnese ocupacional, determinação dos níveis mínimos de audição e reflexos acústicos, antes e após o show de rock. A mensuração do ruído da sala do exame e do palco foi realizada por meio de um dosímetro. Na audiometria tonal, as maiores diferenças pré e pós-exposição foram encontradas nas frequências altas, sendo a orelha direita a que apresentou maiores mudanças temporárias de limiar, sendo mais significantes nas frequências de 2000, 3000, 4000 e $6000 \mathrm{~Hz}$. Na medida do reflexo acústico após o show, a orelha direita obteve o maior índice de ausência de reflexo, com o índice de 40\%; entretanto, foram encontradas diferenças estatisticamente significantes, na presença de reflexo acústico na comparação pré e pós-exposição, apenas na orelha esquerda $(p=3,64)$. Em tal estudo, os autores concluíram que os músicos expostos a níveis de pressão sonora intensos apresentam alteração temporária do limiar e alteração do reflexo acústico. 
O teste do reflexo acústico é uma técnica de extrema importância para a audiologia clínica. É um exame objetivo e rápido, que registra a contração dos músculos da orelha média, na presença de um som de forte intensidade. O limiar do reflexo acústico corresponde à menor intensidade de um som capaz de desencadear o mecanismo de proteção da orelha média frente a sons intensos. Em 1954, este reflexo foi considerado um mecanismo de proteção para a orelha interna, de danos que poderiam ser causados por sons intensos (WEVER; LAWRENCE, 1954).

A relação entre as propriedades do reflexo acústico e a mudança temporária de limiar, não tem sido muito estudada. Em 1983, foi realizado um estudo o qual mostrou a mudança do reflexo acústico após a exposição ao ruído, aumentando o índice de ausência do reflexo após a exposição (GERHARDT; HEPLER, 1983).

Amorim et al. (2008) investigaram a acuidade auditiva de músicos, onde foi possível observar, frente aos resultados obtidos por meio dos exames realizados, que está população apresenta grande risco para desenvolver perda auditiva induzida por níveis de pressão sonora elevados, sendo recrutados 30 músicos, com atuação de no mínimo dois anos para o estudo. Foram encontrados em seus resultados que quando questionados sobre o ambiente de trabalho, 100\% relataram ser ruidoso; e quanto aos sintomas mais frequentes, os mais citados foram o zumbido, seguido de dificuldade de compreensão de fala em ambientes ruidosos. $100 \%$ dos participantes sabiam que o ruído excessivo prejudica a audição. 17\% apresentaram audiograma sugestivo de PAIMPSE e 7\% audiogramas normais com entalhe, quando comparada às médias entre as frequências de $500,1.000$ e $2.000 \mathrm{~Hz}$ e $3.000,4.000$ e $6.000 \mathrm{~Hz}$, verificaram que as dos limiares de frequências mais altas estavam mais rebaixadas em relação às dos limiares de frequências mais baixas. Já nas audiometrias de alta frequência encontrou-se presença de entalhes nas frequências de $12.500 \mathrm{~Hz}$ bilateralmente e na frequência de $14.000 \mathrm{~Hz}$ na orelha direita. Quando correlacionados tempo de profissão com os limiares também foi positivo e significante na frequência de $16.000 \mathrm{~Hz}$ em ambas as orelhas. No exame de emissões otoacústicas evocadas por estímulo transiente (EOEat) foram observadas ausência de em $26,7 \%$ na orelha direita e 23,3\% na orelha esquerda, está ausência ocorreu principalmente na faixa de frequência de 3.000 e $4.000 \mathrm{~Hz}$, nas EOEpd, foram encontradas ausências em frequências isoladas com maior predomínio em 4,5 e $6 \mathrm{KHz}$. 
Segundo estudos realizados por Otubo, Lopes e Lauris (2013), foi observada a presença de entalhe nas frequências de $11.200 \mathrm{~Hz}$ na orelha esquerda, $12.500 \mathrm{~Hz}$ na orelha direita e $16.000 \mathrm{~Hz}$ em ambas as orelhas.

Gonçalves et al. (2009) analisaram a audição de integrantes de uma banda militar, com média de idade de 34,9 anos e tempo de atuação na banda com média de 14,2 anos, quanto aos sintomas, o zumbido foi o mais citado por $76 \%$ dos participantes. Quanto à queixa de dificuldade auditiva, está aumentou de acordo com o tempo de atuação na banda, sendo que participantes com atuação de um a dez anos com tal queixa foi de $30,76 \%$, de onze a vinte anos foi de $30,76 \%$ e de vinte e um a trinta anos foi de 69,23\%. 32\% dos participantes apresentaram alterações auditivas, e as características de PAIR aumentaram conforme o tempo de atuação na banda, sendo encontrado um caso entre um e dez anos de atuação, cinco casos entre onze e vinte anos, e seis casos entre vinte e um e trinta anos de atuação. Durante o ensaio os níveis de pressão sonora encontrados variaram entre 90,1 a $110,30 \mathrm{~dB}(\mathrm{~A})$.

Em São Paulo, dez ritmistas de bateria de uma escola de samba com faixa etária de 20 a 31 anos de idade com tempo médio de 4,7 anos nesta função, foram submetidos à avaliação audiológica e a um questionário. Dos dez participantes, 90\% sentem zumbido e diminuição da audição após os ensaios, e 100\% não utilizam Equipamento de Proteção Individual (EPI) durante os ensaios. Quanto a configuração dos audiogramas, mesmo quando os limiares estavam dentro dos padrões de normalidade, as frequências altas estavam mais elevadas que as baixas e médias. Foi também mensurado o NPS dentro da quadra durantes os ensaios, e as médias gerais foram de 111,42 dB (A) (MONTEIRO; SAMELLI, 2010).

Foi realizado um estudo com uma banda de rock, composta por 1 guitarrista/vocalista, 1 guitarrista, 1 baixista e 1 baterista, com idades entre 21 e 26 anos. Foi mensurado o nível de pressão sonora a qual banda é exposta em seus ensaios e também avaliada a função coclear de seus integrantes, antes e após o ensaio. A medição do nível de pressão sonora foi feita com o medidor de pressão sonora DEC-500 da marca Instrutherm, posicionado na frente da banda, laterais, e fundo, sempre próximo a cada integrante, foi encontrado uma variação de 84 a 105,3 dB (A). A banda relatou ter ensaios diários com no mínimo uma hora de durabilidade e fazer shows semanais. A avaliação da função coclear foi realizada através das emissões otoacústicas evocadas, antes e depois do ensaio, nas 
emissões otoacústicas transientes, apenas um integrante teve mudança após o ensaio, na orelha direita, não passando no teste; já as EOEpd foram analisadas de duas formas, pela relação sinal/ruído, em que todos os integrantes passaram no exame, e pelo valor absoluto da amplitude, observando se está aumentou ou diminuiu após a exposição ao ruído intenso. Foi observada uma diminuição na amplitude de todos os integrantes. (PANELLI et al., 2013).

A exposição ao ruído é uma das causas de lesão da orelha interna, provocando zumbido, perda auditiva e hipersensibilidade a sons. Embora as maiorias dos problemas auditivos venham com o envelhecimento, à população mais jovem definitivamente está sendo cada vez mais exposta a esse risco (COELHO et al., 2004).

Já a surdez é uma lesão "invisível”, mas que provoca sérios danos na relação de comunicação humana com o mundo. A diminuição da audição produz uma redução na percepção de sons e dificulta a compreensão das palavras. A sua evolução depende da causa e da gravidade da lesão. Sendo que se a exposição for repetitiva, a lesão causada na orelha interna poderá ser definitiva, e a surdez, portanto, será irreversível (PALÁCIOS; MARQUEZE, 2006).

É de se considerar que as emissões otoacústicas e a audiometria de altas frequências (de 9 a $16 \mathrm{kHz}$ ) são exames mais sensíveis que a audiometria convencional para detectar as pequenas lesões iniciais nas células ciliadas externas se tivesse sido realizado neste estudo, o número de alterações encontradas seria maior. (AZEVEDO,1997; LOPES et al., 2012)

A audiometria tonal de alta frequência (AT-AF) contribui para a detecção precoce de alterações dos limiares auditivos, promovendo uma rápida intervenção aos danos que elevados níveis de pressão sonora provocam na saúde auditiva. (SÁ et al., 2007; LOPES et al., 2009)

Como a perda auditiva não se manifesta nos primeiros anos de exposição ao som intenso, os jovens podem não se interessar e não ter conhecimento sobre medidas de prevenção auditiva (LACERDA et al., 2011). Embora KEPPLER et al. (2010) tenham dito que é muito cedo para detectar lesões permanentes dos recentes avanços da tecnologia dos equipamentos estéreo-pessoais, VOGEL et al. (2009) referiram que estratégias de prevenção da perda auditiva, nestes jovens, devem ser de responsabilidade das autoridades, e que a indústria da música e os 
fabricantes de equipamentos estéreo-pessoais devem reconhecer esta responsabilidade e criar equipamentos mais seguros.

$\mathrm{Na}$ cidade de Tubarão-SC, 21 músicos atuantes tiveram como principal sintoma que poderia estar relacionado à música o zumbido, seguido de plenitude auricular, dificuldade de compreensão de fala e tontura, as porcentagens foram respectivamente por sintoma, 52,40\%, 38,10\%, 28,60\% e 23,80\%. (MARTINS et al., 2008)

Na cidade de São Paulo- SP, foi realizado um estudo com 23 músicos com idades entre 21 e 38 anos, sendo a maior porcentagem (57\%) entre 21 e 26 anos. Entre as 50 principais queixas auditivas, o zumbido ficou em segundo lugar, atingindo $39 \%$ da população estudada, precedido apenas por intolerância a sons intensos, atingindo 48\% (MAIA; RUSSO, 2008)

Em Bauru- SP, foi realizado um estudo com músicos que atuassem há mais de dois anos, que estivessem expostos a ruídos de 85 dBNPS ou mais e tivessem entre 18 e 40 anos. O estudo teve um total de 30 participantes, e a queixa auditiva mais citada também foi o zumbido, seguida de dificuldade de compreensão de fala em ambientes ruidosos (AMORIM et al., 2008)

Um estudo realizado por Maia et al. (2007) com músicos de orquestras, observou-se que há uma assimetria de resultados audiológicos entre orelhas, tanto para os músicos com limiares dentro da normalidade, como para os que apresentaram perda de audição, evidencia uma característica ototraumática para os músicos.

Currie e Kennedy (2002) afirmam que os músicos não se dão conta que as quedas dos limiares de forma irreversíveis foram causadas em seus ouvidos, pois esse tipo de lesão é invisível e cumulativo. A audição musical é naturalmente vital à sua performance profissional. Assim, muitos músicos preferem correr os riscos a danos auditivos do que a comprometer a qualidade de sua música usando protetores auditivos comuns. Da mesma forma, Vinson (2004) afirma que os músicos estão sob grande risco de perda auditiva, pois começam a profissão com poucos anos de idade e ficam expostos ao longo de suas carreiras. Se esses profissionais não se conscientizarem desde cedo que estão propensos a ter perda auditiva, eles podem acabar sofrendo danos ainda maiores futuramente.

Pfeiffer et al. (2007) concluíram que músicos expostos a níveis de pressão sonora intensos apresentaram alteração temporária do limiar e alteração do reflexo 
acústico e, por esta razão, são profissionais de risco para perda auditiva ocupacional.

\subsection{USO DO EQUIPAMENTO DE PROTEÇÃO INDIVIDUAL (EPI)}

O protetor auditivo é um dispositivo que visa diminuir a transmissão de níveis de pressão sonora elevados aos ouvidos dos indivíduos expostos. Isso acontece porque a onda sonora ao incidir sobre o pavilhão auricular sofre uma modificação, na qual parte é absorvida, outra é refletida e uma terceira parte é transmitida, reduzindo a intensidade que chega à orelha interna (GERGES, 2000).

No caso dos músicos profissionais que não se enquadram na maioria das técnicas tradicionais de controle das exposições ocupacionais, não há alternativa senão o uso de protetores auditivos (GRACIOLLI, 2006).

Os protetores auditivos convencionais do tipo plug atenuam mais nas altas frequências do que em médias e baixas, fazendo com que a voz e a música não fiquem nítidas e se tornem artificiais. Esses protetores podem causar alguns inconvenientes para os indivíduos que trabalham com música, podendo ocasionar: efeito de oclusão, muita atenuação em geral e atenuação exagerada nas frequências altas (NIQUETTE, 2006).

A atenuação proporcionada pelos protetores comuns, se inseridos profundamente na orelha, pode chegar a valores de 30 a 40 dB. Tal atenuação é, muitas vezes, excessiva e desnecessária, podendo resultar em má percepção auditiva (SANTONI, 2008).

A atenuação exagerada nas altas frequências pode ocorrer porque a colocação do protetor na orelha altera o pico de ressonância natural do Meato Acústico Externo (MAE), que é de aproximadamente $17 \mathrm{~dB}$ em $2700 \mathrm{~Hz}$. A perda provocada pela inserção, quando combinada com as características de atenuação do plug, resulta em um corte dos sons de frequências mais altas, por volta de 15 a $20 \mathrm{~dB}$. Tal atenuação interfere no balanço tonal, que também pode resultar em uma má percepção auditiva e, com isso, em exagero ao tocar para compensar a falta das altas frequências (NIQUETTE, 2006).

A principal característica dos protetores auditivos específicos para músicos é ter atenuação uniforme, ou seja, não atenuar mais as frequências altas em relação às médias e baixas, como acontece com protetores comuns. São denominados de 
alta fidelidade (HiFi -highest-fidelity) porque a música mantém sua qualidade original, porém com menor nível sonoro. Os modelos personalizados podem oferecer redução de $9 \mathrm{~dB}, 15 \mathrm{~dB}$ ou $25 \mathrm{~dB}$, de acordo com o filtro utilizado. A escolha do filtro deve ser realizada baseada no tipo de exposição sonora. Já o modelo pré-moldado pode oferecer atenuação de 20 dB (CHASIN, BEHAR, 2003; NIQUETTE, 2006).

A atenuação de ruído dos protetores convencionais, tanto do tipo concha como do tipo plugue, é geralmente baixa em frequências graves e alta em frequências agudas, resultando em distorção dos sons recebidos com o uso do protetor (efeito de oclusão) (GERGES, 2003). Atualmente têm sido oferecidos aos músicos, nos mercados nacional e internacional, protetores auditivos específicos de inserção. Estes protetores permitem um equilíbrio de atenuação de todas as frequências, através da diminuição uniforme do som, evitando o efeito de oclusão e, consequentemente, a distorção do som. As opções vão desde modelos simples com tamanho padrão, que oferecem diferentes atenuações à música, até protetores com moldes personalizados (MENDES; MORATA; MARQUES, 2007).

Para que os músicos tenham sua audição preservada e continuem ouvindo o som da música que estão produzindo sem nenhuma distorção, é necessário o uso de protetores com filtro linear, o que possibilita a audição do som original atenuado, porém com a mesma qualidade, mantendo assim o pico de ressonância natural do meato acústico externo (FREIRE, 2014).

Existem protetores personalizados, manufaturados a partir de uma prémoldagem, possuindo filtros lineares de $9 \mathrm{~dB}, 15 \mathrm{~dB}$ e $25 \mathrm{~dB}$, que podem ser trocados quando necessário. A escolha do filtro para o músico depende do nível pressão sonora, do tempo de exposição e do tipo de instrumento que toca. Caso a opção seja melhor custo-benefício, é indicado o protetor universal, com filtro linear fixo de 20dB (FREIRE, 2014).

Os monitores in-ears trazem muitos benefícios, como melhor qualidade sonora, melhor imagem estéreo, menor esforço vocal, portabilidade, aumento de ganho antes do feedback e menor volume no palco, pois proporcionam ao músico ouvir com clareza e definição a mixagem do som num volume desejável e seguro (FREIRE, 2014).

Existem dois tipos de monitores individuais: os universais e os personalizados. Eles se diferenciam no que os universais têm a vantagem de poder ser utilizado por vários músicos, desde que as espumas sejam substituídas e os 
personalizados são manufaturados especialmente para cada músico (FREIRE, 2014). O monitor in-ear de boa qualidade proporciona um isolamento acústico mínimo de 25dB e deve ser utilizado binaural (FREIRE, 2014).

\subsection{PROGRAMA EDUCATIVO}

Embora não haja tratamento para perda auditiva permanente causada por exposição a altos níveis de pressão sonora, há prevenção; essa prevenção pode ser feita por meio de Programas de Prevenção de Perdas Auditiva (PPPA), que também podem ser chamados de Programas de Conservação Auditiva (PCA) (EL DIB et al., 2008).

Pouco se sabe sobre o que pode ser eficaz em estratégias de prevenção. São poucas as informações sobre a exposição a elevados níveis de pressão sonora nas atividades de lazer, mas acredita-se que através da educação de crianças e adolescentes sobre a importância da audição e as consequências da perda auditiva e as formas de proteção, é possível uma atuação efetiva neste cenário. (ZOCOLI; MORATA, 2010)

Músicos como Pete Townshend (The Who), Rod Stewart, James Hetfield (Metallica), Alex (Van Halen), Lulu Santos e Rogério Flausino (Jota Quest), que são expostos a sons muito intensos, vêm relatando terem desenvolvido não só perda auditiva, como também o zumbido. Eles acreditam que isso se deve à exposição aos níveis elevados de pressão sonora, durante ensaios e shows (MIRANDA; DIAS, 1998).

Um programa de conservação auditiva, quando bem administrado, pode reduzir drasticamente os riscos auditivos associados a altos níveis de exposição sonora, mantendo a qualidade de vida pessoal e profissional (SANTUCCI, 1990).

Santos et al. (1996) definem o Programa de Conservação Auditiva (PCA) como um conjunto de medidas a serem desenvolvidas com o objetivo de prevenir a instalação ou evolução de perdas da audição. Adotar medidas de intervenção é uma forma de prevenir, a fim de eliminar e/ou controlar o ruído, mediante alterações ambientais, de equipamentos e de adequados projetos para novas instalações. Estes autores apresentam também o "protocolo" de aspectos básicos do PCA, que tem como base as recomendações propostas pela OSHA (1993) - 28 CFR 1910.95 Occupational Noise Standard e pelo NIOSH. (SANTOS et al., 1996): 
1. Avaliação e monitoramento da exposição a ruído;

2. Medidas de controle ambiental e organizativos;

3. Avaliação e monitoramento audiológico;

4. Uso de protetores auriculares;

5. Aspectos educativos;

6. Avaliação da eficácia do programa.

A perda da audição é irreversível, podendo afetar o desempenho do músico, por isso qualquer grau de perda auditiva para o músico dificulta sua percepção para alguns tons, timbres, afetando o equilíbrio entre os instrumentos e, em consequência, sua atuação profissional. $O$ cenário atual sugere a necessidade de um maior envolvimento de fonoaudiólogos na promoção da saúde auditiva de músicos (MENDES; MORATA, 2007).

A metodologia ativa é uma importante metodologia que pode ser empregada em grupos, pois levam o ouvinte a refletir sobre seus problemas e o ajudam a solucioná-lo de maneira interativa entre o falante versus ouvinte, fazendo com que o ouvinte não apenas ouça mas interaja no processo de ensino- aprendizagem.

As metodologias de ensino-aprendizagem propõem desafios a serem superados, possibilitando-os de ocupar o lugar de sujeitos na construção do conhecimento, participando da análise do processo assistencial, e colocando o professor como facilitador e orientador desse processo (BRASIL,2007).

O grande desafio da Metodologia Ativa é aperfeiçoar a autonomia individual e uma educação capaz de desenvolver uma visão do todo - transdisciplinar (MITRE et al., 2008), que possibilite a compreensão de aspectos cognitivos, afetivos, socioeconômicos, políticos e culturais, constituindo uma prática pedagógica socialmente contextualizada (BERBEL,1999).

Com base nos resultados desta pesquisa, cujo objetivo era investigar a adaptação do discente em sua formação acadêmica na metodologia ativa, foi possível identificar que os mesmos se percebem ajustados a esse tipo de modelo de ensino. Relatam ter adquirido habilidades de raciocínio clínico, tomada de decisão e sentem-se confiantes na autoaprendizagem. Destacaram o desejo de que os tutores não respondam a seus questionamentos (resposta pronta), mas os auxiliem na construção do conhecimento (MELO; SANT'ANA, 2012). 
As metodologias ativas utilizam a problematização como estratégia de ensinoaprendizagem, com o objetivo de alcançar e motivar o discente, pois, diante do problema, ele se detém, examina, reflete, relaciona a sua história e passa a ressignificar suas descobertas. A problematização pode levá-lo ao contato com as informações e à produção do conhecimento, principalmente com a finalidade de solucionar os impasses e promover o seu próprio desenvolvimento. Ao perceber que a nova aprendizagem é um instrumento necessário e significativo para ampliar suas possibilidades e caminhos, esse poderá exercitar a liberdade e a autonomia na realização de escolhas e na tomada de decisões (CYRINO; TORALLES- PEREIRA, 2004).

Zanotto e Rose (2003) discutem a problematização em Dewey, Saviani e Freire. Para o primeiro, é enfatizado o sujeito ativo, que precisa ter uma situação autêntica de experiência, com propósitos definidos, interessantes e que estimulem o pensamento. Após observar a situação, irá buscar e utilizar as informações e instrumentos mais adequados, devendo o resultado do trabalho ser concreto e comprovado por meio de sua aplicação prática. Para Saviani, a noção do problema se apresenta como em Dewey, porém a busca da resposta é identificada com a reflexão filosófica, que impõe requisitos de radicalidade, rigor e globalidade relacionados dialeticamente. Já em Freire, a ação de problematizar enfatiza a práxis, na qual o sujeito busca soluções para a realidade em que vive e o torna capaz de transformá-las pela sua própria ação, ao mesmo tempo em que se transforma. Nessa ação, ele detecta novos problemas num processo ininterrupto de buscas e transformações

De acordo com Berbel (1998), na problematização, o sujeito percorre algumas etapas e, nesse processo, irá refletir sobre a situação global de uma realidade concreta, dinâmica e complexa, exercitando a práxis para formar a consciência das práxis.

A educação e a conscientização do músico deve ser o foco principal presente nos programas de prevenção e conservação auditiva, onde o objetivo é proteger um dos órgãos mais importantes para o seu desempenho profissional, social, além de ser um mecanismo de defesa de para sua segurança pessoal (ALMEIDA et al., 2008).

É recomendável para a conservação auditiva que os músicos não permaneçam expostos diretamente as caixas de som. É importante também reduzir 
o volume dos equipamentos sonoros nos ensaios; utilizar EPIs quando necessários e evitar exposição extraocupacional ao ruído, como por exemplo a utilização de fones de ouvido com volume alto (ALMEIDA et al., 2008).

Estudo realizado por Fiorini e Santoni (2010) mostrou correlação positiva entre a presença de queixas auditivas e a sensação de diminuição do zumbido após o uso do protetor auditivo, na população dos músicos.

A prevenção é entendida como a adoção de intervenções que têm objetivo a eliminação e/ou controle do ruído. Assim existe um "protocolo" que apresenta as recomendações propostas pela OccupationalSafaty\& Health Administration (OSHA) em 1983 e pelo Nationallnstitute for OccupationalSafetyand Health (NIOSH), que tem como base os aspectos do Programa de Conservação Auditiva: a avaliação e monitoramento da exposição; as medidas de controle ambiental; a avaliação e monitoramento audiológico; o uso de protetores auriculares; os aspectos educativos; e a avaliação de eficácia (MATOS et al., 1999).

Segundo Mendes e Morata (2007), estudos têm demonstrado distúrbios auditivos entre os músicos e, assim como no meio ocupacional, sugerem a necessidade de programas de prevenção de perdas auditivas.

No meio ocupacional, são encontradas várias barreiras para a implementação e continuidade nos programas. Entre os músicos, o assunto torna-se ainda mais delicado (MENDES; MORATA, 2007).

A seguir segue o quadro com o resultado do levantamento sobre formas de conservação da audição entre músicos, estudo realizado por Mendes e Morata (2007). 
Quadro 1 - Programas de conservação auditiva para músicos.

\begin{tabular}{|c|c|c|}
\hline Programa de conservaçăo auditiva para músicos & Referência & Comentários \\
\hline $\begin{array}{l}\text { Uso de proteçăo auditiva de impressăo individual, } \\
\text { modificaçăo acústica no ambiente, orientaçăo ao músico, } \\
\text { acompanhamento audiológico. }\end{array}$ & Santucci ${ }^{(10)}$ & $\begin{array}{l}\text { Impressão do protetor profunda para reduzir fenômeno } \\
\text { de oclusão, orientaçăo sobre riscos da exposiçăo à } \\
\text { música, conhecimento básico de anatomia e fisiologia } \\
\text { da audiçăo. }\end{array}$ \\
\hline $\begin{array}{l}\text { Conscientizaçăo do músico, melhora da qualidade } \\
\text { acústica do local de ensaio. }\end{array}$ & Namur et al. ${ }^{(1)}$ & Audiologista deve ser procurado anterior ao uso. \\
\hline $\begin{array}{l}\text { Avaliaçăo audiológica, levantamento da história médica } \\
\text { e musical, uso de proteçăo auditiva e monitores individuais. }\end{array}$ & Lowery ${ }^{(24)}$ & $\begin{array}{l}\text { Ambientes no geral reverberantes passar a ter material } \\
\text { absorventes nas paredes e teto e carpete pesado no piso. }\end{array}$ \\
\hline $\begin{array}{l}\text { Tratamento acústico no local de ensaio e proteçăo auditiva } \\
\text { adequada. }\end{array}$ & Early e Horstman ${ }^{(17)}$ & $\begin{array}{l}\text { Mantêm a fidelidade de reproduçăo da música, sem } \\
\text { comprometer a habilidade auditiva. }\end{array}$ \\
\hline $\begin{array}{l}\text { Uso de protetores auditivos apropriados, modificaçōes } \\
\text { ambientais e conscientizaçăo dos músicos. }\end{array}$ & Chasin $^{(6)}$ & Elevaçăo dos auto-falantes e amplificadores. \\
\hline $\begin{array}{l}\text { Uso de protetor de atenuaçăo plana (ER-15, ER-20, ER-25, } \\
\text { ER-9) Etymothic Research. }\end{array}$ & Briskey $y^{(25)}$ & $\begin{array}{l}\text { Filtra o som de entrada, diminuindo a intensidade sem } \\
\text { distorçăo. }\end{array}$ \\
\hline $\begin{array}{l}\text { Planejamento cuidadoso do repertório, uso do protetor } \\
\text { auditivo adequado, educação dos músicos, controle } \\
\text { audiológico e distanciamento entre músicos e outras } \\
\text { fontes sonoras. }\end{array}$ & Samelli e Schochat ${ }^{(22)}$ & $\begin{array}{l}\text { Minuto de silêncio entre uma sinfonia e outra, sem } \\
\text { afinaçăo de instrumentos. }\end{array}$ \\
\hline $\begin{array}{l}\text { Conscientizaçăo do músico, melhora da qualidade } \\
\text { acústica do local de ensaio. }\end{array}$ & Marchiori e Mello(13) & Possibilitar a detecçăo precoce da perda auditiva. \\
\hline $\begin{array}{l}\text { Monitoramento audiológico, através de audiomentria tonal, } \\
\text { EOA e teste de reconhecimento de fala no ruído. }\end{array}$ & Kăhäri et al..$^{(5)}$ & Determinar suscetibilidade individual. \\
\hline Acompanhamento audiológico. & Andrade et al..$^{(11)}$ & Conscientizaçăo dos músicos. \\
\hline $\begin{array}{l}\text { Tratamento acústico da sala de ensaio e uso de protetores } \\
\text { auditivos adequados. }\end{array}$ & Mendes et al. ${ }^{(8)}$ & $\begin{array}{l}\text { Para năo ultrapassar nível de pressăo sonora } \\
\text { especificado na NR15. }\end{array}$ \\
\hline Uso de protetores de atenuação uniforme. & Gerges $^{(26)}$ & $\begin{array}{l}\text { Reduz o ruído sem mudar a forma espectral do som } \\
\text { original na frequêencia. }\end{array}$ \\
\hline Uso de Protetor auditivo tipo plugue HiFi ER-20. & Graciolli(27) & Tamanho único, ajustável para o maior conforto. \\
\hline Uso de proteçăo auditiva adequada. & Laitinen et al. ${ }^{(14)}$ & Primordial a motivaçăo do artista e pessoal técnico. \\
\hline $\begin{array}{l}\text { Uso do } \mathrm{N} \text {-acettylcysteine (NAC) - substância antioxidante } \\
\text { como suplemento alimentar. }\end{array}$ & Kwuitko(28) & Proteçăo dos ouvidos para música em forte intensidade. \\
\hline
\end{tabular}

Fonte: Mendes e Morata (2007).

A perda auditiva induzida pelo ruído tem caráter lento e progressivo, sendo somente percebida quando atinge grau acentuado, afetando a comunicação humana de forma irreversível (MENDES; MORATA, 2007).

Os músicos têm as mesmas dificuldades com a exposição à música, porém estes não recebem informações sobre alternativas preventivas. No momento, não 
existe no Brasil nenhuma legislação que os proteja contra os altos níveis de pressão sonora aos quais são expostos, nem sobre programas de conservação auditiva (MENDES; MORATA, 2007).

Mendes e Morata (2007) enfatizam que os programas para prevenção de perdas auditivas (PPPA) são necessários, pois a perda da audição é irreversível, podendo afetar o desempenho do músico. Qualquer grau de perda auditiva para o músico dificulta sua percepção para alguns tons e timbres, afetando o equilíbrio entre os instrumentos e, em consequência, sua atuação profissional. O cenário atual sugere a necessidade de um maior envolvimento de fonoaudiólogos na promoção da saúde auditiva de músicos. 
Proposição 


\section{PROPOSIÇÃO}

\subsection{OBJETIVO GERAL}

Submeter os músicos ao programa de prevenção de perdas auditivas (PPPA) e verificar sua eficácia.

\subsection{OBJETIVO ESPECÍFICO}

Investigar os níveis de pressão sonora em que os músicos estão inseridos durante o ensaio musical e show, traçar o perfil audiológico, elaborar um material instrucional e promover um programa de educação em saúde junto aos componentes das bandas (músicos). 
Materiais e métodos 


\section{MATERIAIS E MÉTODOS}

\subsection{LOCAL}

Este estudo foi conduzido pelo Departamento de Fonoaudiologia da Faculdade de Odontologia de Bauru, da Universidade de São Paulo, Campus de Bauru, após aprovação do Comitê de Ética em Pesquisa desta Faculdade.

Este projeto foi aprovado na reunião ordinária do Comitê de Ética em Pesquisa em Seres Humanos datado de 30/04/2014, de acordo com a Resolução CNS 466/12, CAAE 30315914.7.0000.5417de número 640.183 (Anexo 1).

Os participantes receberam esclarecimentos sobre os objetivos $\mathrm{e}$ procedimentos da pesquisa e foram convidados a assinar um termo de consentimento atestando sua permissão para a participação na pesquisa e utilização dos dados obtidos para fins científicos (Anexo 2).

\subsection{MÉTODO:}

\subsubsection{Detalhamento da proposta}

Participaram desta pesquisa componentes de quatro bandas de rock, contendo uma amostra de16 participantes em idade variada.

A seleção dos participantes foi realizada por meio de convite feito pela pesquisadora a partir das informações de shows realizados nas casas noturnas de Bauru- SP. Após o convite aos integrantes das bandas, foram orientados sobre os objetivos da pesquisa e solicitados a assinarem o Termo de Consentimento Livre e Esclarecido (TCLE).

As bandas participantes foram convidadas a irem até a Clínica de Fonoaudiologia da Universidade de São Paulo para a realização das avaliações audiológicas e aplicação de um questionário elaborado pela pesquisadora. Portanto, foram entregues a cada participante um questionário sobre as características de sua banda musical (Anexo 3). O teste estatístico aplicado neste estudo foram o Teste- $T$ e o teste Qui- Quadrado.

Este estudo foi composto por quatro fases que contemplam o Programa de Prevenção de Perdas Auditivas (PPPA), ao qual tem como objetivo a identificação 
de riscos, monitoramento auditivo, medida de proteção contra ruído e medidas educativas, divididos posteriormente em duas etapas.

Como critério de inclusão, considerou- se o aceite em participar da pesquisa e assinar o TCLE, o tempo mínimo de cinco anos trabalhados com a música sem interrupção, sendo que os componentes que formam a banda deveriam ter no mínimo cinco meses de trabalho junto na banda. As bandas deveriam realizar ensaios semanais de no mínimo três horas diretas (ininterruptas) e fazer shows toda a semana.

Nos critérios de exclusão, adotou-se a recusa de algum dos integrantes das bandas selecionadas, ou seja, todos os componentes deveriam participar do estudo ou a não participação da banda em alguma das fases do programa de prevenção de perdas auditiva e alterações no meato acústico externo que impedissem o uso de EPI.

Tal estudo possuiu duas etapas sendo:

1.1.0. Os músicos, componentes das bandas, foram submetidos ao Programa de Prevenção de Perdas Auditivas (PPPA) que contemplam:

1.1.1. Medição do Nível de Pressão Sonora (NPS) nos ensaios e shows: a pesquisadora foi até o local onde as bandas participantes realizam seus ensaios e show, a fim de medir o NPS por meio do medidor de pressão sonora Instrutherm. O manuseio desse equipamento durante o ensaio foi direcionando o microfone do aparelho de forma a ficar no ponto de encontro do ruído, já durante a medição realizada no show o equipamento ficou a uma distância de aproximadamente três metros do palco. A ordem das bandas analisadas ocorreu conforme sua agenda para receber a pesquisadora.

1.1.2. Avaliação audiológica: a avaliação audiológica foi realizada por meio dos procedimentos descritos a seguir:

1.1.2.1. Entrevista específica: histórico de saúde geral e da audição dos participantes, assim como sua inserção na área musical (tempo de estudo, intensidade sonora, tipo de instrumento etc.);

1.1.2.2. Audiometria Tonal Liminar por via aérea e via óssea e de altas frequências: foi realizada a pesquisa dos limiares auditivos por via aérea nas frequências de $0,25 \mathrm{~Hz}$ a $20 \mathrm{KHz}$. A avaliação para audiometria tonal convencional (AT-AC) e audiometria tonal de altas frequências (AT- AF) foi 
realizada em cabine audiométrica, sendo utilizado o audiômetro AC 40/Interacoustics para apresentação de estímulos via fones do tipo TDH 39 e HDA 200 respectivamente. Foi utilizado o método descendenteascendente (LOPES; MUNHOZ; BOZZA, 2015), para a pesquisa dos limiares tonais, sendo estabelecido o limiar auditivo em $50 \%$ das respostas positivas à detecção do som.

Os estímulos sonoros foram diminuídos de $10 \mathrm{em} 10 \mathrm{~dB}$ até que o indivíduo deixasse de apresentar resposta comportamental ao som (levantar a mão quando ouvisse). A partir de então, o estímulo foi aumentado $5 \mathrm{~dB}$ até se obter novamente a resposta. $O$ limiar auditivo foi determinado como a menor intensidade de som capaz de eliciar uma resposta auditiva em $50 \%$ das apresentações.

Para audiometria tonal por via óssea, foi utilizado o mesmo método descendente-ascendente (LOPES; MUNHOZ; BOZZA, 2015) para pesquisar o limiar auditivo nas frequências de $0,5 \mathrm{~Hz}$ a $4 \mathrm{KHz}$. A pesquisa por via óssea foi realizada quando os limiares de via aérea estavam rebaixados, sendo utilizado um vibrador ósseo posicionado na mastoide.

As audiometrias foram classificadas, de acordo com a Organização Mundial de Saúde - OMS (2014), com relação ao grau de perda auditiva (audição normal, leve, moderada, severa e profunda) pela média entre as frequências que recebem essa classificação até $4 \mathrm{kHz}(500,1.000,2.000$ e $4.000 \mathrm{kHz}$ ). Foram classificadas também, de acordo com a Portaria oㅜ 19 do Ministério do Trabalho, que estabelece que a diferença entre as médias aritméticas dos limiares auditivos no grupo de frequências de $3.000,4.000$ e $6.000 \mathrm{~Hz}$ seja igual ou ultrapasse $10 \mathrm{~dB}$ NA ou a piora em pelo menos uma das frequências de $3.000,4.000$ ou $6.000 \mathrm{~Hz}$ seja igual ou ultrapasse $15 \mathrm{~dB}$ NA. Para a classificação da AT- AF, adotou-se 0 trabalho de Burguetti, Peloggia e Carvallo (2004) para cada frequência e faixa etária. Foram estabelecidos os seguintes valores para normalidade por faixa etária (Tabela 1). 
Tabela 1 - Valores de corte para normalidade na audiometria de altas frequências em $\mathrm{dB}$ NA, por faixa etária, segundo Burguetti, Peloggia e Carvallo (2004).

\begin{tabular}{|c|c|c|c|c|c|c|c|}
\hline & $9 \mathrm{KHz}$ & $10 \mathrm{KHz}$ & $12,5 \mathrm{KHz}$ & $14 \mathrm{KHz}$ & $16 \mathrm{KHz}$ & $18 \mathrm{KHz}$ & $20 \mathrm{KHz}$ \\
\hline \multicolumn{8}{|l|}{ Faixa etária } \\
\hline 20- 29a. & 15 & 15 & 15 & 15 & 30 & 30 & 10 \\
\hline 30- 39a. & 30 & 30 & 35 & 45 & 35 & 55 & 15 \\
\hline$\geq 40 \mathrm{a}$. & 30 & 35 & 55 & 90 & 60 & 40 & 20 \\
\hline
\end{tabular}

Legenda: a- anos de idade

Fonte: Burguetti, Peloggia e Carvallo (2004).

O estímulo utilizado para pesquisa do liminar auditivo durante a audiometria tonal liminar convencional (AT-AC) e audiometria tonal de alta frequência (AT- AF), foi o warble.

1.1.2.3. Logoaudiometria: foram pesquisados o Limiar de Reconhecimento de Fala (LRF) utilizando palavras dissílabo se o Índice Percentual de Reconhecimento de Fala (IPRF), para avaliar a habilidade de perceber e reconhecer os sons da fala.

Os participantes foram orientados a repetir as palavras apresentadas a viva-voz e repeti-las como entendesse. Para o LRF, foram consideradas como aceitável as respostas iguais ou até $10 \mathrm{~dB}$ acima da média tritonal (500, 1000 e $200 \mathrm{~Hz}$ ) na ATL (SANTOS; RUSSO, 1991). Para o IPRF, a porcentagem de acertos considerada estava entre $88 \%$ e 100\% (GATES; CHAKERES, 1988).

O equipamento utilizado para a realização da Logoaudiometria foi o audiômetro AC 40/ Interacoustics, e para apresentação de estímulos via fones foi utilizado o TDH 39.

1.1.2.4. Imitanciometria: dois tipos de testes são realizados:

Timpanometria, que avalia a complacência da orelha média, ou seja, a condutância sonora das estruturas das orelhas externa e média e o Reflexo Estapédico, que avalia a integridade do arco reflexo estapediano e, por consequência, de forma indireta, as estruturas das orelhas média e interna, nervo auditivo e tronco cerebral. Foi utilizado o Imitanciometro multifrequêncial AT 235 para ambos os testes, nas frequências de 500 , 1000,2000 e $4000 \mathrm{~Hz}$. As curvas timpanométricas foram classificadas de acordo com a proposta de Jerger (1970); os reflexos acústicos ipsilaterais 
entre 80 e 95 dB NA e contralaterais entre 90 e 105 dB NA foram considerados normais, segundo a classificação de Carvallo et al. (2000). Antecendo a realização do exame, o participante foi orientado a permanecer sentado confortavelmente e em silêncio. Os testes foram realizados fora da cabina acústica, em sala tratada acusticamente.

1.1.2.5. Pesquisa das emissões otoacústicas evocadas (ILO 292) que incorpora o software ILOv6-Otodynamics: investiga a funcionalidade das células ciliadas externas, permitindo a investigação das deficiências auditivas de origem periférica de neonatos, população especial e qualquer outra faixa etária. A pesquisa das emissões otoacústicas auxilia no diagnóstico diferencial da perda auditiva sensorioneural. Para registrar as Emissões Otoacústicas Evocadas por estímulos transientes (EOEt) foi utilizado o estímulo do tipo click, caracterizado por ser de curta duração composto por uma faixa de frequências abrangente, predominantemente entre $500 \mathrm{e}$ $4000 \mathrm{~Hz}$. Esse estímulo transiente estimula a cóclea em diferentes regiões, desde a base até o ápice e quando presente, sugere que os limiares audiométricos estão próximos da normalidade (LONSBURRYMARTIN et al., 2001). Já o registro das emissões otoacústicas evocadas por produto de distorção (EOEpd) é eliciado a partir da interação não linear de dois tons puros apresentados simultaneamente, que resulta em um terceiro tom (distorção). A frequência primária mais baixa é denominada $\mathrm{f} 1$, enquanto que a frequência primária mais alta é chamada f2. Ambas se relacionam na razão de 1,22, ou seja, $\mathfrak{f} 2 / \mathfrak{f} 1=1,22$. Devido à característica de não linearidade da cóclea, a distorção é observada de forma mais proeminente na relação de $2 f 1-f 2$. Já seus respectivos níveis, L1 e L2, devem manter uma diferença na qual L1>L2, em média 10 dBNPS (decibel nível de pressão sonora), a fim de tornar o teste mais sensível (LONSBURRY-MARTIN et al.,2001). Segundo GORGA et al.(2002), as EOEpd estão presentes em indivíduos com audição próxima à normalidade e vão reduzindo conforme aumenta o grau da perda auditiva. O critério utilizado para presença de respostas foi o de GORGA (1996) que preconiza que EOEpd está presente quando a resposta, em dBNPS, está pelo menos 6 dBNPS acima do primeiro desvio padrão do 
ruído equivalente da frequência avaliada ou 3 dBNPS acima do segundo desvio padrão do ruído.

Para aqueles que não obtiveram respostas durante a avaliação das EOAPD, foram pesquisadas as respostas das curvas de crescimento (dp growth rate).

1.1.3. Workshop: esta etapa foi realizada por meio do workshop desenvolvido pela pesquisadora, objetivando a conscientização e o aperfeiçoamento dos profissionais participantes. Foi realizado um workshop de forma que as bandas fossem trabalhadas conjuntamente. A metodologia utilizada para tal foi a Metodologia Ativa, a fim de conscientizá-los sobre a importância de se manter atitudes preventivas a distúrbios auditivos.

Os temas abordados no conteúdo do workshop foram a respeito sobre o que é e como ocorre a PAINPSE, importância da realização de avaliações audiológicas de rotina, importância do repouso auditivo durante 24 horas após exposição a níveis de pressão sonora (NPS) elevados e utilizar equipamentos de proteção individual ("protetores auditivos").

1.2.0. Verificar a efetividade do PPPA/workshop: para avaliação da eficácia das atividades, foram aplicados questionários antes e após o workshop. O primeiro tinha o objetivo de avaliar o que os músicos sabem sobre Fonoaudiologia, o que conhecem da profissão, como acreditam que esse profissional atua, se já fizeram algum acompanhamento fonoaudiológico e se possuem conhecimentos sobre protetores auditivos. Quanto ao segundo, foi aplicado ao término do workshop com o intuito de qualificar as informações expostas pelos instrutores, podendo observar no questionário se houve mudança de comportamento em relação à Fonoaudiologia e sobre o risco de perda auditiva (Anexo 4).

Foi elaborado um website ${ }^{2}$ que abordaram o caminho do som e como escutamos, os cuidados a serem tomados com a saúde auditiva desta população, a importância do uso dos protetores auditivos (EPI) e da implementação do PPPA, o repouso auditivo e como a Fonoaudiologia atua neste processo. Foi utilizada linguagem simples para que a comunicação

\footnotetext{
2 Disponível em: <http://saudeauditiva.wix.com/samb>.
} 
fosse efetiva, além conter imagens e vídeos ilustrativos, sendo ambos de fácil compreensão ao público-alvo.

Os esclarecimentos de dúvidas ocorreram durante o workshop, onde foram reservados momentos para essa atividade, além do contato com a pesquisadora que esteve disposta a responder às dúvidas dos participantes durante todo o processo de realização do projeto. 
$\underline{\text { Resultados }}$ 


\section{RESULTADOS}

\subsection{CARACTERIZAÇÃO DA AMOSTRA}

Foram convidados para este estudo 10bandas de rock, por meio de convites realizados pela pesquisadora, a partir das informações de shows realizados nas casas noturnas de Bauru- SP. As bandas obedeciam aos fatores de inclusão e exclusão para o estudo. Sete bandas compareceram à Clínica de Fonoaudiologia, contudo apenas quatro concluíram o estudo, já que todos os integrantes da banda participaram de todas as etapas. A amostra foi composta por 16 participantes (4 bandas) do sexo masculino (100\%), sendo que 13 (81,25\%) apresentavam zumbido bilateral do tipo apito, ou seja, apenas 3 (18,75 \%) participantes não apresentavam zumbido e em razão disso o estímulo utilizado para pesquisa do liminar auditiva durante a audiometria tonal liminar convencional (AT-AC) e audiometria tonal de alta frequência (AT- AF) foi o warble. A idade dos participantes variou entre 21 e 36 anos.

Devido ao fato de as bandas serem compostas por diferentes instrumentos, analisamos estatisticamente por associação aqueles instrumentos (voz, guitarra, baixo e bateria) que estavam presentes nas quatro bandas, já aqueles que não estavam presentes em todas as bandas (trompete e trombone) foram analisados separadamente, de forma a ser realizado uma análise estatística descritiva.

Os participantes responderam ao questionário sobre as características da banda musical, elaborado pela pesquisadora; passaram por avaliação audiológica, composta pela inspeção do Meato Acústico Externo (MAE), audiometria tonal liminar convencional(AT-AC)por via aérea e via óssea e audiometria tonal de alta frequência (AT-AF), logoaudiometria, imitanciometria, Emissões Otoacústicas Evocadas por estímulo transiente (EOEt) e por produto de distorção (EOApd), assim como a pesquisa da curva de crescimento ( $d p$ growth rate). Além de responderem ao questionário e passarem por avaliação audiológica, também passaram pelas demais etapas do Programa de Prevenção de Perdas Auditivas (PPPA).

Todos os participantes estavam em repouso acústico de, no mínimo 24 horas, antes de realizarem os exames audiológicos.

Neste capítulo é apresentada a proposta de Programa de Prevenção de Perdas Auditivas (PPPA) desenvolvida e sua análise estatística dos resultados à 
qual os músicos foram submetidos. Assim, para fins didáticos, esse capítulo será dividido em duas partes:

5.1.0. Submeter os músicos, componentes das bandas, ao Programa de Prevenção de Perdas Auditivas (PPPA) que contempla quatro etapas: medição do Nível de Pressão Sonora (NPS) nos ensaios e shows, avaliação audiológica (inspeção do Meato Acústico Externo (MAE), exames audiológicos e entrevista específica), seleção do equipamento de proteção individual (EPI) e realização do workshop.

5.2.0. Verificar a efetividade do PPPA/workshop por meio de aplicação de questionários antes e após a sua realização.

\subsubsection{Submeter os músicos, componentes das bandas, ao Programa de Prevenção de Perdas Auditivas (PPPA)}

\subsubsection{Medição do Nível de Pressão Sonora (NPS) nos ensaios e shows}

A pesquisadora dirigiu-se até o local onde as bandas participantes realizam seus ensaios e show, a fim de medir o Nível de Pressão Sonora (NPS), sendo este realizado por meio do Medidor de pressão sonora Instrutherm.

De acordo com a norma regulamentadora $n^{\circ} 15$ (NR 15) que estabelece que os limites de tolerância para ruídos contínuos ou intermitentes são de 85 dB (A) por 8 horas diárias de trabalho, para ruídos de impacto (que duram menos que 1 segundo e têm intervalos maiores que 1 segundo), o Limite de Tolerância é de 130 $\mathrm{dB}$ (linear) ou $120 \mathrm{~dB}(\mathrm{C})$. Os trabalhadores que ficam expostos a níveis maiores que os estabelecidos devem ter sua exposição neutralizada usando equipamentos de proteção individual (EPI), afim de preservar sua audição, como demonstrado naTabela2.

As intensidades do NPS coletadas durante ensaio e show tiveram resultados apresentados na Tabela3 acima do permitido por lei já citada anteriormente; contudo, tais coletas referem-se a um tempo médio de 1 hora, período em que a pesquisadora coletou os dados. 
Tabela 2 - NR.15 limites de tolerância x tempo de exposição para ruídos contínuos ou intermitentes.

Nível de ruído dB (A)

Máxima exposição diária permitida

\begin{tabular}{lc}
85 & $8 \mathrm{~h}$ \\
86 & $7 \mathrm{~h}$ \\
87 & $6 \mathrm{~h}$ \\
88 & $5 \mathrm{~h}$ \\
89 & $4,5 \mathrm{~h}$ \\
90 & $4 \mathrm{~h}$ \\
91 & $3,5 \mathrm{~h}$ \\
92 & $3 \mathrm{~h}$ \\
93 & $2,40 \mathrm{~h}$ \\
94 & $2,15 \mathrm{~h}$ \\
95 & $2 \mathrm{~h}$ \\
96 & $1,45 \mathrm{~h}$ \\
98 & $1,15 \mathrm{~h}$ \\
100 & $1 \mathrm{~h}$ \\
102 & $45 \mathrm{~min}$. \\
104 & $35 \mathrm{~min}$. \\
105 & $30 \mathrm{~min}$. \\
106 & $25 \mathrm{~min}$. \\
108 & $20 \mathrm{~min}$. \\
110 & $15 \mathrm{~min}$. \\
112 & $10 \mathrm{~min}$. \\
114 & $8 \mathrm{~min}$. \\
115 & $7 \mathrm{~min}$. \\
\hline &
\end{tabular}

Fonte: Norma Regulamentadora n 15 - NR15. 
Tabela 3 - NPS produzido pela banda durante ensaio e show.

\begin{tabular}{llll}
\hline & BANDA & Durante ensaio & Durante show \\
B1 & Máximo & $106.9 \mathrm{dBNPS}$ & $106.2 \mathrm{dBNPS}$ \\
& Mínimo & $103.3 \mathrm{dBNPS}$ & \\
B2 & Máximo & $109.2 \mathrm{dBNPS}$ & $106.3 \mathrm{dBNPS}$ \\
B3 & Mínimo & $106.3 \mathrm{dBNPS}$ & \\
& Máximo & $106.2 \mathrm{dBNPS}$ & $106.2 \mathrm{dBNPS}$ \\
& Mínimo & $102.3 \mathrm{dBNPS}$ & \\
& & $106.2 \mathrm{dBNPS}$ & $106.2 \mathrm{dBNPS}$ \\
& Máximo & $105.3 \mathrm{dBNPS}$ & \\
\hline
\end{tabular}

Legenda: dBNPS- decibel Nível de Pressão Sonora.

Fonte: Munhoz (2015)

Das quatro bandas analisadas, apenas uma (B4) não realiza seus ensaios em estúdio próprio para tal, ou seja, seu local de ensaio é improvisado em um dos quartos da residência de um dos integrantes.

A disposição das bandas durante o ensaio não se mantém durante as apresentações shows em $100 \%$ da amostra. A esse respeito, alegaram que 0 espaço durante os shows se modificam e assim torna-se necessário o ajuste da banda ao espaço ofertado ainda que se preservem as mesmas posições em todos os ensaios.

Podemos observar as disposições dos músicos durante os ensaios nas Figuras 1, 2, 3 e 4 . 


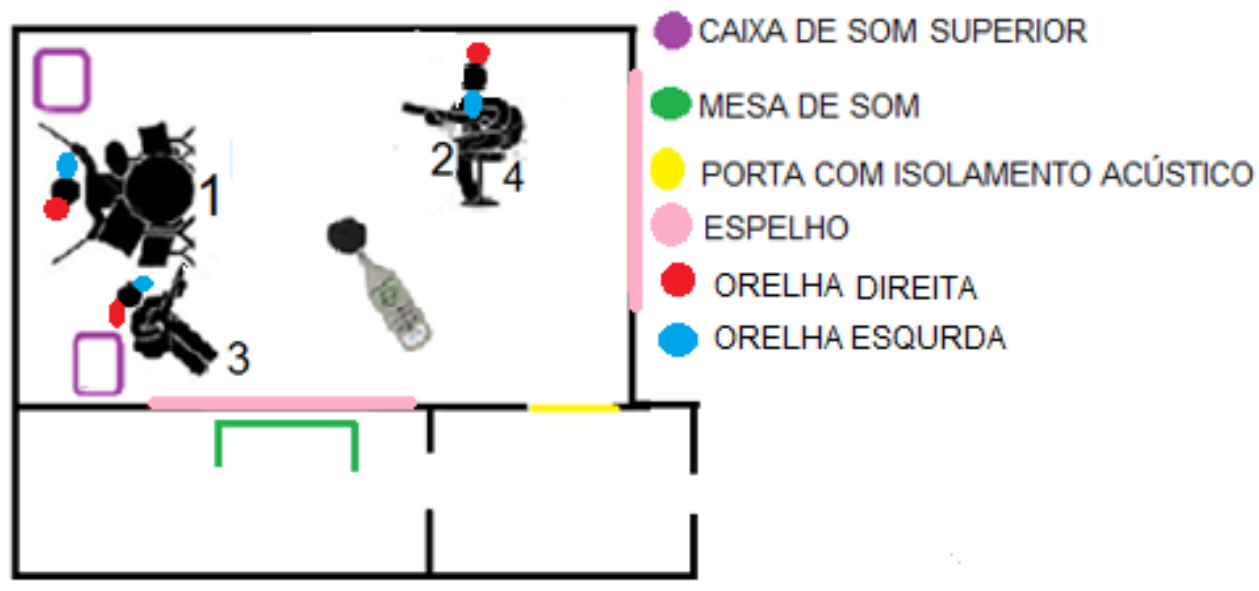

Figura1 - Disposição dos músicos da B1 durante ensaio.

Legenda: B1- banda 1; 1 - baterista; 2- vocal; 3- baixista; 4- guitarrista.

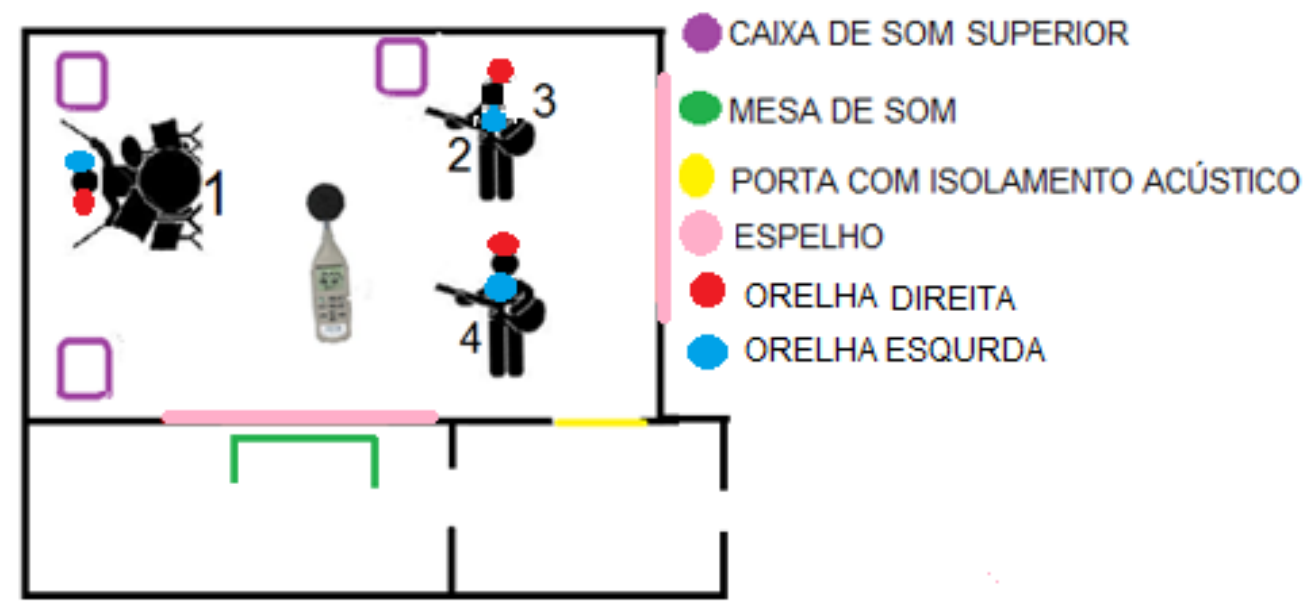

Figura 2- Disposição dos músicos da B2 durante ensaio

Legenda: B2- banda 2; 1- baterista; 2- vocal; 3- baixista; 4- guitarrista 


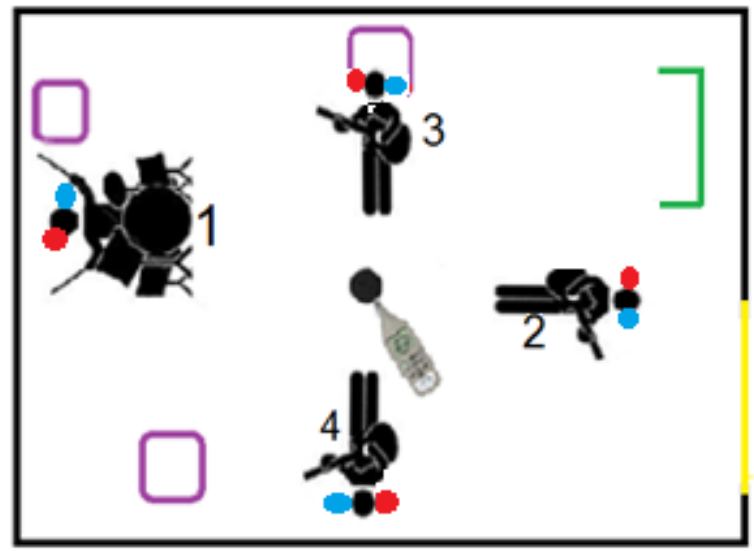

CAIXA DE SOM SUPERIOR

MESA DE SOM

PORTA COM ISOLAMENTO ACÚSTICO

ORELHA DIREITA

ORELHA ESQURDA

Figura 3 - Disposição dos músicos da B3 durante ensaio.

Legenda: B3- banda 3; 1- baterista; 2- vocal; 3- baixista; 4- guitarrista

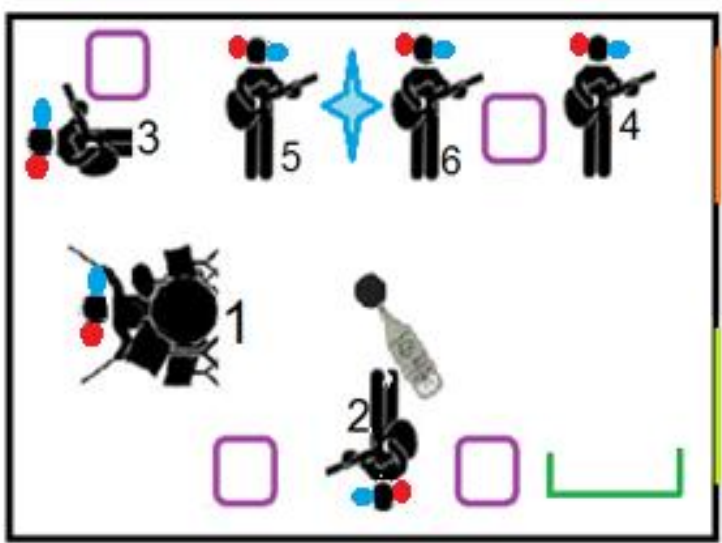

JANELA SEM ISOLAMENTO ACÚSTICO

PORTASEM ISOLAMENTO ACÚSTICO

CAIXA DE SOM NO CHÃO

MESA DE SOM

VENTILADOR

ORELHA DIREITA

ORELHA ESQURDA

Figura 4 - Disposição dos músicos da B4 durante ensaio.

Legenda: B4- banda 4; 1- baterista; 2- vocal; 3- baixista; 4- guitarrista; 5- trompete; 6- trombone.

\subsubsection{Entrevista específica e Avaliação audiológica}

\subsubsection{Entrevista especifica}

Os participantes obedeceram aos critérios de exclusão adotando-se a recusa de algum dos integrantes das bandas selecionadas, ou a não participação da banda em alguma das fases do programa de prevenção de perdas auditiva e alterações no meato acústico externo que impedissem o uso de EPI.

Após o participante concordar em participar da pesquisa e assinar o TCLE, foi orientado para que respondesse às questões contidas no questionário afim de 
caracterizar a banda, assim como as características individuais de cada integrante, tal questionário (Anexo 5) foi utilizado na entrevista específica.

Os participantes levaram em média cerca de dez minutos para responderem às 16 questões; e em 100\% dos casos não sabiam o que eram sintomas não auditivos, sendo necessário a intervenção da pesquisadora.

A amostra foi composta por 16 participantes (4 bandas) do sexo masculino (100\%) e a idade dos participantes variou entre 21 e 36 anos. As análises estatísticas realizadas foram comparando as bandas e os instrumentos em que estavam presentes em todas (voz, guitarra, baixo e bateria).

Primeiramente serão apresentados os resultados referentes à população da pesquisa; a seguir será realizada a comparação entre bandas. Por fim, iremos discutir os resultados de acordo com os instrumentos já mencionados anteriormente.

Quando questionado sobre os sintomas não auditivos, três participantes $(18,75 \%)$ disseram ter dificuldades em entender fala no ruído, um $(6,25 \%)$ relatou ter insônia, um $(6,25 \%)$ rouquidão, três $(18,75 \%)$ sensibilidade a qualquer ruído após apresentações de forma que precisam se isolar, sendo que nenhum dos participantes tiveram dois sintomas não auditivos associados, ou seja, em uma amostra composta por 16 (100\%) participantes, 8 (50\%) apresentavam algum sintoma não auditivo.

Aqueles que não relataram apresentar sintomas não auditivos, dois (12,5\%) participantes queixaram-se que o som da bateria incomoda e um $(6,25 \%)$ que manifestava dificuldades em ouvir o violão afinado na frequência de $100 \mathrm{KHz}$.

Podemos observar que 11 (68,75\%) dos 16 (100\%) participantes possuem algum tipo de queixa.

Quanto aos sintomas auditivos 13 (81,25\%), dos 16 (100\%) participantes, relataram ter zumbido bilateral do tipo apito, e apenas um $(6,25 \%)$ apresenta zumbido unilateral do lado esquerdo do tipo apito, ou seja, $14(87,5 \%)$ participantes apresentam zumbido e apenas dois (12,5\%) participantes não apresentavam o sintoma.

Dois participantes fazem uso de EPI, sendo que um deles foi quem se queixou de sentir sensibilidade a qualquer ruído após apresentações e ainda informou que a queixa melhorou após ensaios, contudo permanece após os shows, já que o EPI não é próprio para quem trabalha com música e assim não faz o uso durante suas apresentações, pois acaba atrapalhando em vez de ajudar. 
Ao comparamos os resultados por bandas, temos B1 e B2 com $100 \%$ dos componentes apresentando zumbido, sendo bilateral do tipo apito; B3com $50 \%$ dos componentes da banda apresentam zumbido, e este é bilateral do tipo apito, e B4 apresenta em $100 \%$ dos componentes da banda apresentam zumbido, contudo em apenas um caso $(6,25 \%)$ o zumbido é unilateral a esquerda. Tais resultados podem ser observamos no Gráfico 1.

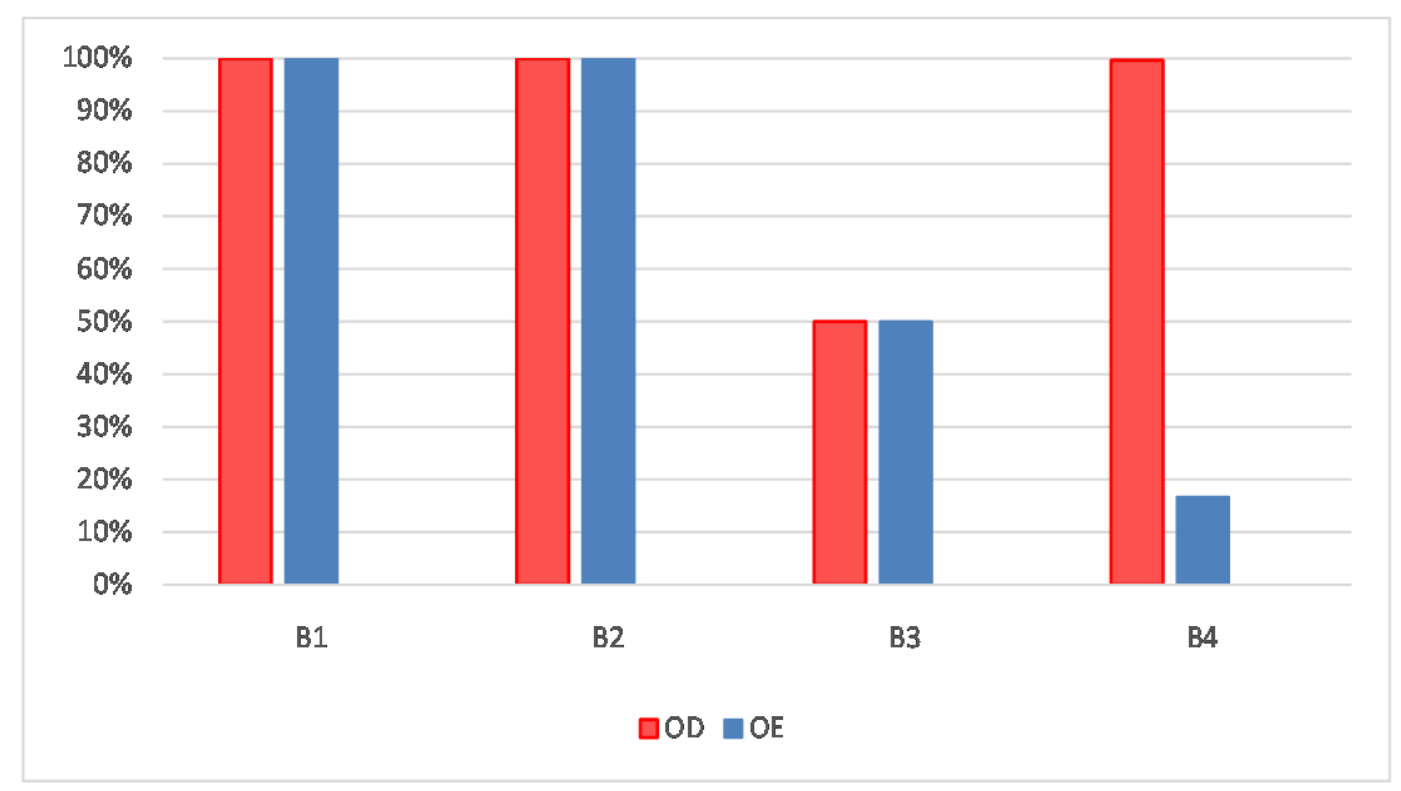

Gráfico 1 - Lateralidade do zumbido x presença de zumbido nos componentes da banda.

Ao realizar a associação das bandas e a presença de zumbido após o show, encontramos em $100 \%$ dos componentes da B1 a presença de zumbido somente após realizarem o show, 100\%da B2 apresenta zumbido após o show e em 66,7\% dos casos ele aparece a toda hora; já na B3, daqueles que apresentam zumbido, $100 \%$ dos casos ele aparece após o show, e 50\% ele permanecem o tempo todo independentemente de estar ou não se apresentando, por fim a B4 todos (100\%) relatam apresentar zumbido após o show e $50 \%$ deles sentem zumbido a todo o momento (Gráfico 2). 


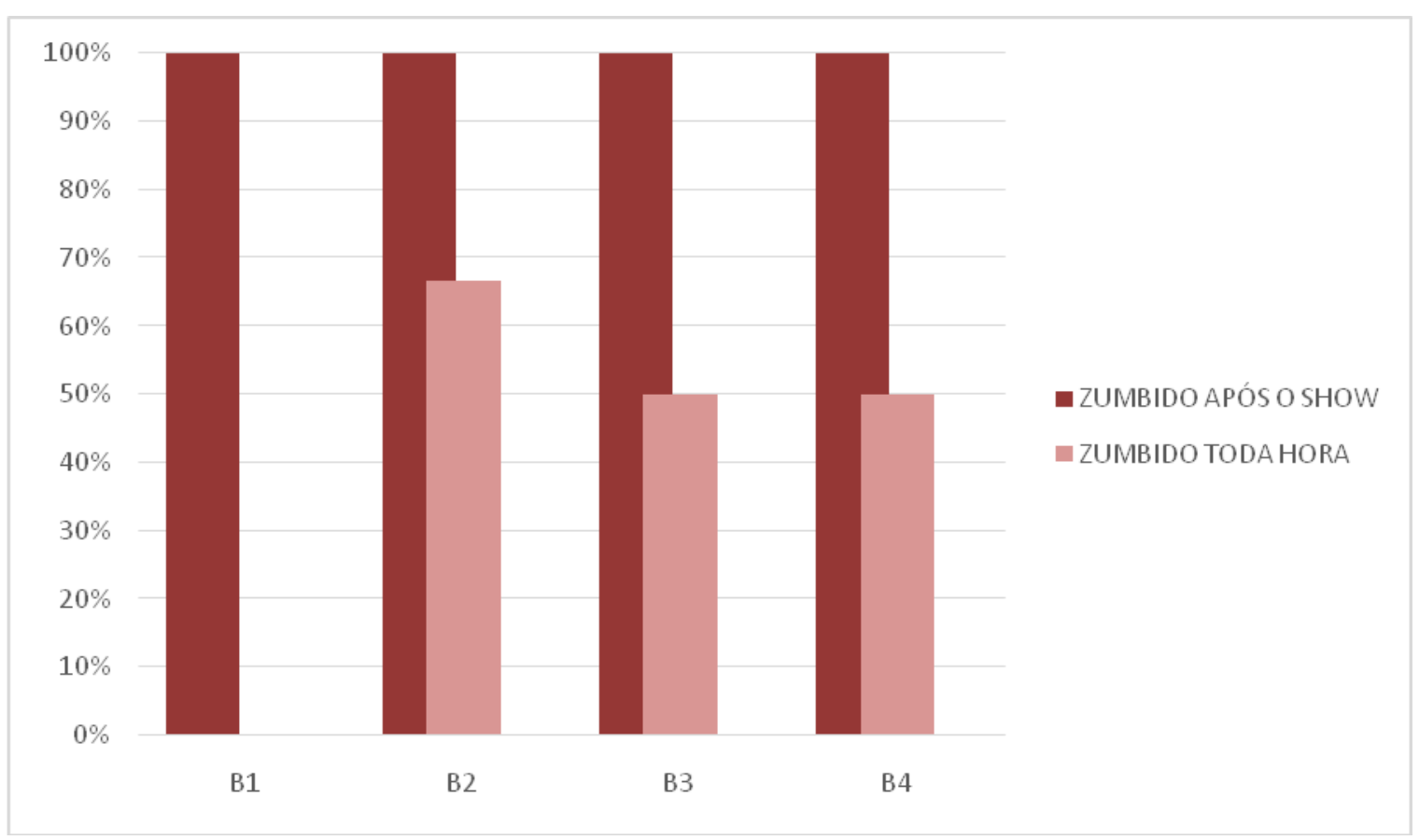

Gráfico 2 - Caracterização da presença do zumbido por banda.

A B1 ensaia cinco horas semanais, e os três (100\%) integrantes da B1 apresentam zumbido e nenhum ( $0 \%$ ) tem a toda hora, a B2 que também possui três integrantes (100\%) que ensaiam por dez horas semanais, todos eles têm zumbido e apenas um (33,33\%) apresenta a toda hora. Já a B3, com seus quatro integrantes (100\%) que ensaiam por cinco horas, seus dois (50\%) componentes queixam-se de zumbido, mas só um (25\%) tem a toda hora. Por fim, a B4 que também realiza ensaios por cinco horas semanais e é composta por seis (100\%) integrantes, todos apresentam zumbido, mas só três $(50 \%)$ têm a toda hora. Portanto a presença do zumbido percebida a toda hora pelo participante não teve correlação com o tempo médio de ensaio realizado pelas bandas como se observa no Gráfico 3. 


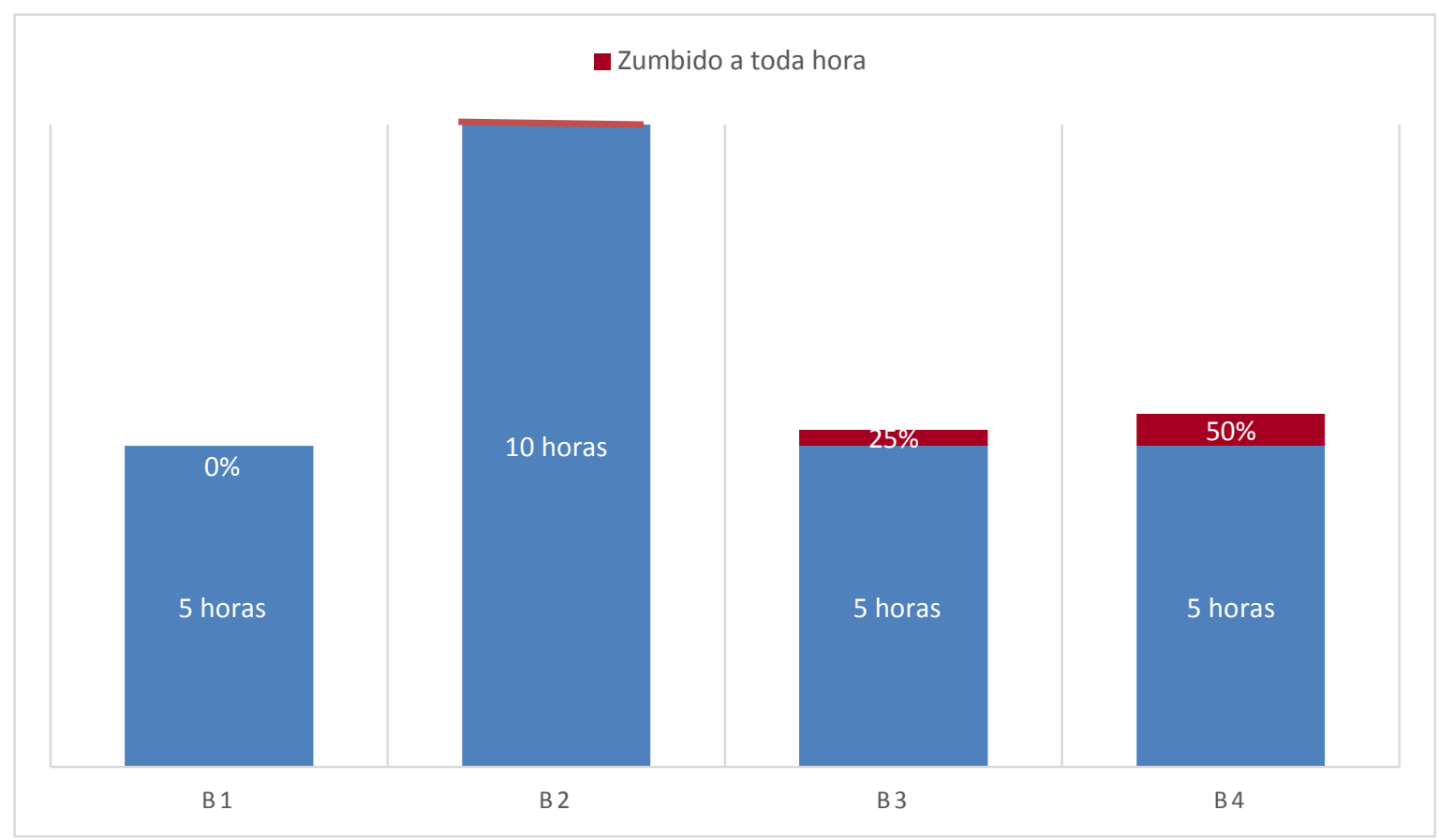

Gráfico 3 - Tempo em horas de ensaio x presença de zumbido a toda hora.

O número de apresentações realizadas pelas bandas variou entre dois e cinco shows, sendo de dois para B4, três para B3, quatro para B1 e de cinco para B2. Porém não encontramos correlação entre o número de apresentações realizadas por semana com a intensidade da presença de zumbido a toda hora e após os shows. Vale lembrar que 14 (87,5\%) participantes da amostra total apresentam zumbido e estes mesmos apresentam zumbido após o show.

Foi realizado por fim a análise dos resultados estatísticos, utilizando a associação entre os instrumentos (analisados separadamente) e os sintomas auditivos e não auditivos descritos pelos participantes.

As ordens dos instrumentos analisados são: voz, guitarra, baixo e bateria.

Quando realizado a associação entre voz e zumbido, não houve correlação entre eles $(p=1)$, pois cinco $(83,33 \%)$ cantores apresentavam zumbido, apenas um $(16,67 \%)$ não tinha zumbido, sendo este bilateral do tipo apito; e dos participantes que não são cantores, 80\% têm zumbido e 20\%não, como observado no Gráfico 4. 


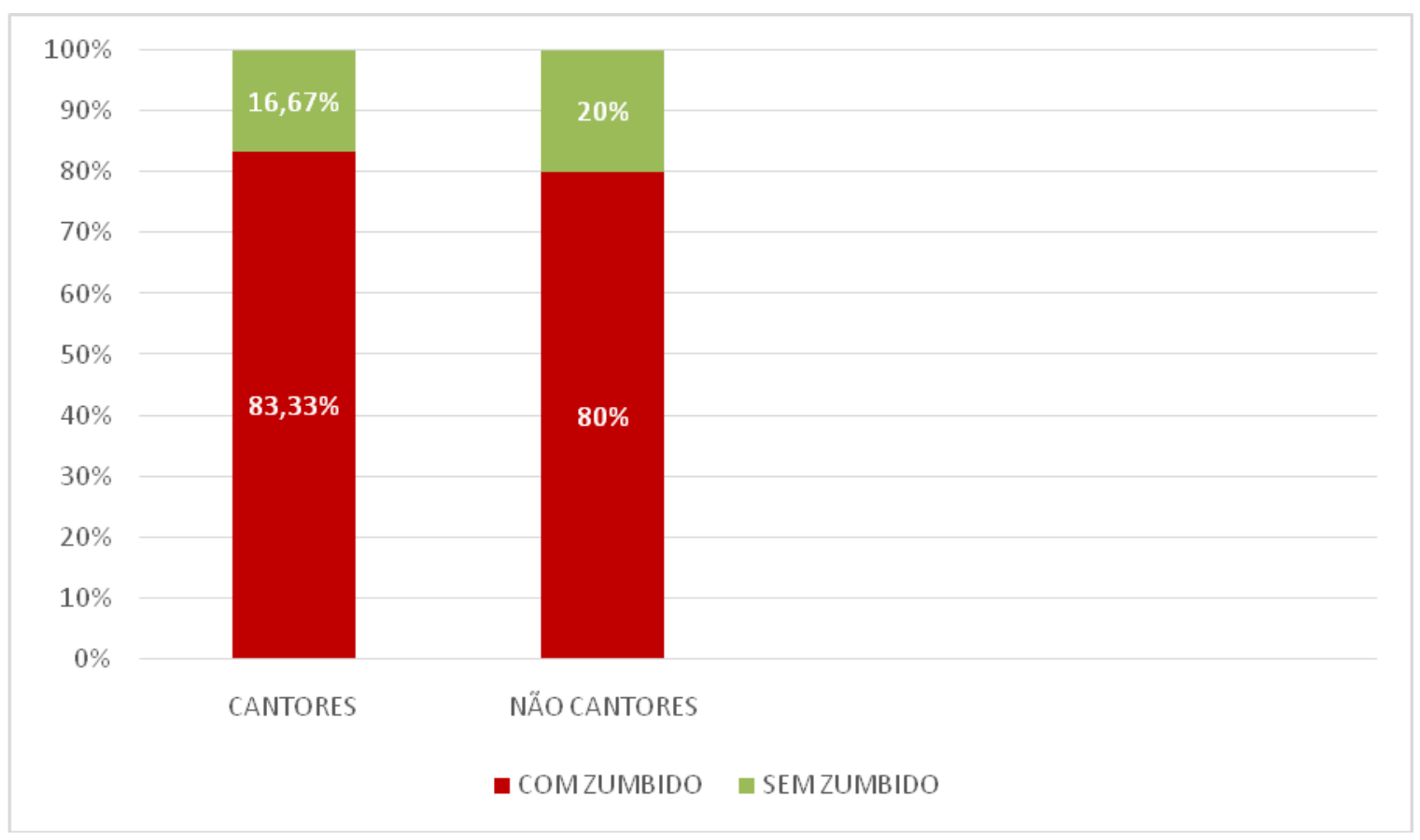

Gráfico 4 - Relação do instrumento voz (cantores) x presença de zumbido.

83, 33\% dos cantores apresentam zumbido após o show, e 16,67\% não, já aqueles que não são cantores $90 \%$ sentem zumbido após o show e $10 \%$ não o sentem, também não tiveram correlação $(p=1,0)$.

Ao serem questionados sobre a presença de zumbido nos cantores a toda hora, vimos que 33, 33\% deles têm zumbido a toda hora enquanto 66,67\% não. Já $30 \%$ dos não cantores apresentam o zumbido a toda hora e $70 \%$ não apresentam $(p=1,0)$.

Dos $100 \%$ dos cantores, $16,67 \%$ apresentam dificuldade em entender fala no ruído e $83,33 \%$ não, e $20 \%$ dos não cantores apresentam tal dificuldade e $80 \%$ não, contudo não tivemos associação entre dificuldade em entender fala e o instrumento voz (cantores) $(p=1,0)$.

Ao compararmos a insônia e voz (cantores) também não houve significância, pois, o valor de $p$ é maior que $0,05(p=0,375)$, sendo que nenhum $(0 \%)$ dos cantores possuem insônia e 10\% dos não cantores possuem insônia.

Por fim também não encontramos significância entre sensibilidade a ruído e voz (cantores), obtendo $p=1,0$.

Em nenhum dos casos foram encontrados significância ao realizarmos a comparação entre os sintomas apresentados anteriormente e o instrumento voz 
(cantores), uma vez que para os resultados obtidos serem alvo de relevância p deve ser menor a 0,05 $(p<0,05)$.

Esses resultados repetem-se para as associações realizadas com os instrumentos guitarra e bateria. Já para o instrumento baixo (baixista) houve significância quando comparado a dificuldades em entender a fala no ruído, pois $75 \%$ dos participantes que tocam baixo apresentam tal dificuldade $(p=0,007)$, como demonstra o Gráfico 5.

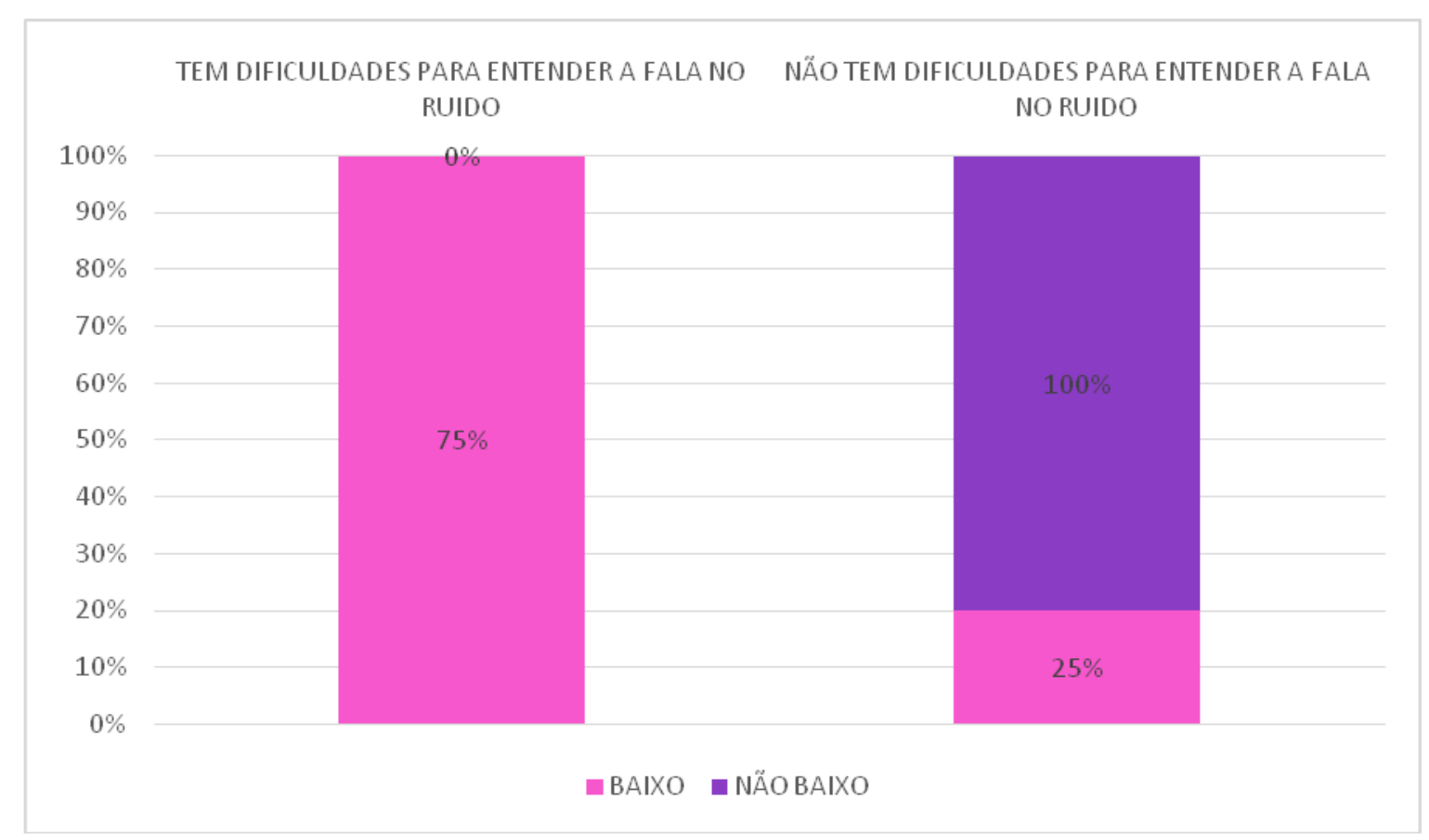

Gráfico 5 - Comparação entre o músico que utiliza o instrumento baixo e a presença de dificuldades em entender a fala no ruído.

\subsubsection{Avaliação audiológica}

Foi utilizado o aplicativo Randomizers e selecionado a opção Dice Roller, que contém os números da peça de um dado, que ao ser clicado em Randomize o mesmo começa a randomizar, de forma a aparecerem os números obtidos no dado. Essa estratégia foi utilizada para a realização dos exames em que necessitava da resposta subjetiva do participante na avaliação audiológica, afim de identificar em qual orelha se iniciaria cada procedimento e assim evitando qualquer possível alteração de resultado. Os números pares referiam-se a Orelha Direita (OD) e os impares a Orelha Esquerda (OE). Conforme os números iam aparecendo, a 
pesquisadora já os passava para a lateralidade a que correspondiam. As randomizações foram, portanto, realizadas para cada procedimento e seguidas conforme ordem de chegada de cada participante para avaliação audiológica, sendo este realizado por banda, como se observa nasTabelas 4,5 e6.

Tabela 4: Lateralidade das orelhas a iniciarem a Audiometria tonal Liminar Convencional e de Alta Frequência.

Procedimento: Audiometria Tonal convenciona e Audiometria Tonal de Alta Frequência

\begin{tabular}{lllllll}
\hline BANDA & $\mathbf{1}^{\circ} \mathbf{d a}$ & $\mathbf{2}^{\circ} \mathbf{d a}$ & $\mathbf{3}^{\circ} \mathbf{d a}$ & $\mathbf{4}^{\circ} \mathbf{d a}$ & $\mathbf{5}^{\circ} \mathbf{d a}$ & $6^{\circ}$ da banda \\
banda & banda & banda & banda & banda & \\
B1 & OE & OD & OD & OE & OE & OE \\
B2 & OE & OD & OD & OE & OE & OE \\
B3 & OE & OD & OD & OE & OE & OE \\
B4 & OE & OD & OD & OE & OE & OE \\
\hline
\end{tabular}

Legenda: OD- orelha direita; OE- orelha esquerda.

Tabela 5: Lateralidade das orelhas a iniciarem a Logoaudiometria (SRT):

Procedimento: Logoaudiometria (SRT)

\begin{tabular}{|c|c|c|c|c|c|c|}
\hline BANDA & $\begin{array}{l}1^{\circ} \mathrm{da} \\
\text { banda }\end{array}$ & $\begin{array}{l}2^{\circ} \mathrm{da} \\
\text { banda }\end{array}$ & $\begin{array}{l}3^{\circ} \mathrm{da} \\
\text { banda }\end{array}$ & $\begin{array}{l}4^{\circ} \mathrm{da} \\
\text { banda }\end{array}$ & $\begin{array}{l}5^{\circ} \mathrm{da} \\
\text { banda }\end{array}$ & $6^{\circ}$ da banda \\
\hline B1 & OD & OE & OE & OE & OD & OD \\
\hline B2 & OD & OE & OE & OE & OD & OD \\
\hline B3 & OD & OE & OE & OE & OD & OD \\
\hline B4 & OD & OE & OE & OE & OD & OD \\
\hline
\end{tabular}

Legenda: OD- orelha direita; OE- orelha esquerda. 
Tabela 6- Lateralidade das orelhas a iniciarem a Logoaudiometria (IRF)

Procedimento: Logoaudiometria (SRT)

\begin{tabular}{lllllll}
\hline BANDA & $\begin{array}{c}\mathbf{1}^{\circ} \mathbf{d a} \\
\text { banda }\end{array}$ & $\begin{array}{c}\mathbf{2}^{\circ} \mathbf{d a} \\
\text { banda }\end{array}$ & $\begin{array}{c}\mathbf{3}^{\circ} \mathbf{d a} \\
\text { banda }\end{array}$ & $\begin{array}{c}\mathbf{4}^{\circ} \mathbf{d a} \\
\text { banda }\end{array}$ & $\begin{array}{c}\mathbf{5}^{\circ} \mathbf{d a} \\
\text { banda }\end{array}$ & $\mathbf{6}^{\circ}$ da banda \\
B1 & OE & OE & OD & OD & OE & OE \\
B2 & OE & OE & OD & OD & OE & OE \\
B3 & OE & OE & OD & OD & OE & OE \\
B4 & OE & OE & OD & OD & OE & OE
\end{tabular}

Legenda: OD- orelha direita; OE- orelha esquerda.

\section{Inspeção do Meato Acústico Externo (MAE)}

Durante a realização da inspeção do MAE, foi encontrada alguma barreira que acabava impedindo a realização dos outros procedimentos em quatro participantes, sendo dois $(50 \%)$ da B3, um $(33,33 \%)$ da B2 e um $(16,67 \%)$ da B4, a barreira encontrada nesses participantes foi à rolha de cera.

Dos que apresentam a rolha de cera da B3, um participante (MUS003) tinha tal impedimento na OD e ou outro (MUS004) na OE, no da B4 (MUS006) a rolha de cera estava OD e da B2 (MUS022) na OD.

A rolha de cera foi removida em todos os participantes pelo médico otorrinolaringologista, e os participantes retornaram para avaliação audiológica.

5.1.2.2. Audiometria Tonal Liminar Convencional e de Alta Frequência: Audiometria Tonal Liminar Convencional (AT-AC)

Para os achados audiológicos da B1, B2, B3 e B4, de acordo com a classificação de perda auditiva adotada pela Organização Mundial de Saúde (OMS) (2014) e com a Portaria ํo 19 do Ministério do Trabalho, obtiveram-se limiares auditivos que variaram dentro do limite de normalidade, ou seja, de zero a 25 dBNA. As médias dos limiares por frequências foram analisados por bandas e por instrumentos e ambos estão representados nas tabelas a seguir (Tabelas 7 a 14). 
Tabela7 - Média dos limiares por frequência de acordo com B1.

\begin{tabular}{ccccccccc}
\hline & $\mathbf{2 5 0 H z}$ & $\mathbf{5 0 0 H z}$ & $\mathbf{1 K H z}$ & $\mathbf{2} \mathbf{K H z}$ & $\mathbf{3 K H z}$ & $\mathbf{4 K H z}$ & $\mathbf{6 K H z}$ & $\mathbf{8 K H z}$ \\
\hline OD dBNA) & 10,0 & 10,0 & 8,3 & 3,3 & 8,3 & 6,6 & 0,0 & 0,0 \\
OE dBNA) & 8,3 & 10,0 & 6,6 & 3,3 & 8,3 & 8,3 & 1,6 & 0,0
\end{tabular}

Legenda: Hz- Hertz; dBNA- nível de audição; OD- orelha direita; OE- orelha esquerda.

Tabela8 -Média dos limiares por frequência de acordo com B2.

\begin{tabular}{ccccccccc}
\hline & $\mathbf{2 5 0 H z}$ & $\mathbf{5 0 0 H z}$ & $\mathbf{1 K H z}$ & $\mathbf{2 K H z}$ & $\mathbf{3 K H z}$ & $\mathbf{4 K H z}$ & $\mathbf{6 K H z}$ & $\mathbf{8 K H z}$ \\
\hline OD dBNA) & 3,3 & 6,6 & 6,6 & 6,6 & 11,6 & 15,0 & 6,6 & 1,6 \\
OE dBNA) & 5,0 & 5,0 & 10,0 & 10,0 & 15,0 & 15,0 & 10,0 & 5,0 \\
\hline
\end{tabular}

Legenda: Hz- Hertz; dBNA- nível de audição; OD- orelha direita; OE- orelha esquerda.

Tabela 9 -Média dos limiares por frequência de acordo com B3.

\begin{tabular}{ccccccccc}
\hline & $\mathbf{2 5 0 H z}$ & $\mathbf{5 0 0 H z}$ & $\mathbf{1 K H z}$ & $\mathbf{2 K H z}$ & $\mathbf{3 K H z}$ & $\mathbf{4 K H z}$ & $\mathbf{6 K H z}$ & $\mathbf{8 K H z}$ \\
\hline OD (dBNA) & 5 & 6,2 & 7,5 & 7,5 & 12,5 & 15,0 & 16,2 & 7,5 \\
OE (dBNA) & 2,5 & 7,5 & 7,5 & 6,2 & 15,0 & 15,0 & 12,5 & 7,5
\end{tabular}

Legenda: Hz- Hertz; dBNA- nível de audição; OD- orelha direita; OE- orelha esquerda.

Tabela 10 -Média dos limiares por frequência de acordo com B4.

\begin{tabular}{ccccccccc} 
& $\mathbf{2 5 0 H z}$ & $\mathbf{5 0 0 H z}$ & $\mathbf{1} \mathbf{K H z}$ & $\mathbf{2} \mathbf{K H z}$ & $\mathbf{3 K H z}$ & $\mathbf{4 K H z}$ & $\mathbf{6 K H z}$ & $\mathbf{8 K H z}$ \\
\hline OD dBNA) & 7,5 & 8,3 & 8,3 & 12,5 & 11,6 & 8,3 & 6,6 & 8,3 \\
OE dBNA) & 6,6 & 7,5 & 9,2 & 11,6 & 12,5 & 11,6 & 5,8 & 4,1
\end{tabular}

Legenda: Hz- Hertz; dBNA- nível de audição; OD- orelha direita; OE- orelha esquerda.

Tabela11 - Média dos limiares por frequência de acordo com o instrumento voz.

\begin{tabular}{lcccccccc}
\hline & $\mathbf{2 5 0 H z}$ & $\mathbf{5 0 0 H z}$ & $\mathbf{1 K H z}$ & $\mathbf{2 K H z}$ & $\mathbf{3 K H z}$ & $\mathbf{4 K H z}$ & $\mathbf{6 K H z}$ & $\mathbf{8 K H z}$ \\
\hline OD dBNA) & 7,5 & 8,33 & 6,6 & 5,8 & 9,1 & 11,6 & 13,3 & 8,3 \\
OE dBNA) & 5,0 & 8,3 & 8,3 & 5,8 & 10,8 & 11,6 & 12,5 & 8,3 \\
\hline
\end{tabular}

Legenda: Hz- Hertz; dBNA- nível de audição; OD- orelha direita; OE- orelha esquerda. 
Tabela 12 - Média dos limiares por frequência de acordo com o instrumento guitarra.

\begin{tabular}{lcccccccc}
\hline & $\mathbf{2 5 0 H z}$ & $\mathbf{5 0 0 H z}$ & $\mathbf{1 K H z}$ & $\mathbf{2 K H z}$ & $\mathbf{3 K H z}$ & $\mathbf{4 K H z}$ & $\mathbf{6 K H z}$ & $\mathbf{8 K H z}$ \\
\hline OD dBNA) & 6,3 & 8,1 & 8,6 & 9,5 & 12,2 & 11,3 & 8,1 & 5,4 \\
OE dBNA) & 5,0 & 8,0 & 7,0 & 6,0 & 14,0 & 12,0 & 5,0 & 5,0
\end{tabular}

Legenda: Hz- Hertz; dBNA- nível de audição; OD- orelha direita; OE- orelha esquerda.

Tabela13 - Média dos limiares por frequência de acordo com o instrumento baixo.

\begin{tabular}{ccccccccc}
\hline & $\mathbf{2 5 0 H z}$ & $\mathbf{5 0 0 H z}$ & $\mathbf{1 K H z}$ & $\mathbf{2 K H z}$ & $\mathbf{3 K H z}$ & $\mathbf{4 K H z}$ & $\mathbf{6 K H z}$ & $\mathbf{8 K H z}$ \\
\hline OD dBNA) & 10,0 & 13,7 & 11,2 & 8,7 & 13,7 & 16,2 & 13,7 & 5,0 \\
OE dBNA) & 6,2 & 8,7 & 11,2 & 13,7 & 13,7 & 17,5 & 16,2 & 7,5 \\
\hline
\end{tabular}

Legenda: Hz- Hertz; dBNA- nível de audição; OD- orelha direita; OE- orelha esquerda.

Tabela 14 - Média dos limiares por frequência de acordo com o instrumento bateria.

\begin{tabular}{lcccccccc}
\hline & $\mathbf{2 5 0 H z}$ & $\mathbf{5 0 0 H z}$ & $\mathbf{1 K H z}$ & $\mathbf{2 K H z}$ & $\mathbf{3 K H z}$ & $\mathbf{4 K H z}$ & $\mathbf{6 K H z}$ & $\mathbf{8 K H z}$ \\
\hline OD dBNA) & 3,7 & 6,2 & 8,7 & 12,5 & 15,0 & 11,2 & 5,0 & 2,5 \\
OE dBNA) & 7,5 & 8,7 & 10,0 & 7,5 & 15,0 & 13,7 & 5,0 & 1,2
\end{tabular}

Legenda: Hz- Hertz; dBNA- nível de audição; OD- orelha direita; OE- orelha esquerda.

A seguir serão apresentados nas tabelas 15 e 16 os valores em porcentagem da presença de entalhe encontrados nas frequências de $2 \mathrm{KHz}, 4 \mathrm{KHz}, 6 \mathrm{KHz}$ e $8 \mathrm{KHz}$ de acordo com as bandas (Tabela 17) e com os instrumentos (Tabela 18).

Tabela 15 - Porcentagem de presença de entalhe por frequência de acordo com as bandas.

\begin{tabular}{ccccc}
\hline & $\mathbf{2 K H z}$ & $\mathbf{4 H z}$ & $\mathbf{6 K H z}$ & $\mathbf{8 K H z}$ \\
\hline B1 & $0 \%$ & $0 \%$ & $0 \%$ & $0 \%$ \\
B2 & $0 \%$ & $33,33 \%$ & $33,33 \%$ & $0 \%$ \\
B3 & $0 \%$ & $0 \%$ & $50 \%$ & $25 \%$ \\
B4 & $33,33 \%$ & $0 \%$ & $16,67 \%$ & $16,67 \%$
\end{tabular}

Legenda: Hz- Hertz; \%- porcentagem

Tabela 16 - Porcentagem de presença de entalhe por frequência de acordo com os instrumentos.

\begin{tabular}{ccccc}
\hline & $\mathbf{2 K H z}$ & $\mathbf{4 H z}$ & $\mathbf{6 K H z}$ & $\mathbf{8 K H z}$ \\
\hline Voz & $0 \%$ & $0 \%$ & $0 \%$ & $0 \%$ \\
Guitarra & $0 \%$ & $25 \%$ & $0 \%$ & $0 \%$ \\
Baixo & $25 \%$ & $0 \%$ & $75 \%$ & $0 \%$ \\
Bateria & $25 \%$ & $0 \%$ & $0 \%$ & $0 \%$
\end{tabular}

Legenda: Hz- Hertz; \%- porcentagem 


\section{Audiometria Tonal de Alta Frequência (AT- AF):}

Para os achados audiológicos da AT- AF dos participantes da B1, B2, B3 e B4, foi utilizada a classificação do trabalho desenvolvido por Burguetti, Peloggia e Carvallo (2004) para cada frequência e faixa etária (Tabela 1).

As tabelas 17, 18, 19 e 20 contêm os valores das médias dos limiares por frequências analisados por bandas, e as tabelas 21, 22, 23 e 24 por instrumentos.

Tabela17 - Média dos limiares por frequência de acordo com B1.

\begin{tabular}{lcccccccc}
\hline & $\mathbf{9 K H z}$ & $\mathbf{1 0 H z}$ & $\mathbf{1 1 2 0 0 K H z}$ & $\mathbf{1 2 5 0 0 K H z}$ & $\mathbf{1 4 K H z}$ & $\mathbf{1 6 K H z}$ & $\mathbf{1 8 K H z}$ & $\mathbf{2 0 K H z}$ \\
\hline OD (dBNA) & 1,6 & 0,0 & 3,3 & 3,3 & 1,6 & 6,6 & 6,6 & 3,3 \\
OE (dBNA) & 1,6 & 0,0 & 0,0 & 0,0 & 0,0 & 1,6 & 0,0 & 2,5
\end{tabular}

Legenda: Hz- Hertz; dBNA- nível de audição; OD- orelha direita; OE- orelha esquerda.

Tabela 18 - Média dos limiares por frequência de acordo com B2.

\begin{tabular}{lcccccccc}
\hline & $\mathbf{9 K H z}$ & $\mathbf{1 0 H z}$ & $\mathbf{1 1 2 0 0 K H z}$ & $\mathbf{1 2 5 0 0 K H z}$ & $\mathbf{1 4 K H z}$ & $\mathbf{1 6 K H z}$ & $\mathbf{1 8 K H z}$ & $\mathbf{2 0 K H z}$ \\
\hline OD (dBNA) & 3,3 & 1,6 & 5,0 & 6,6 & 3,3 & 1,6 & 1,6 & 0,0 \\
OE (dBNA) & 10,0 & 6,6 & 8,3 & 6,6 & 6,6 & 5,0 & 15,0 & 1,6
\end{tabular}

Legenda: Hz- Hertz; dBNA- nível de audição; OD- orelha direita; OE- orelha esquerda.

Tabela 19- Média dos limiares por frequência de acordo com B3.

\begin{tabular}{lcccccccc}
\hline & $\mathbf{9 K H z}$ & $\mathbf{1 0 H z}$ & $\mathbf{1 1 2 0 0 K H z}$ & $\mathbf{1 2 5 0 0 K H z}$ & $\mathbf{1 4 K H z}$ & $\mathbf{1 6 K H z}$ & $\mathbf{1 8 K H z}$ & $\mathbf{2 0 K H z}$ \\
\hline OD (dBNA) & 12,5 & 12,5 & 16,2 & 16,2 & 17,2 & 17,5 & 7,5 & 6,2 \\
OE (dBNA) & 6,2 & 11,2 & 12,5 & 16,2 & 17,5 & 10,0 & 25,0 & 8,7
\end{tabular}

Legenda: Hz- Hertz; dBNA- nível de audição; OD- orelha direita; OE- orelha esquerda.

Tabela20 - Média dos limiares por frequência de acordo com B4.

\begin{tabular}{lcccccccc}
\hline & $\mathbf{9 K H z}$ & $\mathbf{1 0 H z}$ & $\mathbf{1 1 2 0 0 K H z}$ & $\mathbf{1 2 5 0 0 K H z}$ & $\mathbf{1 4 K H z}$ & $\mathbf{1 6 K H z}$ & $\mathbf{1 8 K H z}$ & $\mathbf{2 0 K H z}$ \\
\hline OD (dBNA) & 7,5 & 7,5 & 11,6 & 7,5 & 9,1 & 14,2 & 7,0 & 0,0 \\
OE (dBNA) & 5,8 & 7,5 & 9,1 & 6,6 & 10,0 & 18,3 & 13,0 & 5,0
\end{tabular}

Legenda: Hz- Hertz; dBNA- nível de audição; OD- orelha direita; OE- orelha esquerda. 
Tabela21 - Média dos limiares por frequência de acordo com o instrumento voz.

\begin{tabular}{lcccccccc}
\hline & $\mathbf{9 K H z}$ & $\mathbf{1 0 H z}$ & $\mathbf{1 1 2 0 0 K H z}$ & $\mathbf{1 2 5 0 0 K H z}$ & $\mathbf{1 4 K H z}$ & $\mathbf{1 6 K H z}$ & $\mathbf{1 8 K H z}$ & $\mathbf{2 0 K H z}$ \\
\hline OD (dBNA) & 9,1 & 8,3 & 12,5 & 15,8 & 14,1 & 15,8 & 7,0 & 3,3 \\
OE (dBNA) & 6,6 & 9,1 & 11,6 & 12,5 & 13,3 & 12,5 & 8,3 & 9,0
\end{tabular}

Legenda: Hz- Hertz; dBNA- nível de audição; OD- orelha direita; OE- orelha esquerda.

Tabela22 - Média dos limiares por frequência de acordo com o instrumento guitarra.

\begin{tabular}{lcccccccc}
\hline & $\mathbf{9 K H z}$ & $\mathbf{1 0 H z}$ & $\mathbf{1 1 2 0 0 K H z}$ & $\mathbf{1 2 5 0 0 K H z}$ & $\mathbf{1 4 K H z}$ & $\mathbf{1 6 K H z}$ & $\mathbf{1 8 K H z}$ & $\mathbf{2 0 K H z}$ \\
\hline OD (dBNA) & 4,0 & 7,0 & 7,0 & 8,0 & 6,0 & 8,0 & 6,2 & 2,0 \\
OE (dBNA) & 4,0 & 9,0 & 7,0 & 8,0 & 5,0 & 5,0 & 13,3 & 5,0
\end{tabular}

Legenda: Hz- Hertz; dBNA- nível de audição; OD- orelha direita; OE- orelha esquerda.

Tabela 23 - Média dos limiares por frequência de acordo com o instrumento baixo.

\begin{tabular}{lcccccccc}
\hline & $\mathbf{9 K H z}$ & $\mathbf{1 0 H z}$ & $\mathbf{1 1 2 0 0 K H z}$ & $\mathbf{1 2 5 0 0 K H z}$ & $\mathbf{1 4 K H z}$ & $\mathbf{1 6 K H z}$ & $\mathbf{1 8 K H z}$ & $\mathbf{2 0 K H z}$ \\
\hline OD (dBNA) & 11,2 & 7,5 & 15,0 & 12,5 & 13,7 & 16,2 & 6,2 & 5,0 \\
OE (dBNA) & 8,7 & 8,7 & 11,2 & 12,5 & 17,5 & 12,5 & 10,0 & 7,5
\end{tabular}

Legenda: Hz- Hertz; dBNA- nível de audição; OD- orelha direita; OE- orelha esquerda.

Tabela24 - Média dos limiares por frequência de acordo com o instrumento bateria.

\begin{tabular}{lcccccccc}
\hline & $\mathbf{9 K H z}$ & $\mathbf{1 0 H z}$ & $\mathbf{1 1 2 0 0 K H z}$ & $\mathbf{1 2 5 0 0 K H z}$ & $\mathbf{1 4 K H z}$ & $\mathbf{1 6 K H z}$ & $\mathbf{1 8 K H z}$ & $\mathbf{2 0 K H z}$ \\
\hline OD (dBNA) & 7,5 & 6,2 & 8,7 & 5,0 & 3,7 & 3,7 & 3,3 & 1,2 \\
OE (dBNA) & 6,5 & 5,0 & 7,5 & 6,2 & 6,2 & 5,0 & 6,6 & 2,5
\end{tabular}

Legenda: Hz- Hertz; dBNA- nível de audição; OD- orelha direita; OE- orelha esquerda.

As tabelas 25 e 26 contêm os valores da presença de entalhe (dados em porcentagem) encontrados em todas as frequências de AT- AF. As tabelas foram analisadas de acordo com as bandas (Tabela 25) e instrumentos (Tabela 26).

Tabela 25 - Porcentagem de presença de entalhe por frequência de acordo com as bandas.

\begin{tabular}{cccccccc}
\hline & $\mathbf{9 K H z}$ & $\mathbf{1 0 H z}$ & $\mathbf{1 1 2 0 0 K H z}$ & $\mathbf{1 2 5 0 0 K H z}$ & $\mathbf{1 4 K H z}$ & $\mathbf{1 6 K H z}$ & $\mathbf{1 8 K H z}$ \\
\hline B1 & $0 \%$ & $0 \%$ & $0 \%$ & $0 \%$ & $0 \%$ & $33,33 \%$ & $33,33 \%$ \\
B2 & $33,33 \%$ & $0 \%$ & $0 \%$ & $0 \%$ & $0 \%$ & $0 \%$ & $66,67 \%$ \\
B3 & $25 \%$ & $0 \%$ & $0 \%$ & $25 \%$ & $0 \%$ & $25 \%$ & $0 \%$ \\
B4 & $0 \%$ & $16,67 \%$ & $16,67 \%$ & $0 \%$ & $16,67 \%$ & $16,67 \%$ & $33,33 \%$
\end{tabular}

Legenda: Hz- Hertz; \%- porcentagem 
Tabela 26 - Porcentagem de presença de entalhe por frequência de acordo com os instrumentos.

\begin{tabular}{cccccccc}
\hline & $\mathbf{9 K H z}$ & $\mathbf{1 0 H z}$ & $\mathbf{1 1 2 0 0 K H z}$ & $\mathbf{1 2 5 0 0 K H z}$ & $\mathbf{1 4 K H z}$ & $\mathbf{1 6 K H z}$ & $\mathbf{1 8 K H z}$ \\
\hline Voz & $0 \%$ & $0 \%$ & $0 \%$ & $0 \%$ & $0 \%$ & $25 \%$ & $0 \%$ \\
Guitarra & $25 \%$ & $25 \%$ & $0 \%$ & $0 \%$ & $0 \%$ & $0 \%$ & $50 \%$ \\
Baixo & $25 \%$ & $0 \%$ & $0 \%$ & $0 \%$ & $25 \%$ & $50 \%$ & $0 \%$ \\
Bateria & $0 \%$ & $0 \%$ & $0 \%$ & $0 \%$ & $0 \%$ & $0 \%$ & $50 \%$
\end{tabular}

Legenda: Hz- Hertz; \%- porcentagem

\subsubsection{Logoaudiometria}

Os resultados obtidos para o Limiar de Reconhecimento de Fala (LRF) mostram-se compatíveis dentro dos valores de normalidade, sendo iguais ou até 10 dB acima da média tritonal (500, 1000 e $200 \mathrm{~Hz}$ ) na AT-AC (SANTOS; RUSSO, 1991). Aqueles encontrados para o Índice Percentual de Reconhecimento de Fala (IPRF) dos participantes também estiveram dentro dos valores de normalidade entre $88 \%$ e 100\% (GATES; CHAKERES, 1988), conforme podemos observar na Tabela 27 , contudo os valores de $88 \%$ (IPRF) encontrados em dois participantes são os mesmos que relataram ter dificuldade em entender fala no ruído.

Tabela 27 - Participantes e limiar de obtido do LRF e a porcentagem de acertos do IPRF.

\begin{tabular}{ccccc}
\hline PARTICIPANTE & \multicolumn{3}{c}{ LRF (SRT) } & \multicolumn{2}{c}{ IPRF } \\
\hline MUS002 & 5 & 15 & $100 \%$ & $100 \%$ \\
MUS003 & 20 & 20 & $100 \%$ & $96 \%$ \\
MUS004 & 10 & 10 & $100 \%$ & $100 \%$ \\
MUS005 & 15 & 5 & $96 \%$ & $92 \%$ \\
MUS006 & 15 & 10 & $92 \%$ & $92 \%$ \\
MUS007 & 5 & 5 & $100 \%$ & $96 \%$ \\
MUS010 & 20 & 15 & $96 \%$ & $96 \%$ \\
MUS011 & 20 & 20 & $92 \%$ & $96 \%$ \\
MUS012 & 15 & 15 & $92 \%$ & $96 \%$ \\
MUS015 & 10 & 10 & $100 \%$ & $100 \%$ \\
MUS017 & 10 & 5 & $88 \%$ & $92 \%$ \\
MUS018 & 15 & 15 & $100 \%$ & $100 \%$ \\
MUS020 & 10 & 15 & $96 \%$ & $96 \%$ \\
MUS021 & 20 & 15 & $88 \%$ & $88 \%$ \\
MUS022 & 20 & 20 & $100 \%$ & $96 \%$ \\
MUS023 & 10 & 15 & $96 \%$ & $100 \%$ \\
\hline
\end{tabular}

Legenda: Na cor vermelha - orelha direita; na cor azul- orelha esquerda. 


\subsubsection{Imitanciometria}

Durante a avaliação da pesquisa da curva timpanométrica, encontramos em 15 $(93,75 \%)$ dos 16 participantes (100\%) da pesquisa curva timpanométrica do Tipo A bilateralmente, e em apenas um (6,25\%) caso foi traçado curva do tipo Ad bilateralmente, de acordo com acordo a proposta de Jerger (1970).

O desencadeamento do reflexo acústico estapediano que avalia a integridade do arco reflexo estapediano e, por consequência, de forma indireta, as estruturas das orelhas média e interna, nervo auditivo e tronco cerebral foi obtido entre 95 e 105 $\mathrm{dB}$ em todos os participantes que obtiveram respostas, segundo a classificação de Carvallo et al. (2000).

Obteve- se como resultado ausência no reflexo ipsilateral da OD na frequência de $2 \mathrm{KHz}$ em um dos participantes (6,25\%) da amostra total de 16 (100\%), nove $(56,25 \%)$ também tiveram ausência na $\mathrm{OD}$, mas na frequência de $4 \mathrm{KHz}$ e em dez $(62,5 \%)$ participantes na frequência de $4 \mathrm{KHz}$ na OE.

Os resultados de ausência de reflexo contralateral na OD para a população total de 16 participantes (100\%) foram de duas (12,5\%) ausências na frequência de $500 \mathrm{KHz}$, uma $(6,25 \%)$ em $1 \mathrm{KHz}$, uma $(6,25 \%)$ em $2 \mathrm{KHz}$ e oito (50\%) para a frequência de $4 \mathrm{HKz}$. Obtivemos também ausência de reflexo contralateral na $O E$, sendo eles dois $(12,5 \%)$ na frequência de $500 \mathrm{Kz}$, quatro $(25 \%)$ em $1 \mathrm{KHz}$, dois $(12,5 \%)$ em $2 \mathrm{KHz}$ e dez (62,5\%) na frequência de $4 \mathrm{KHz}$.

Apenas três (18,75\%) participantes dos 16 (100\%) tiveram presentes de reflexo ipsilateral e contralateral bilateralmente, dois (12,5\%) tiveram ausência em duas frequências e onze (68,75\%) apresentaram pelo menos quatro ausências de reflexos nas frequências pesquisadas sendo Ipsi ou contralateral.

As bandas que mais tiveram ausência de resposta em alguma frequência foram B2 e B3 com 100\% de seus integrantes, seguidas por B4 com 50\% e B1 com 67\%, conforme mostra o Gráfico 6.

Também foi realizada a comparação entre os instrumentos e a ausência e presença de reflexo (Ipsi e/ ou contralateral) na frequência de 4KHz (Gráfico 7). 


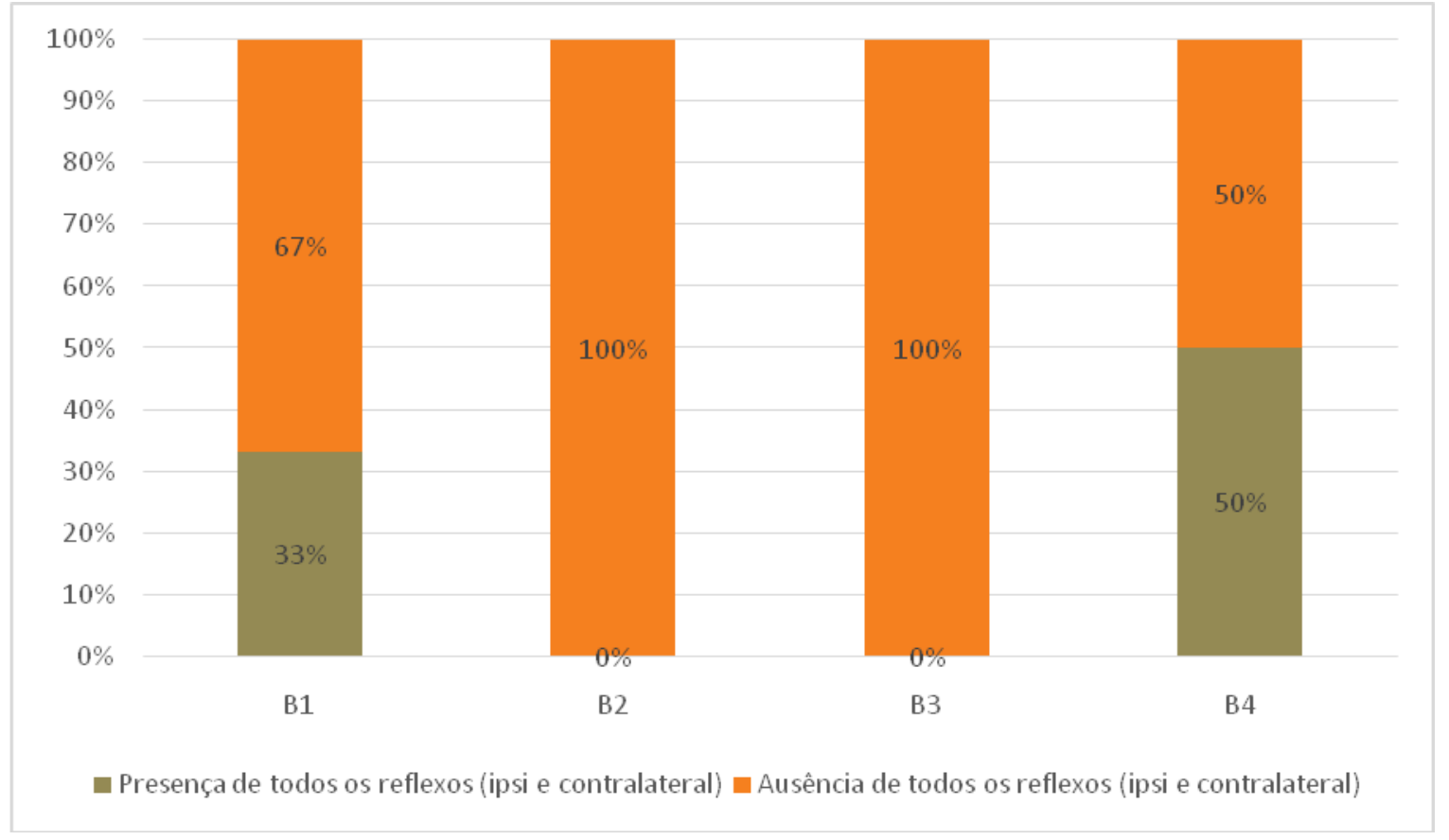

Gráfico 6 - Comparação entre as bandas e ausência de reflexo (Ipsi e/ ou contralateral)

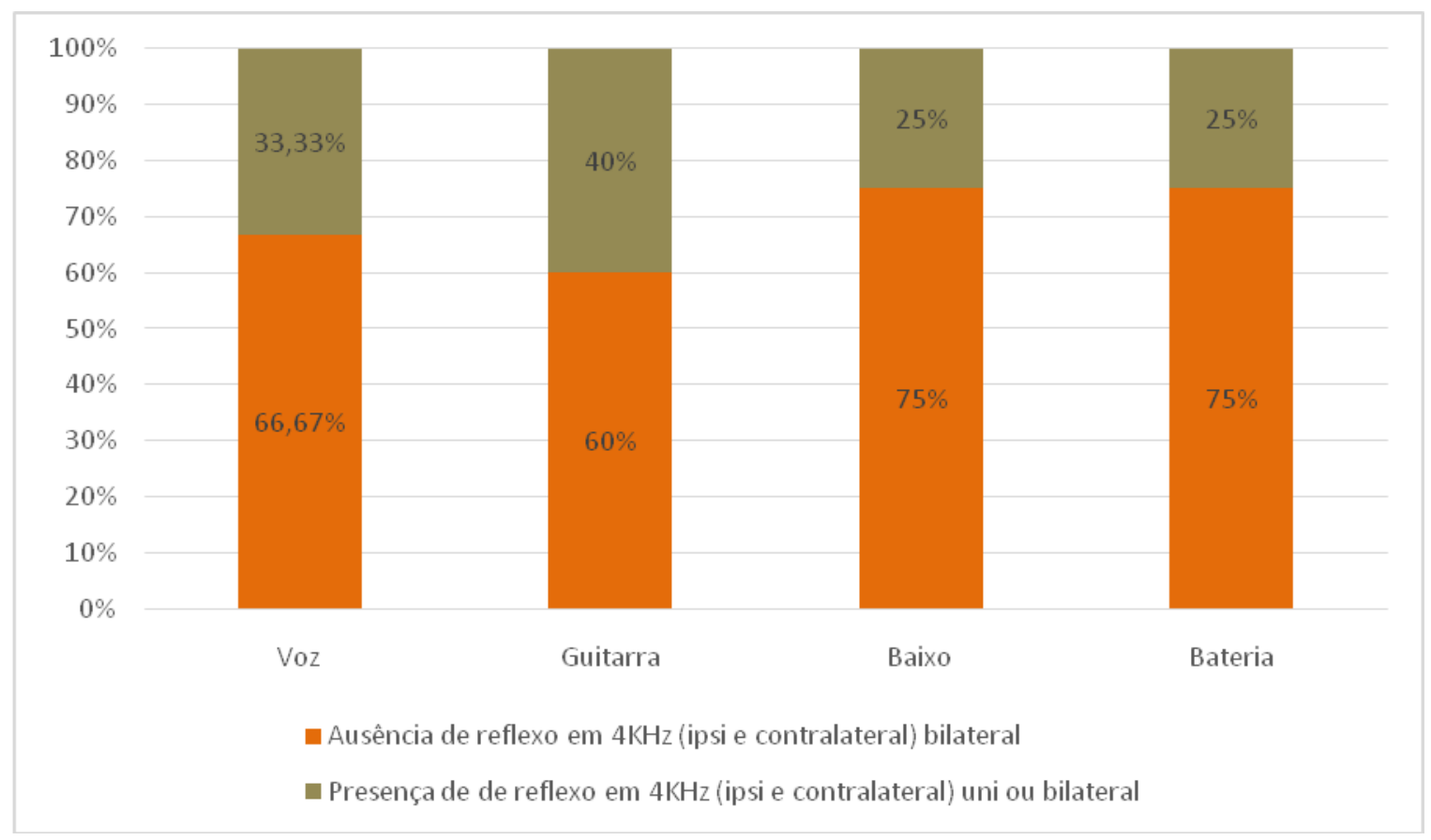

Gráfico 7 - Comparação entre os instrumentos, ausência e presença de reflexo (Ipsi e/ ou contralateral) na frequência de $4 \mathrm{KHz}$. 


\subsubsection{Emissões Otoacústicas Evocadas (EOE)}

A análise dos achados das EOE por estímulo transiente (EOEt) e por produto de distorção (EOEpd) foram realizados por meio comparação entre as frequências e bandas (B1, B2, B3 e B4) e frequências versus instrumentos (voz, guitarra, baixo e bateria). Obteve-se normalidade, ou seja, presença das EOEpd na frequência de $2 \mathrm{KHz}$ bilateralmente nos 16 (100\%) participantes do estudo, assim como na frequência de $3 \mathrm{KHz}$ na orelha direita e, por esse motivo, não foi realizada a comparação nessas frequências.

Não houve correlações entre a presença de resposta das frequências das Emissões Otoacústicas Evocadas por estímulo transiente para cada banda (Tabela 28). Já para as EOEpd, houve correlação na frequência de $6 \mathrm{KHz}$ conforme representa a Tabela 29.

Tabela 28 - Presença de resposta em porcentagem das Frequências das Emissões Otoacústicas Evocadas por estímulo transiente de acordo com cada banda analisada.

\begin{tabular}{|c|c|c|c|c|c|c|c|c|}
\hline \multirow[b]{2}{*}{$\mathrm{e}$} & \multicolumn{4}{|c|}{ OD } & \multicolumn{4}{|c|}{ OE } \\
\hline & $1 \mathrm{KHz}$ & $2 \mathrm{KHz}$ & $3 \mathrm{KHz}$ & $4 \mathrm{KHz}$ & $1 \mathrm{KHz}$ & $2 \mathrm{KHz}$ & $3 \mathrm{KHz}$ & $4 \mathrm{KHz}$ \\
\hline B1 & $33,33 \%$ & $100 \%$ & 16,67 & $66,67 \%$ & $100 \%$ & $100 \%$ & $66,67 \%$ & $66,67 \%$ \\
\hline B2 & $66,67 \%$ & $66,67 \%$ & 16,67 & $33,33 \%$ & $100 \%$ & $33,33 \%$ & $33.33 \%$ & $33,33 \%$ \\
\hline B3 & $75 \%$ & $100 \%$ & $25 \%$ & $25 \%$ & $75 \%$ & $50 \%$ & $75 \%$ & $50 \%$ \\
\hline . B4 & $100 \%$ & $83,33 \%$ & 16,67 & $16,67 \%$ & $100 \%$ & $66,67 \%$ & $83,33 \%$ & $50 \%$ \\
\hline
\end{tabular}

Legenda: KHz- Hertz; OD- orelha direita; OE- orelha esquerda.

Tabela 29 - Presença de resposta em porcentagem das Frequências das Emissões Otoacústicas Evocadas por produto de distorção de acordo com cada banda analisada.

\begin{tabular}{lccccccc}
\hline & \multicolumn{3}{c}{ OD } & \multicolumn{5}{c}{ OE } \\
\hline & $1 \mathrm{KHz}$ & $4 \mathrm{KHz}$ & $6 \mathrm{KHz}^{*}$ & $1 \mathrm{KHz}$ & $3 \mathrm{KHz}$ & $4 \mathrm{KHz}$ & $6 \mathrm{KHz}^{*}$ \\
B1 & $66,67 \%$ & $100 \%$ & $100 \%$ & $66,67 \%$ & $100 \%$ & $100 \%$ & $100 \%$ \\
B2 & $100 \%$ & $100 \%$ & $100 \%$ & $100 \%$ & $66,67 \%$ & $66,67 \%$ & $66,67 \%$ \\
B3 & $100 \%$ & $75 \%$ & $50 \%$ & $100 \%$ & $100 \%$ & $100 \%$ & $25 \%$ \\
B4 & $100 \%$ & $100 \%$ & $100 \%$ & $100 \%$ & $83,33 \%$ & $100 \%$ & $100 \%$
\end{tabular}

Legenda: $\mathrm{KHz}$ - Hertz; OD- orelha direita; OE- orelha esquerda. * $\mathrm{p} \leq 0,05$ 
Também não foram encontradas correlações entre a presença de resposta das frequências das EOEt para cada banda (Tabela 30) assim como para as EOEpd (Tabela 31).

Tabela 30 - Presença em porcentagem das Frequências das Emissões Otoacústicas Evocadas por estímulo transiente de acordo com cada instrumento analisado.

\begin{tabular}{lcccccccc}
$\mathrm{L}$ & \multicolumn{7}{c}{ OD } & \multicolumn{5}{c}{ OE } \\
$\mathrm{e}$ & $1 \mathrm{KHz}$ & $2 \mathrm{KHz}$ & $3 \mathrm{KHz}$ & $4 \mathrm{KHz}$ & $1 \mathrm{KHz}$ & $2 \mathrm{KHz}$ & $3 \mathrm{KHz}$ & $4 \mathrm{KHz}$ \\
Voz & $66,67 \%$ & $100 \%$ & $100 \%$ & $50 \%$ & $100 \%$ & $66,67 \%$ & $83,33 \%$ & $66,67 \%$ \\
Guitarra & $80 \%$ & $100 \%$ & $80 \%$ & $60 \%$ & $100 \%$ & $80 \%$ & $100 \%$ & $80 \%$ \\
Baixo & $50 \%$ & $100 \%$ & $75 \%$ & $0 \%$ & $100 \%$ & $50 \%$ & $25 \%$ & $0 \%$ \\
Bateria & $75 \%$ & $75 \%$ & $50 \%$ & $25 \%$ & $75 \%$ & $50 \%$ & $50 \%$ & $50 \%$ \\
\hline
\end{tabular}

Legenda: KHz- Hertz; OD- orelha direita; OE- orelha esquerda.

Tabela 31 - Presença em porcentagem das Frequências das Emissões Otoacústicas Evocadas por estímulo transiente de acordo com cada instrumento analisado.

\begin{tabular}{lccccccc}
\hline \multicolumn{7}{c}{ OD } & \multicolumn{5}{c}{ OE } \\
\hline Voz & $1 \mathrm{KHz}$ & $4 \mathrm{KHz}$ & $6 \mathrm{KHz}$ & $1 \mathrm{KHz}$ & $3 \mathrm{KHz}$ & $4 \mathrm{KHz}$ & $6 \mathrm{KHz}$ \\
Guitarra & $100 \%$ & $100 \%$ & $83,33 \%$ & $83,33 \%$ & $100 \%$ & $100 \%$ & $50 \%$ \\
Baixo & $75 \%$ & $100 \%$ & $100 \%$ & $80 \%$ & $100 \%$ & $100 \%$ & $80 \%$ \\
Bateria & $100 \%$ & $75 \%$ & $75 \%$ & $100 \%$ & $75 \%$ & $75 \%$ & $75 \%$ \\
\hline
\end{tabular}

Legenda: KHz- Hertz; OD- orelha direita; OE- orelha esquerda.

Oito dos 16 participantes não obtiveram respostas durante a avaliação das EOEpd; portanto foram pesquisadas as respostas das curvas de crescimento ( $d p$ growth rate), realizando sua comparação com lateralidade, sendo também comparadas as bandas e as frequências que necessitaram das pesquisadas ( $d p$ growth rate), e a relação entre os instrumentos e as frequências da curva de crescimento (dp growth rate), conforme apresentado nos Gráficos 8, 9 e10 respectivamente. 


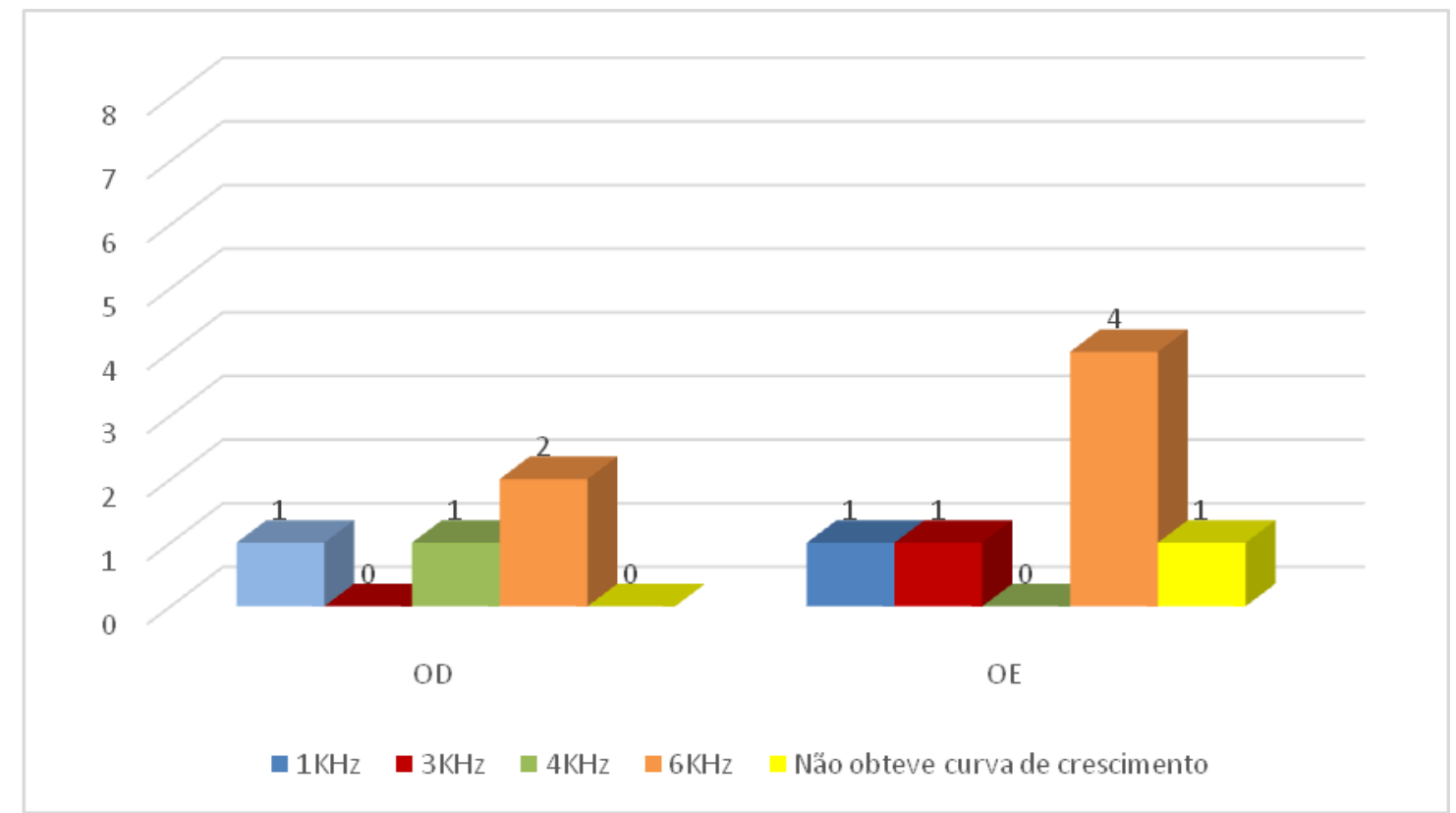

Gráfico 8 - Comparação entre lateralidade e as frequências que foram pesquisadas a curva de crescimento ( $d p$ growth rate).

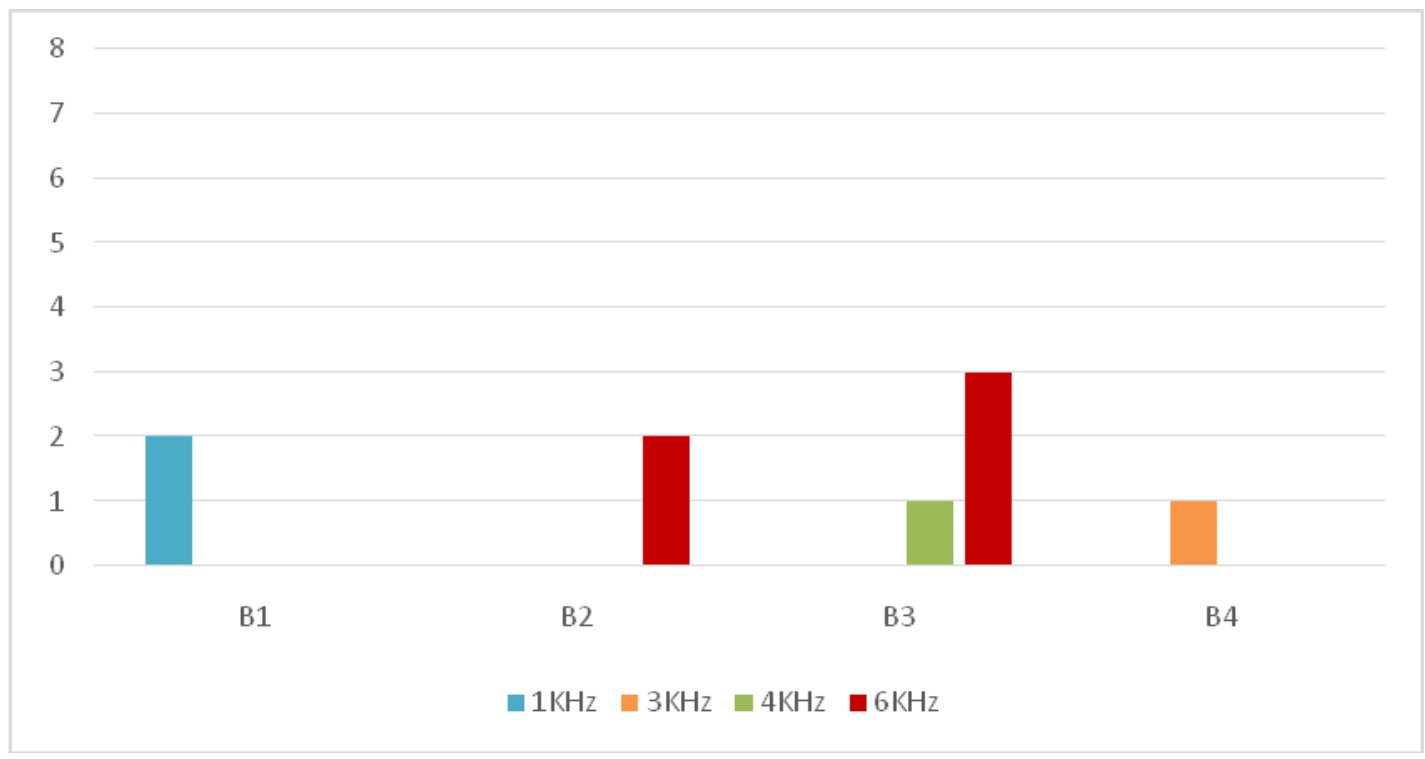

Gráfico 9 - Relação entre as bandas e as frequências da curva de crescimento (dp growth rate). 


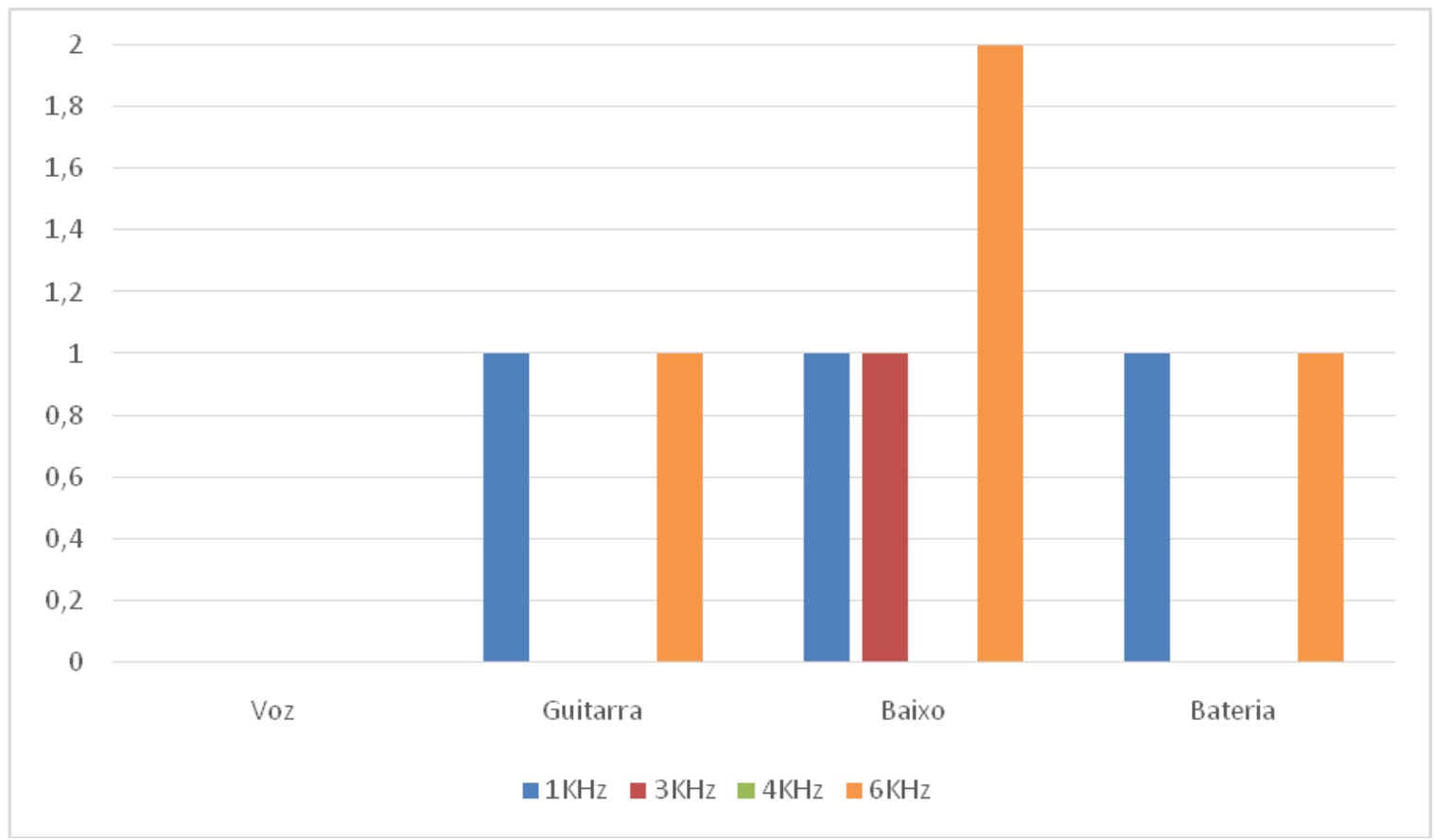

Gráfico 10 - Relação entre os instrumentos e as frequências da curva de crescimento ( $d p$ growth rate).

Nos participantes que realizaram a curva de crescimento ( $d p$ growth rate), foi encontrada resposta em $75 \mathrm{dBNA}$, sendo que, em um dos oito casos nos quais realizou-se o teste na frequência de $6 \mathrm{KHs}$, não foi encontrado resposta.

\subsubsection{WORKSHOP}

O workshop foi realizado com o objetivo de conscientizar e aperfeiçoar os conhecimentos dos músicos participantes.

O evento ocorreu em uma mesma data e horário para que todas as bandas pudessem participar juntas e assim contribuírem e compartilharem umas com os outros seus conhecimentos. O workshop teve duração de 4 horas e 30min, sendo 30min para aplicação de questionário, 1hora e 30min para discutirmos sobre acústica, tratamento e isolamento acústico no ambiente de ensaio, 1 hora destinada à saúde vocal e 1 hora e 30 min para abordagem sobrea saúde auditiva. 
A fim de conscientizá-los sobre a importância de se manter atitudes preventivas a distúrbios auditivos, utilizamos o website ${ }^{3}$ desenvolvido no grupo de pesquisa de saúde auditiva em músicos.

Os temas abordados no conteúdo do workshop foram sobre os seguintes tópicos:

1. Início - boas-vindas ao site e explicação do objetivo.

2. Caminho do som - explicação fisiológica sobre o caminho do som até nosso cérebro.

3. O que é perda auditiva? - Quanto ao tipo e ao grau.

4. O que é perda auditiva induzida por ruído? - Abordagem correlacionando à perda auditiva a níveis elevados de pressão sonora.

5. Como prevenir - EPl's? - Abordagem dos protetores específicos para músicos, que permitem a atenuação do som, mas também o retorno da música.

6. Tempo de exposição a níveis elevados de pressão sonora - tabela ilustrativa sobre o tempo de exposição e o dano causado à audição.

7. Como a fonoaudiologia pode ajudar - abordagem do papel do fonoaudiólogo da prevenção à reabilitação.

8. Sobre - identidade das pesquisadoras envolvidas no projeto.

A ferramenta utilizada para desenvolvimento do site permite que o público acesse a todo o conteúdo sem que haja a necessidade de um cadastro prévio. Ao final de cada página, existe uma caixa de contato que permite o envio de sugestões e críticas. Esta caixa era acessada pela pesquisadora e assim respondia de forma imediata.

Veem-se a seguir as figuras das telas do web site disponibilizados por meio de páginas no Wix.

${ }^{3}$ Disponível em: <http://saudeauditiva.wix.com/samb>. 
Figura 5- Início

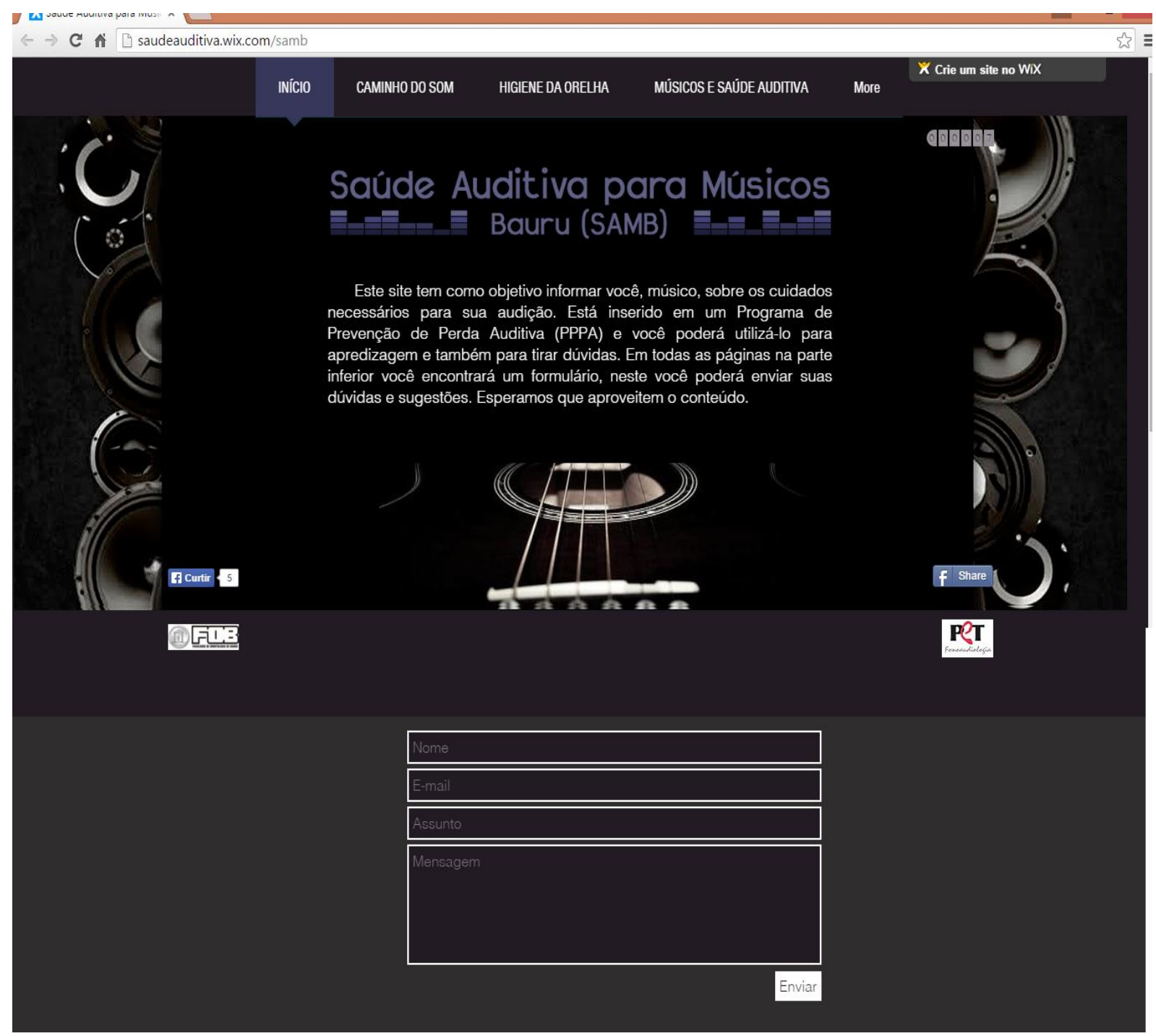


Figura 6 - Caminho do som.

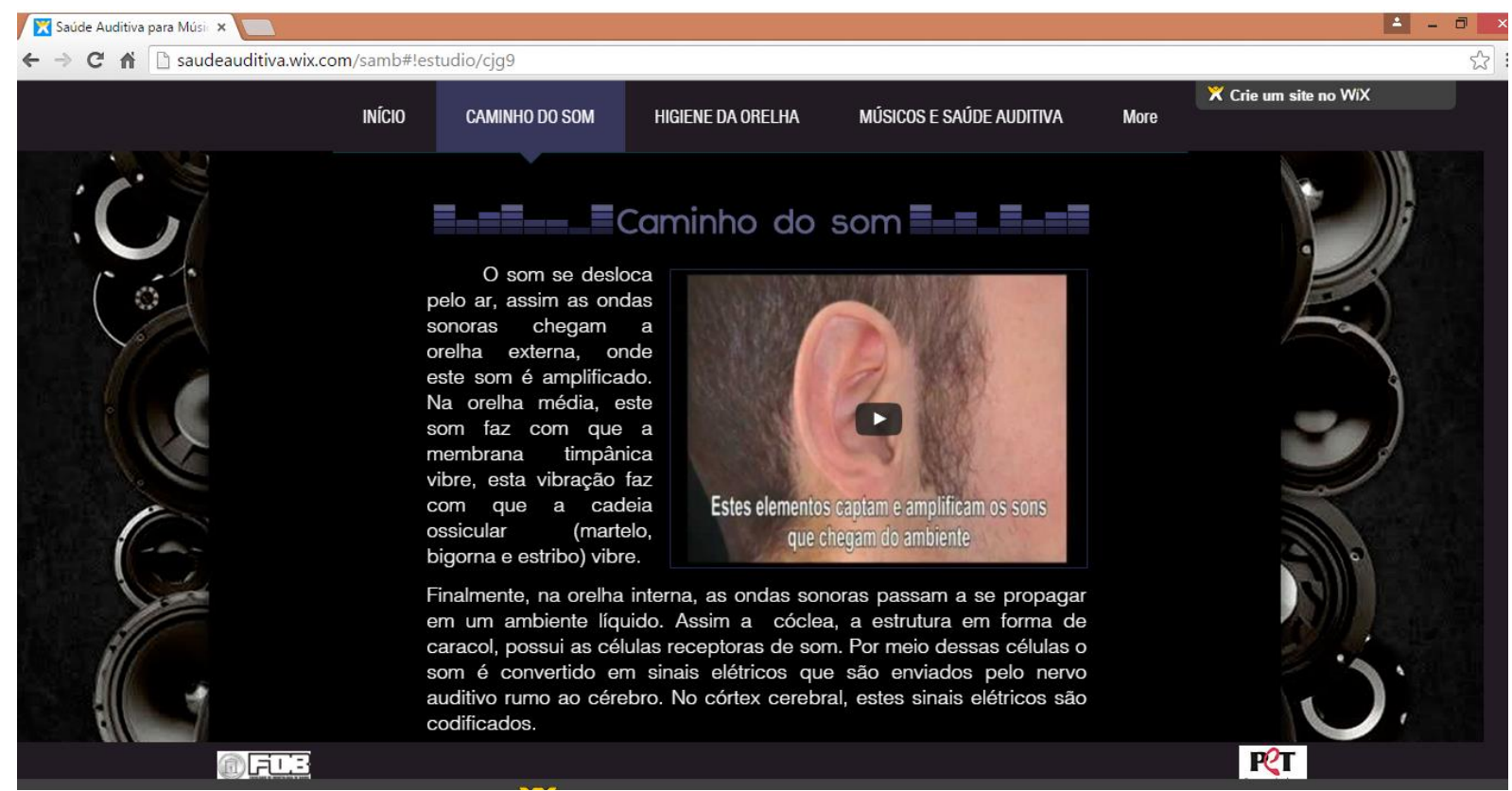

Figura 7 - Higiene da orelha.

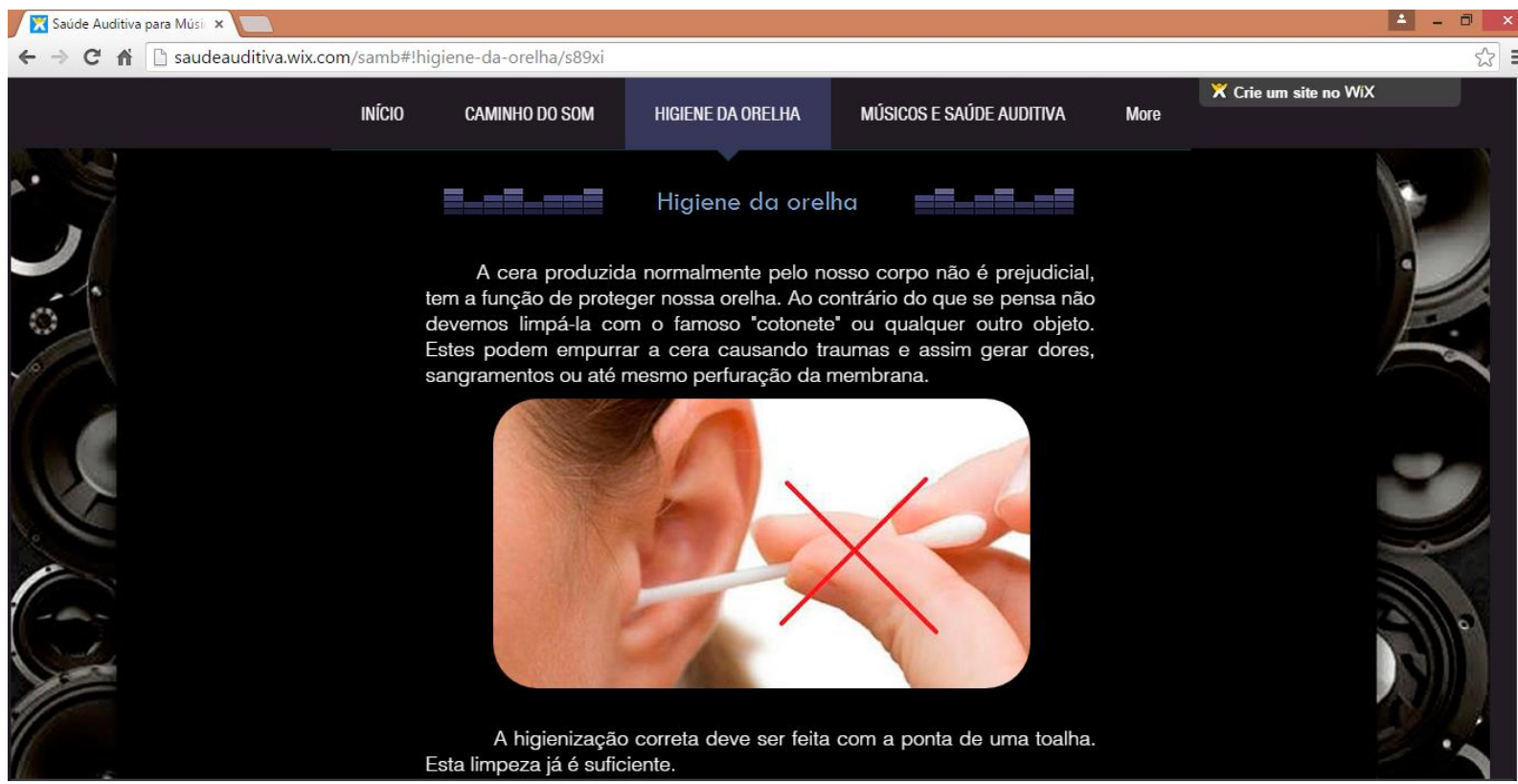


Figura 8 - O que é perda auditiva?

$\Rightarrow \mathbf{C}$ กี $\square$ saudeauditiva.wix.com/samb\#!o-que--perda-auditiva/c1h2c

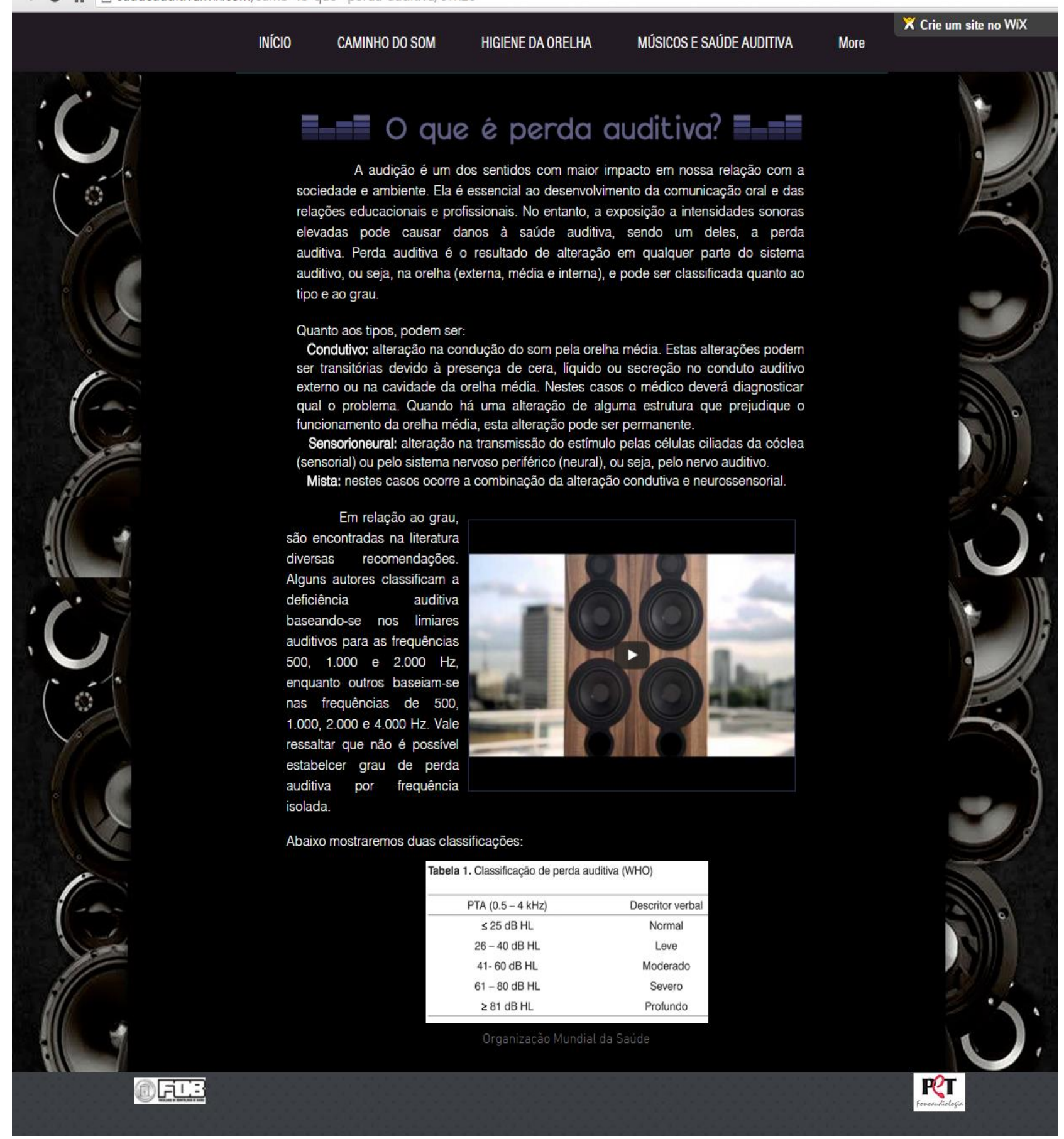


Figura 9 - Perda Auditiva Induzida por Ruído (PAIR).

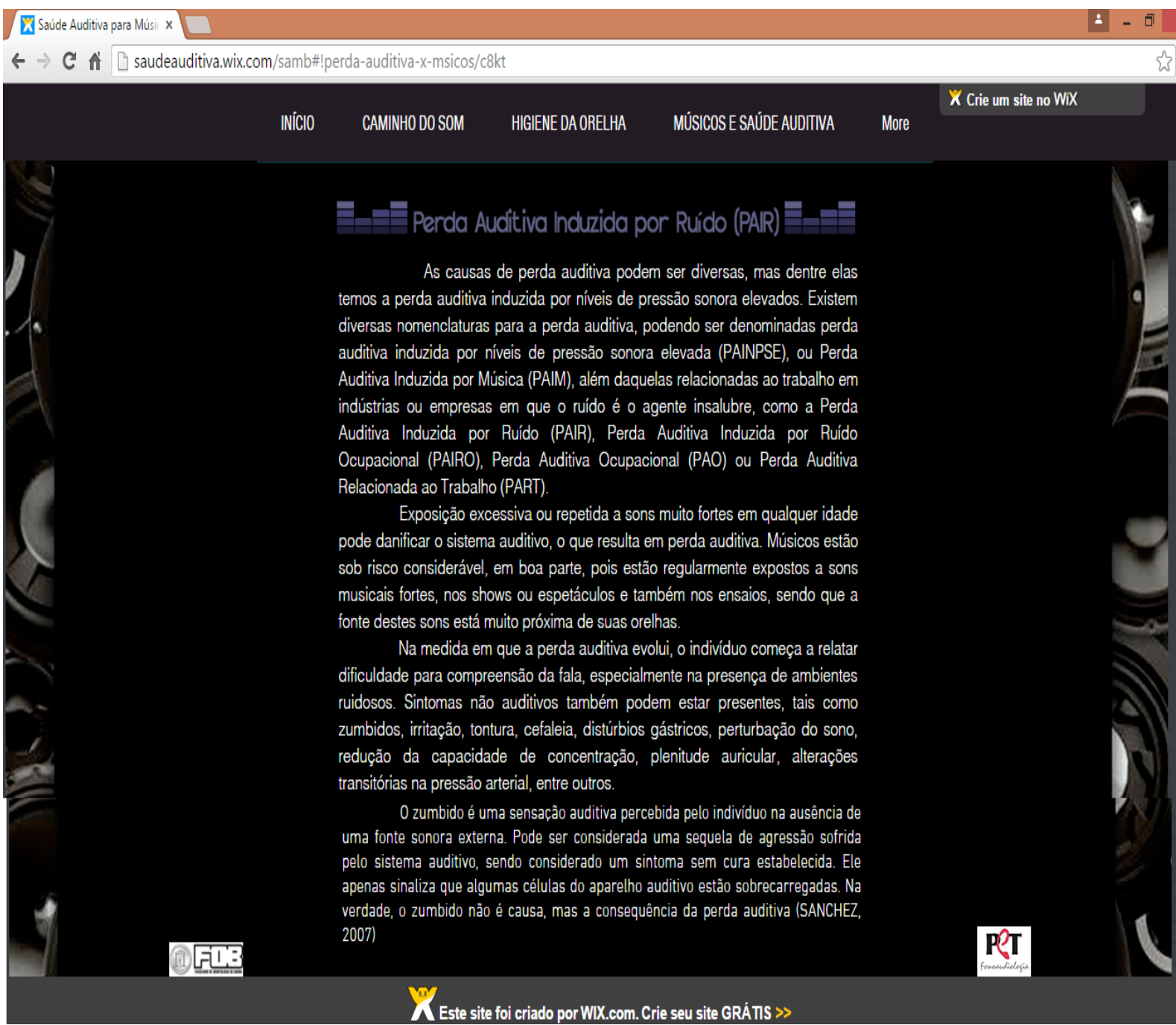


Figura 10 - Como prevenir.

T Saúde Auditiva para Músi $\times \square$

C กิ saudeauditiva.wix.com/samb\#!como-prevenir/c1kn5

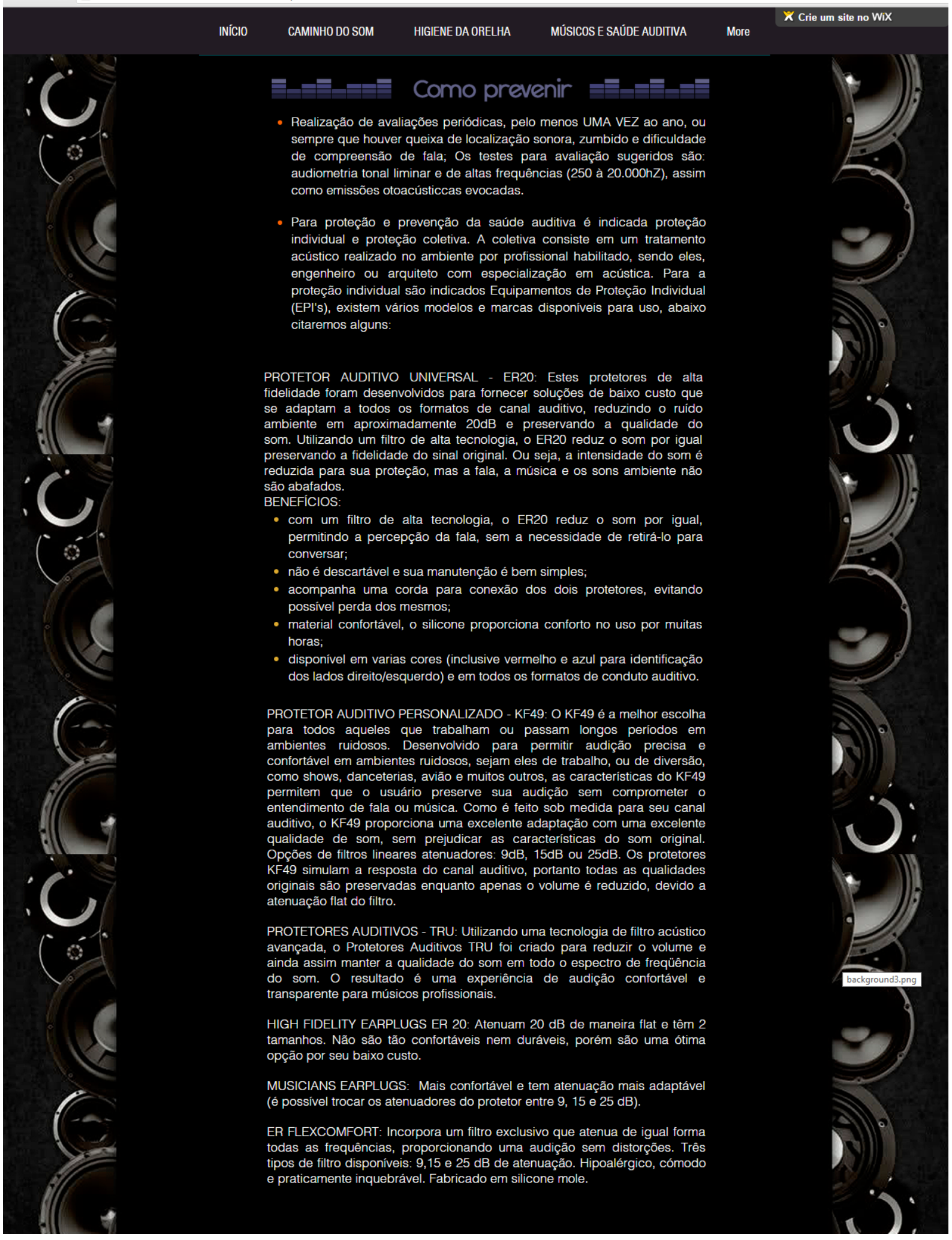


Figura 11 - Tempo de exposição x intensidade, segundo NR15.

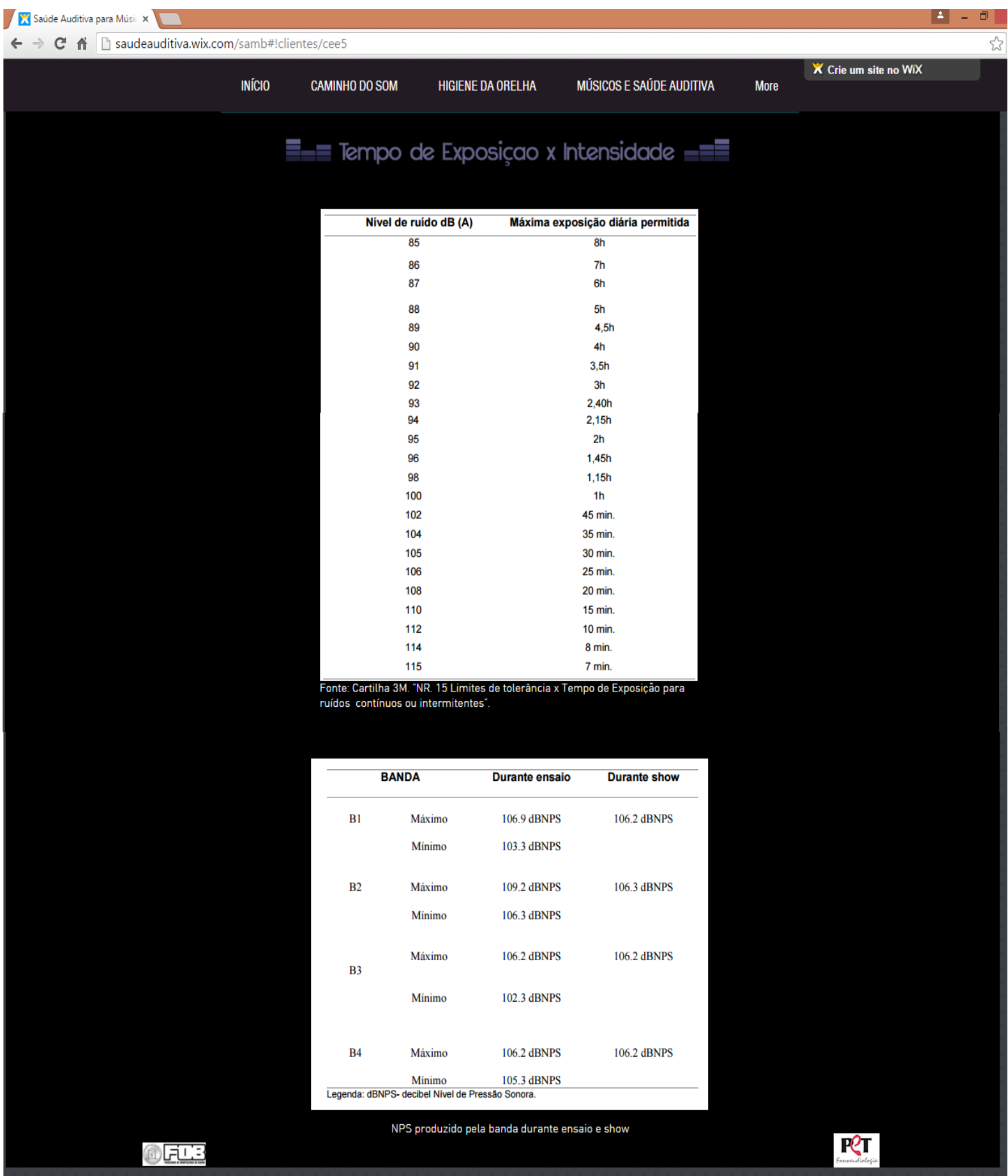


Figura 12 - Atuação Fonoaudiológica.

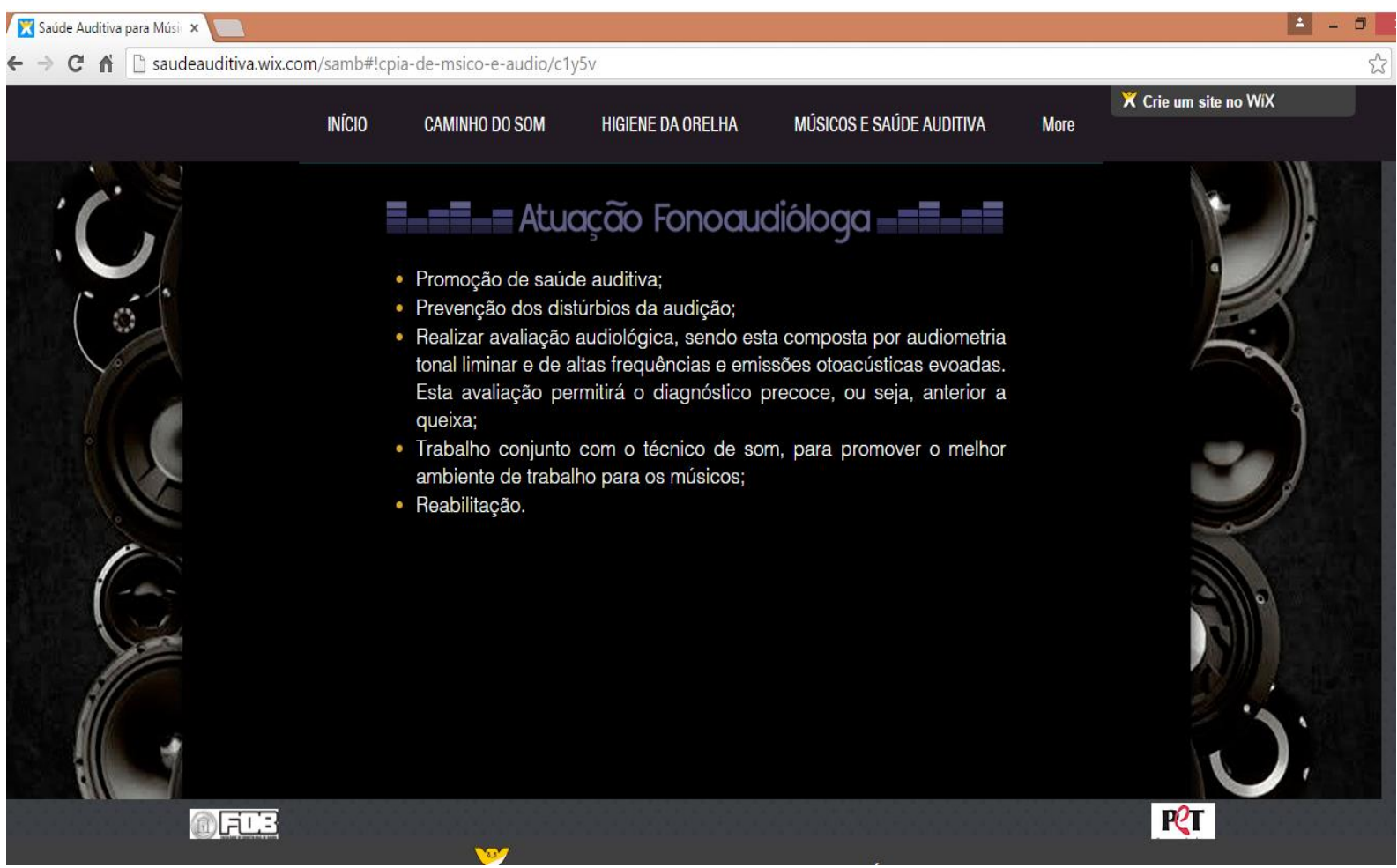


Figura 13 - Resultados obtidos na pesquisa.

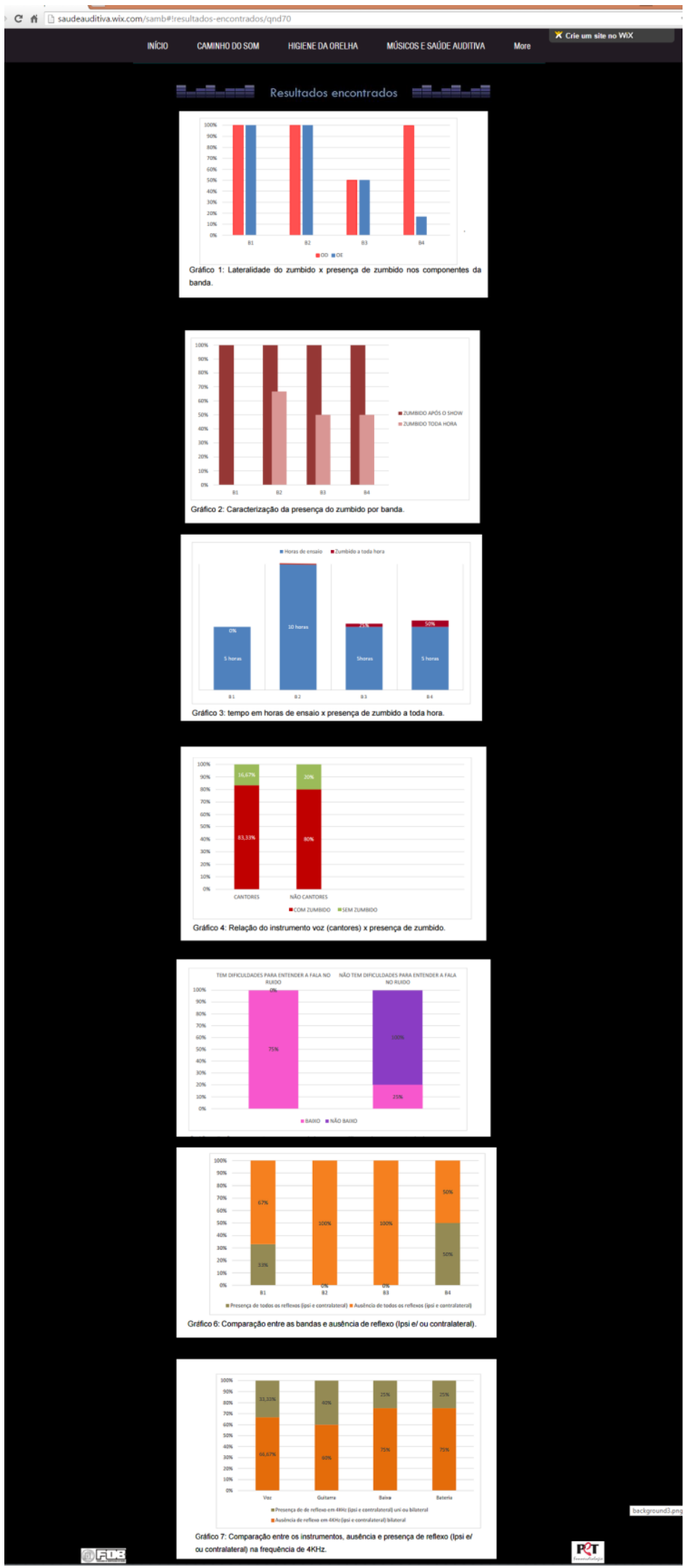


Figura 14 - Sobre.

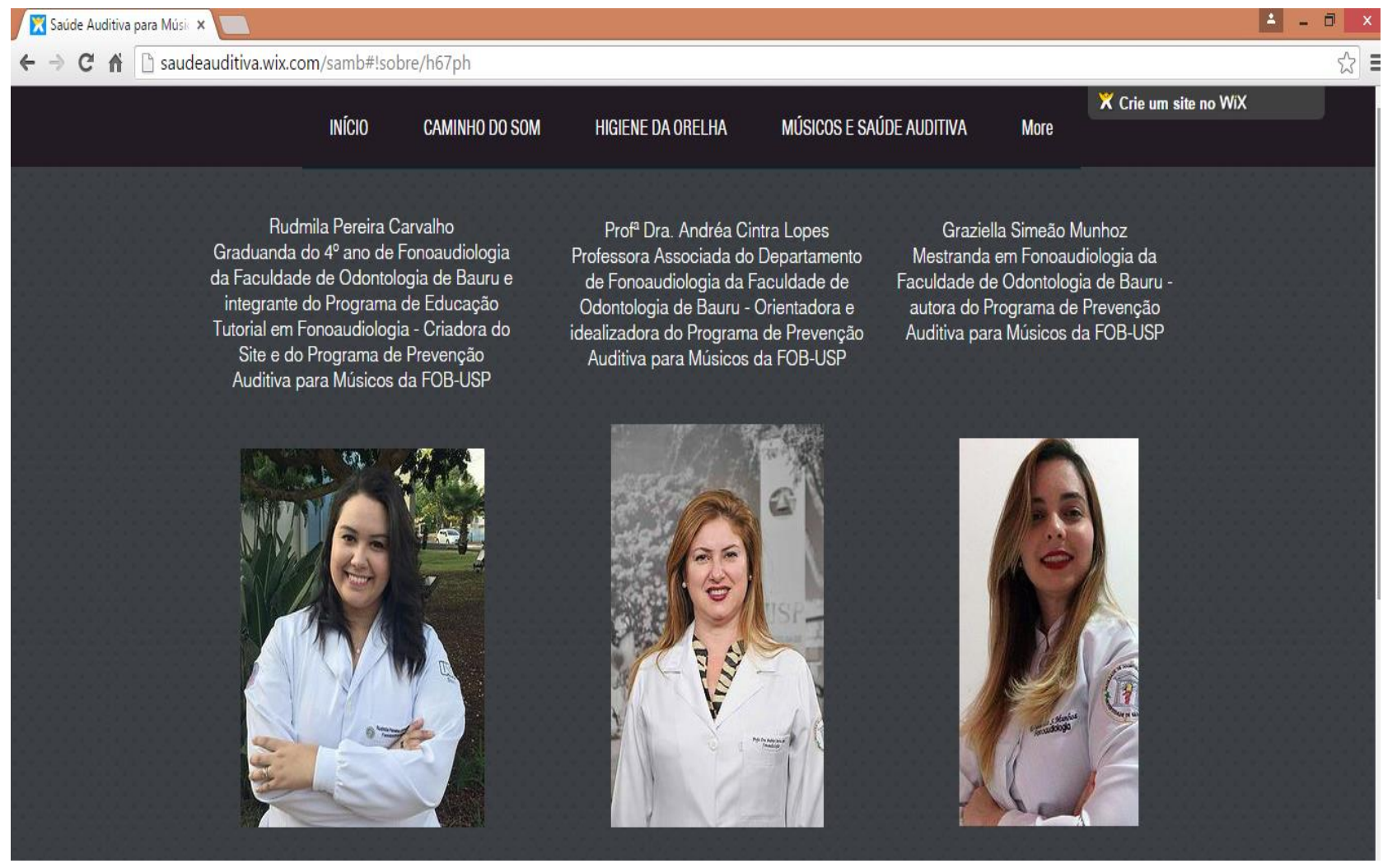

As figuras e vídeos foram selecionadas com o objetivo de serem atuais, de fácil entendimento e que despertassem o interesse e a motivação do público alvo. Todas as figuras e vídeos possuem legendas para facilitar o entendimento do que está sendo exemplificado e para possibilitar uma maior exploração da figura por parte do indivíduo.

Todos os textos elaborados foram avaliados por meio do Índice de Leitura Flesch como forma de deixar o mais compatível possível com o nível de escolaridade, de acordo com a idade do público alvo. As porcentagens obtidas em cada um dos tópicos estão representadas na Tabela 32. 
Tabela 32 - Valores obtidos - Índice de Leitura Flesch.

\begin{tabular}{ccc}
\hline TÓPICO & PORCENTAGEM & CLASSIFICAÇÃO \\
\hline Início & $50 \%$ & Fácil \\
Caminho do Som & $64 \%$ & Fácil \\
O que é perda auditiva? & $52 \%$ & Fácil \\
Perda auditiva induzida por ruído & $49 \%$ & Difícil \\
Como prevenir - EPI's & $47 \%$ & Difícil \\
Tempo de exposição à NPS & $57 \%$ & Fácil \\
Como a fonoaudiologia pode ajudar & $45 \%$ & Difícil
\end{tabular}

\subsubsection{Verificar a eficácia do PPPA/ workshop}

A pesquisadora construiu um formulário utilizando a ferramenta docsgoogle para enviar às bandas participantes, a fim de decidirem a melhor data e período para realização do workshop. O endereço ${ }^{4}$ para acesso do formulário foi enviado às bandas separadamente para preservar as suas identidades.

Os componentes das bandas (músicos) foram orientados a decidirem a data e o período, contudo apenas um dos integrantes ficaria como responsável para preencher o formulário (Figura 15), totalizando assim os quatro formulários, um por banda. Após o formulário ser preenchido pelo representante da banda e enviado, este era encaminhado diretamente para o e-mail da pesquisadora e então era gerado uma planilha no excel, onde conseguimos observar as respostas, como exemplificado na Figura 16.

\footnotetext{
${ }^{4}$ Disponível em:

$<$ https://docs.google.com/forms/d/1aKiAjRODtdQzBPtmGeKLJ239PBioqFFvaJmtG7ZLb_U/viewform? $\mathrm{C}=0 \& \mathrm{~W}=1>$.
} 
Figura 15 - Formulário utilizado para decisão da data e período para o workshop.

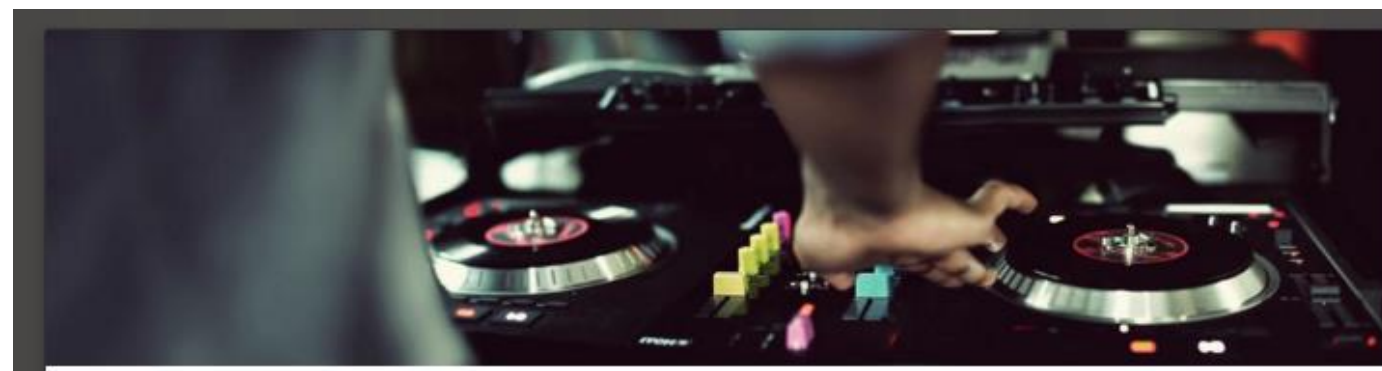

\section{PPPA PARA MÚSICOS: WORKSHOP}

*Obrigatório

De acordo com a banda: Qual a melhor data para a realização do workshop? *

0 workshop terá duração de até 3 horas. Os temas abordados serão: saúde auditiva, saúde vocal e como

realizar a acústica para o estúdio. Vale lembrar que o workshop trata-se de uma consultoria voltada para o músico e todos os componentes da banda precisam estar presentes.

16/11/2015 ( $2^{\mathrm{a}}$ feira $)$

$17 / 11 / 2015$ ( $3^{\mathrm{a}}$ feira $)$

$18 / 11 / 2015$ ( $4^{\mathrm{a}}$ feira)

$20 / 11 / 2015$ ( $6^{\mathrm{a}}$ feira)

21/11/2015 (sábado)

Outro:

Qual periodo?*

Qual período?*

Manhã

Tarde

Noite

Qual o nome da sua banda? *

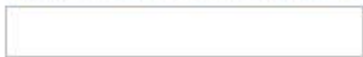

\section{Enviar}

Nunca envie senhas pelo Formulários Google.

Powered by

Aoogle Forms
Este conteúdo não foi criado nem aprovado pelo Google Denunciar abuso - Termos de Serviço - Termos Adicionais

Legenda: PPPA- Programa de Prevenção de Perdas Auditivas. 
Figura 16 - Planilha de resultados gerados pelo excel após envio de resposta do formulário.

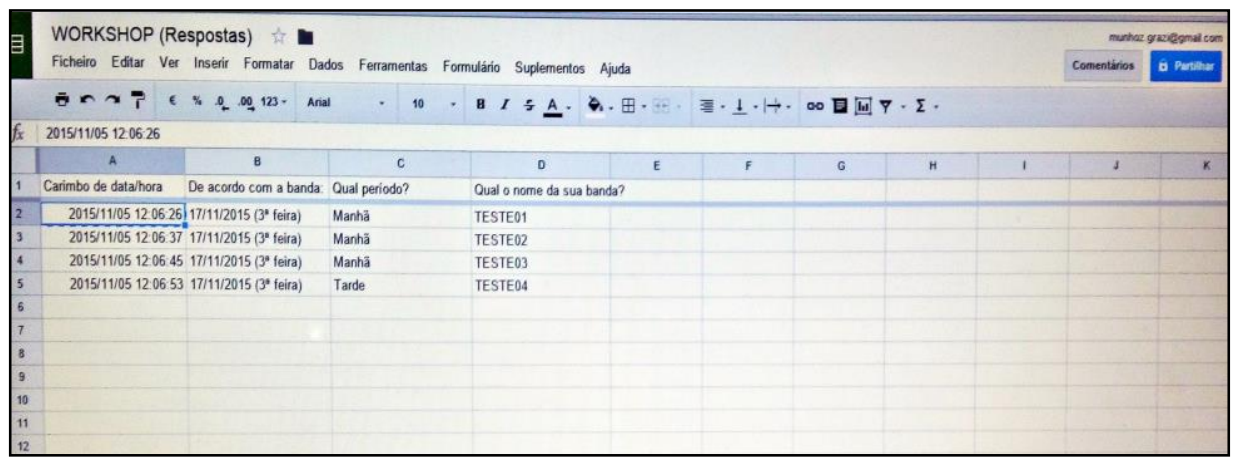

O website desenvolvido pelo grupo de pesquisa passou por avaliação da disposição de imagens, vídeos, cores, tamanho da fonte, disposição dos textos e toda a imagem visual do site. Este passou por um web designer que emitiu opiniões sobre quais seriam as mudanças necessárias para que o visual se tornasse agradável e estimulante para o público alvo. Após a avaliação, as mudanças foram feitas e os resultados podemos ver conforme as figuras apresentadas anteriormente.

O web site foi utilizado como ferramenta durante o workshop, e, por meio dos questionários antes e depois da oficina, pudemos verificar sua efetividade

Quanto ao segundo questionário, foi aplicado ao término do workshop com o intuito de qualificar as informações expostas pelos instrutores, podendo observar no questionário se houve mudança de comportamento em relação à Fonoaudiologia e sobre o risco de perda auditiva (Anexo 4).

Os resultados dos questionários aplicados antes do workshop foram os seguintes:

Quanto à questão número um (01), que questionava o que o músico sabia sobre a Fonoaudiologia, os participantes da B1 responderam que é a ciência que abrange o conhecimento na audição, fala, fonética, bem como as articulações e respiração, sendo sua aplicação corretiva ou preventiva, desde cantores até pessoas com má formação.

Os integrantes da B2 disseram que é o estudo da saúde vocal e auditiva; estuda a fisiologia da audição e da fala e, por fim, estuda o sistema auditivo, aparelhos receptores e reprodutores de som; estuda o funcionamento do organismo e as melhores formas de usá-lo afim de garantir a saúde de todos os sistemas. 
Já os integrantes da B3 responderam que é a área da saúde responsável pelos cuidados do aparelho auditivo e vocal; é o estudo da audição e a ciência que estuda a anatomia e fisiologia da audição.

Aqueles integrantes da B4 responderam que a Fonoaudiologia estuda a audição; é a área que estuda o processo de comunicação, voz, audição e também auxilia as pessoas que têm dificuldades em falar e ouvir; é a área que estuda voz e audição; corrige o comportamento vocal.

$\mathrm{Na}$ questão número dois na qual se perguntava sobre como eles acreditam que o fonoaudiólogo trabalha com os profissionais da música, as respostas obtidas na B1 foi que o Fonoaudiólogo trabalha com o aquecimento e desaquecimento vocal, com o conhecimento morfológico e fisiologia para ajudar o músico a fazer o seu uso correto. Os membros da B2 responderam que o fonoaudiólogo trabalha analisando as deficiências no músico e instruindo-os para a prática da correção, também realiza orientações para o melhor uso e saúde do nosso sistema auditivo. Por fim, trabalha a saúde e qualidade no canto e saúde auditiva. Já os da B3 disseram que o Fonoaudiólogo auxilia com as técnicas adequadas de execução e preservação dos emissores e receptores sonoros do músico, auxiliando-os também a amenizar os danos causados pela exposição a níveis elevados de ruído. Por fim, os da B4 afirmaram que acreditam que o Fonoaudiólogo realize trabalhos afim de preservar e preparar a voz do músico, orientando-o sobre os cuidados vocais e na melhor maneira de se utilizar a voz. Também ajuda na prevenção da perda auditiva, adquirida através da exposição a volumes elevados.

Quanto à questão número três, que referia sobre se o participante já havia passado por algum acompanhamento Fonoaudiológico as respostas foram: B1$33,33 \%$ passaram por acompanhamento fonoaudiológico, devido ao fato de sentir queimações e desconforto vocal após apresentação em shows. 66,67\% dos participantes da B2 disseram ter passado por acompanhamento fonoaudiológico para obter orientações referentes a canto e saúde vocal. Já na B3, nenhum $(0 \%)$ realizou acompanhamento com fonoaudiólogo (a) e na B4, 16,67\% disseram ter realizado acompanhamento fonoaudiológico, pois era disfluente (gagueira). Como demonstrado no gráfico a seguir (Gráfico 11). 


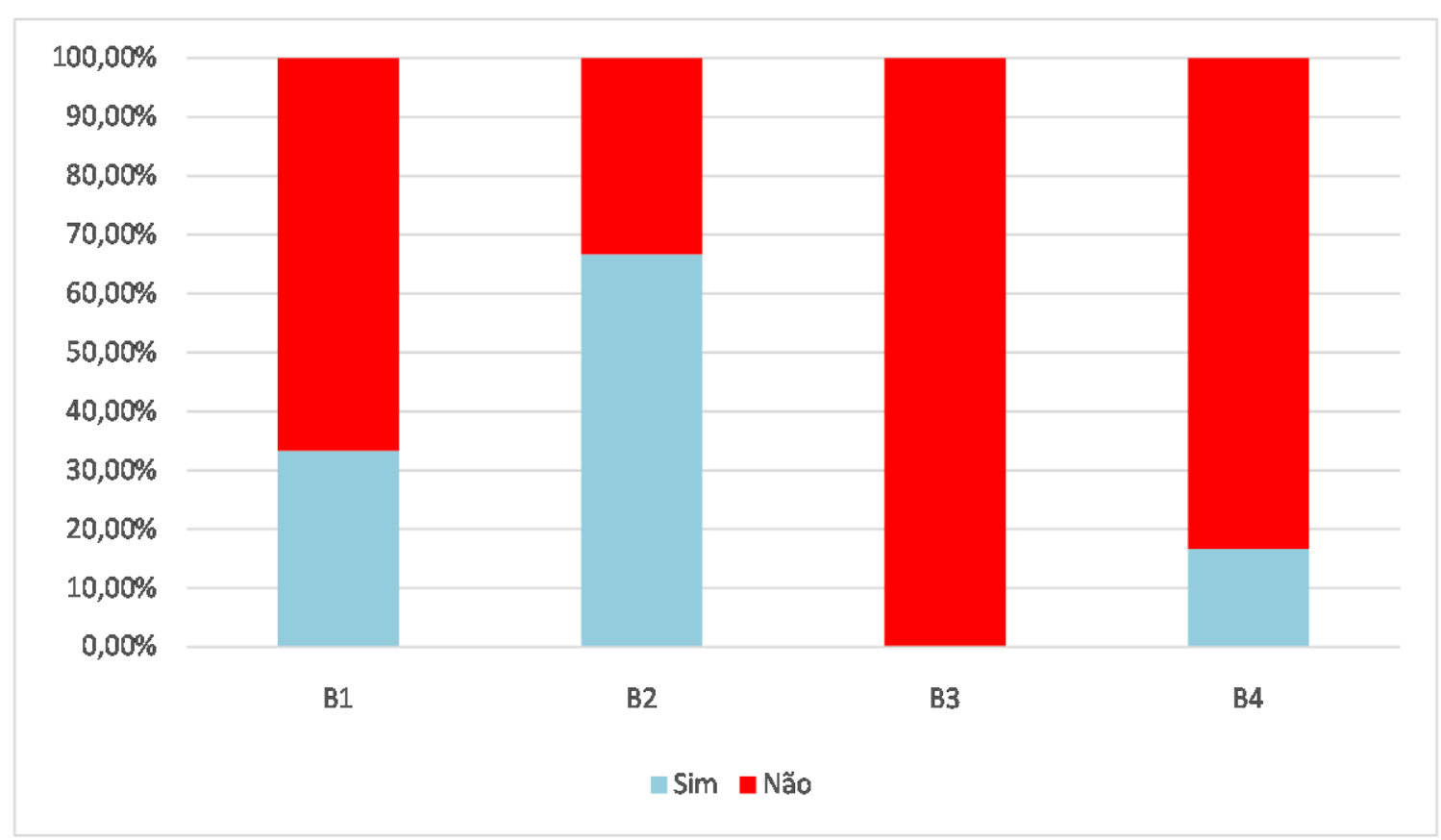

Gráfico 11 - Distribuição da necessidade de ter realizado acompanhamento Fonoaudiológico por banda.

Quanto à questão número quatro que averiguava o que o participante sabia sobre protetores auditivos, os resultados obtidos foram, na B1, que os protetores limitam o volume excessivo que chega até nossos ouvidos. Em B2, que são redutores e absorvem o som externo, protegem a audição e que também pode ser adequado à necessidade de cada pessoa. Para B3, são instrumentos de auxílio à proteção auricular que dependem da aplicação devida para bloquear, filtrar e até amplificar, dependendo da frequência. São usados para proteção do aparelho auditivo, cuidando de perdas futuras na audição. Já para B4, eles filtram determinadas frequências, oferece proteção e conforto e têm como objetivo diminuir as perdas auditivas no músico.

A questão número cinco que perguntava se o participante fazia uso de protetores auditivos, e caso o fizesse qual era o protetor que utilizava e oporquê de seu uso, encontramos que, na B1 e B2, nenhum (0\%)dos músicos faz uso de protetores auditivos, na B3 apenas 33,33\% quase nunca fazem uso de protetores do tipo plug durante os ensaios, e na B4, 16,67\% fazem uso raramente do protetor auditivo Se315 durante os ensaios e shows.

Quanto à questão número sete que solicitava para escreverem sobre suas críticas e sugestões referentes ao trabalho proposto, B1 parabenizou o trabalho de extensão praticado alegando ser importante em seu ambiente de trabalho (para o 
músico) e solicitaram que o trabalho continuasse. Como sugestão, tanto B2 como B3 disseram para que o trabalho fosse expandindo a um público ainda maior e parabenizaram pela iniciativa. Já B4 disse ter valido muito a pena participar do workshop e do trabalho como um todo, elogiando o profissionalismo da Fonoaudióloga e pesquisadora deste estudo, pois sempre conduziu o trabalho seriamente e sempre explicou e respondeu a todas as dúvidas. Por fim, agradeceram por lembrarmos da sua classe trabalhadora (a dos músicos), de forma a ajudá-la, defendendo a segurança no trabalho que em sua concepção, deveria ser oferecida também pelo governo.

Quando questionada se reconhecem alguma importância no fato de terem participado da pesquisa (questão número oito), todas as bandas responderam positivamente em $100 \%$ dos resultados obtidos. Sendo que, para B1, o conhecimento adquirido, a aplicação das informações e as dicas em shows irão melhorar seu desempenho. Para B2, o conhecimento que essa pesquisa proporcionou fez com que passasse a se preocupar com a saúde auditiva. A B3 relatou que irão conseguir a partir de então amenizar o estrago provocado pela exposição ao ruído em sua audição e voz. Por fim, aB4 disse que foram transmitidas as informações e os conhecimentos necessários para que, se colocados em prática, notariam melhoras nas condições de trabalho no meio musical, além de oferecer conforto e qualidade tanto em longo quanto em curto prazo. Também disseram ter aprendido sobre audição, a importância da voz, os processos do som, a saúde da voz e da audição e o quanto é importante cuidar de ambos.

Já quando o participante foi questionado (questão número seis) sobre o que aprendeu após o workshop e se iria tentar colocar em prática em sua vida diária, obtivemos os seguintes resultados: B1diz ter aprendido que são necessários os cuidados com a saúde em geral, principalmente com a voz e a audição já que são instrumentos de seu trabalho.B2, relatou ter aprendido sobre os cuidados com a voz, a higiene da orelha e o cuidado necessário com a exposição ao ruído.

B3, "aprendemos a ter disciplina e consequentemente a ter amor próprio, além de colocar em pratica os ensinamentos passados referente a saúde auditiva e vocal sem ter vergonha de fazer ou tomar cuidados" e por fim B4, "aprendemos que as cordas vocais, audição e som que são instrumentos importantes". "Que os cuidados que devemos ter com a voz, como a realização de exercícios de 
aquecimento e desaquecimento vocal, assim forçando menos a voz durante shows e ensaios, como também a melhora na acústica no local do ensaio, são essenciais".

A importância da prevenção e cuidados relacionados à exposição do ruído para proteger e cuidar da audição, assim como após o show, e o repouso auditivo, foram itens citados pelos participantes da B4.

\subsection{Resumo dos achados encontrados no tópico Resultados}

Resumindo, podemos observar a partir dos resultados encontrados no estudo:

O Nível de Pressão Sonora (NPS) durante os ensaios e apresentações/shows, estão acima do permitido para uma jornada de trabalho de 4horas (tempo em que realizam cada ensaio e show) sem EPI de acordo com a NR 15, podendo causar alterações auditivas irreversíveis;

A entrevista específica mostrou:

- Os sintomas não auditivos estão presentes em $68,75 \%$ da população total da amostra;

- Presença de zumbido bilateral do tipo apito em $100 \%$ dos casos na B1 e B2, $50 \%$ na B3 e $100 \%$ em B4;

- Presença de zumbido após o show em $100 \%$ dos casos e em todas as bandas;

- Maiores dificuldades de compreensão de fala no ruído nos músicos que tocam baixo.

Os testes audiológicos realizados identificaram:

- Maiores médias dos limiares audiológicos por frequência das bandas estudadas em $500 \mathrm{~Hz}$ e $3 \mathrm{KHz}$ (B1), $3 \mathrm{KHz}$ e $4 \mathrm{KHz}$ (B2), $3 \mathrm{KHz}, 4 \mathrm{KHz}$ e $6 \mathrm{KHz}$ (B3) e em $3 \mathrm{KHz}$ (B4);

- As maiores médias dos limiares audiológicos por frequência dos instrumentos estudados foram em $3 \mathrm{KHz}, 4 \mathrm{KHz}$ e $6 \mathrm{KHz}$ (voz), $3 \mathrm{KHz}$ e $4 \mathrm{KHz}$ (guitarra), $3 \mathrm{KHz}, 4 \mathrm{KHz}$ e $6 \mathrm{KHz}$ (baixo) e $3 \mathrm{KHz}, 4 \mathrm{KHz}$ (bateria);

- Presença de entalhe nas frequências de $2 \mathrm{KHz}, 4 \mathrm{KHz}, 6 \mathrm{KHz}$ e $8 \mathrm{KHz}$ na audiometria tonal liminar; já na audiometria de altas frequências em todas as frequências apareceram ao menos um caso;

- Logoaudiometria com resultados dentro da normalidade; 
- Imitanciometria: curva tipo A; reflexo presentes entre 95 e $105 \mathrm{~dB}$ quando surgia respostas e reflexos ausentes em $4 \mathrm{KHz}$ (Ipsi e contralateral);

- EOE por estímulo transiente: ausência de resposta em $4 \mathrm{KHz}$ para todos os baixistas bilateralmente $(100 \%)$;

- EOE por produto de distorção: ausência de respostas em $50 \%$ da amostra na frequência de $6 \mathrm{KHz}$;

- Curva de crescimento (dp growth rate) com resposta em $75 \mathrm{~dB}$ em quase $100 \%$ dos casos em que houve necessidade de sua realização.

- Quanto aos achados obtidos da avaliação realizada pelos participantes (músicos) referente ao website, os resultados mostraram que o mesmo atende às necessidades propostas, ou seja, a promoção da saúde auditiva em músicos. 
$\underline{\text { Discussão }}$ 


\section{DISCUSSÃO}

Uma vez que se é sabido que a música e o uso de amplificadores estéreos pessoais, como os fones de ouvido, vêm provocando perdas auditivas e, por terem sido tema em debates sociais, estudos científicos, reportagens, rodas de amigos, conversas de pais e filhos, dentre outros, vêm provocando mudanças de comportamento das pessoas.

Portanto, o uso dos estéreos pessoais, que utilizamos para apreciar e ouvir música se utilizados de maneira errada pode causar perdas auditivas. O que ocorre então quando esse som que muitas vezes é agradável às nossas orelhas se torna o ruído presente em nosso ambiente de trabalho.

E quando não há legislação fiscalizadora, nem leis que reconhecem a música como ruído presente no ambiente de trabalho para o músico, afinal ser músico também é uma profissão.

A fim de entender, responder e tentar encontrar medidas que possam ajudar nesse processo, idealizamos tal estudo e realizamos o Programa de Prevenção de Perda Auditiva (PPPA) para músicos e verificamos sua efetividade, pois tem por objetivo modificar o comportamento dos músicos em relação a sua audição, uma vez que, constantemente, estão expostos a sons elevados. Assim, é muito comum o surgimento de lesões irreversíveis para a audição.

Este capítulo apresenta as discussões referente à proposta de PPPA para músicos que foi desenvolvido, sendo assim para fins didáticos, esse capítulo foi dividido em duas partes:

6.1. Submeter os músicos, componentes das bandas, ao Programa de Prevenção de Perdas Auditivas (PPPA) que contemplam quatro etapas: medição do Nível de Pressão Sonora (NPS) nos ensaios e shows, avaliação audiológica (inspeção do Meato Acústico Externo (MAE), exames audiológicos e entrevista específica), seleção do Equipamento de Proteção Individual (EPI) e realização do workshop.

6.2. Verificar a eficácia do PPPA/workshop por meio de aplicação de questionários antes e depois da sua realização.

\subsubsection{Submeter os músicos, componentes das bandas, ao programa de prevenção de perdas auditivas (PPPA)}




\subsubsection{Medição do Nível de Pressão Sonora (NPS) nos ensaios e shows}

O ruído é um dos mais significantes agentes nocivos à saúde, principalmente à audição, e está presente não só em ambientes de trabalho como também de lazer. Nas doenças adquiridas no ambiente de trabalho, a Perda Auditiva Induzida por Ruído (PAIR), ou Perda Auditiva Induzida por Níveis de Pressão Sonora Elevada (PAINPSE) é uma das mais comuns (LOPES, 2012).

Os dados obtidos neste estudo - mostram que o NPS está muito acima do permitido por lei para manterem-se expostos a eles sem a utilização do EPI.

As medições realizadas com um medidor do nível de pressão sonora tanto durante o ensaio como durante o show foram de 102.3dBNPS a 109.2dBNPS e 106.2 a 106.3dBNPS, respectivamente, o que corrobora com estudos realizados por Fernandes et al. (1996) onde verificaram a intensidade do ruído presente em casas noturnas, utilizando um medidor do nível de pressão sonora ETB-142-A.

Fernandes et al. (1996), concluíram que há possibilidade de desenvolver perda auditiva, visto que a intensidade do ruído presente variou entre $78 \mathrm{~dB}$ a 111 $\mathrm{dB}$ e as medições no interior de três estabelecimentos noturnos com música amplificada realizadas por Regazzi (1996) em que o nível de ruído médio verificado foi considerado prejudicial, variando de $96 \mathrm{~dB}$ a $103 \mathrm{~dB}$.

Se compararmos o tempo de exposição a que o trabalhador pode ficar exposto ao NPS sem o uso de EPI (a partir de $85 \mathrm{~dB}(\mathrm{~A})$, é necessário o uso de EPI) e o NPS coletado tanto durante o ensaio, como as apresentações da banda, os mesmos poderiam trabalhar (tocar) por volta de $25 \mathrm{~min}$ apenas sem o uso de proteção.

Tal resultado indica que estes profissionais necessitam fazer uso do EPI para trabalharem sem prejudicar sua saúde auditiva e assim manter a qualidade de seu trabalho.

Mendes e Morata, (2007) verificaram os níveis de pressão sonora de diversos grupos musicais como orquestras sinfônicas e grupos carnavalescos. Considerando todos os estudos referenciados por eles, os resultados mostraram que o nível mínimo encontrado foi de $79 \mathrm{~dB}(\mathrm{~A})$ e o máximo de $117 \mathrm{~dB}(\mathrm{~A})$. Porém, o menor nível máximo encontrado foi de $94,7 \mathrm{~dB}(A)$, sendo que a intensidade de $100 \mathrm{~dB}(A)$ foi 
ultrapassada na maioria dos estudos, o que coloca o músico em situação de risco para a audição.

No Brasil, estudos sobre incômodo na população não são comuns e, quando ocorrem, frequentemente são executados por engenheiros que focam a atenção na avaliação quantitativa da poluição sonora (FIORINI, 2015).

$\mathrm{Na}$ fonoaudiologia, os estudos sobre ruído e seus efeitos na saúde são realizados em populações de trabalhadores de indústrias, partindo das exposições ocupacionais. Porém o ruído é um problema de saúde pública extensivo a toda a população e, dessa forma, os estudos sobre incômodo e outros efeitos deletérios à saúde são importantes não somente para a avaliação qualitativa dos índices de poluição, mas, principalmente, na geração de subsídios para as ações de educação em saúde (FIORINI, 2015).

Segundo estudos realizados por Verbeek et al. (2015), foram encontradas evidências de que a legislação pode induzir melhoras técnicas no ambiente de trabalho que levam a uma redução mensurável nos níveis de exposição ao ruído.

\subsubsection{Entrevista específica}

Dos entrevistados, $75 \%$ dos baixistas (baixo) relataram apresentar dificuldades em entender a fala no ruído. Durante avaliação audiológica nos 100\% dos músicos que tocam baixo, notou-se a presença de entalhe em $75 \%$ deles na frequência de $6 \mathrm{KHz}$, o que corrobora com os estudos de Carmo (1999). Para esse autor, a alta intensidade utilizada com frequência pode levar a uma lesão irreversível, e que a perda auditiva em $6.000 \mathrm{~Hz}$ leva a uma maior dificuldade em discriminar o som, entender a fala em ambientes ruidosos.

A presença de zumbido bilateral do tipo apito fora encontrada em $81,75 \%$ da população total estudada, assim como a presença de zumbido bilateral do tipo apito em todos os músicos participantes (100\%) após o show. Tais resultados corroboram com Einhorn (2009) que afirma que inúmeros músicos de rock têm admitido que sofrem de zumbido e relataram ter seus desempenhos musicais limitados ou mesmo terem se aposentado da profissão de músico por causa desse problema. Os músicos que mais apresentaram queixas de zumbido após a exposição a níveis de pressão sonora elevados são os violinistas e os bateristas, em função da 
proximidade do instrumento a uma única orelha e da posição dos pratos na altura de ambas as orelhas (FREIRE,2014).

\subsubsection{Avaliação audiológica}

\subsubsection{Inspeção do Meato Acústico Externo (MAE)}

A onda sonora é captada e amplificada pelo pavilhão auricular, passa então pelo meato acústico externo fazendo com que a membrana timpânica vibre. $O$ martelo, que se integra à membrana timpânica, é deslocado e, por ser articulado à bigorna e ao estribo, move os ossículos (GINSBERG; WHITE, 1989), iniciando o processo da audição. Vê-se que a integridade e a ausência de impedimento do MAE são essenciais para que não se constate um déficit auditivo. Sendo assim, houve a necessidade da retirada do corpo obstrutor (rolha de cera) que impedia a realização dos exames audiológicos naqueles participantes que apresentam tal característica, para que, só após a passagem do som estar sem obstrução, possam ser realizados os exames (LOPES; MUNHOZ; BOZZA, 2015).

5.1.2.2 Audiometria Tonal Liminar Convencional (AT- AC) e Audiometria Tonal de Alta Frequência (AT- AF)

A audiometria tonal limiar convencional é considerada a base da avaliação audiológica, sendo o primeiro teste que a compõe. Tem como objetivo determinar os limiares mínimos de audibilidade de um indivíduo para as frequências de $250 \mathrm{~Hz}$ a $8.000 \mathrm{~Hz}$. Essa técnica de avaliação é a mais utilizada para a detecção de perdas auditivas em indivíduos expostos a níveis elevados de pressão sonora, sejam esses níveis de ruído ou de música, principalmente com intensidades acima de $85 \mathrm{~dB}(\mathrm{~A})$, (BRASIL, 1998; SANTOS, 2007).

Em relação às perdas auditivas neurossensoriais, a audiometria tonal de altas frequências vem sendo utilizada como uma forma de detectar precocemente tais alterações, para que a prevenção seja realizada antes que lesões mais significativas se instalem, efetivando o conceito de Promoção da Saúde (OTUBO, 2013).

A perda auditiva induzida por níveis de pressão sonora elevados ocorre pela exposição sistêmica e prolongada ao som intenso (> 85 dB (A)/ 8 horas/dia). De início insidioso, suas características principais são a cronicidade e a irreversibilidade, 
uma vez que acomete as células ciliadas do órgão de Corti (HENDERSON 1995; FERREIRA, 1998). Além disso, segundo o Comitê Nacional de Ruído e Conservação Auditiva (1999), não somente o tempo de exposição e a intensidade sonora, mas também a suscetibilidade individual, é considerada como um fator para o aparecimento da perda auditiva.

Segundo a NR7, Anexo I (1998), será considerada perda auditiva induzida por níveis de pressão sonora elevada as alterações dos limiares auditivos decorrentes da exposição ocupacional sistemática ao som intenso. Tendo como características principais a irreversibilidade e a progressão gradual com o tempo de exposição ao risco, inicialmente acomete as frequências de $3000 \mathrm{~Hz}, 4000 \mathrm{~Hz}$ ou $6000 \mathrm{~Hz}$, seguindo-se das frequências de $8000 \mathrm{~Hz}, 500 \mathrm{~Hz}$ e por último $250 \mathrm{~Hz}$.

Neste estudo, encontramos maiores médias dos limiares audiológicos por frequência das bandas estudadas em $500 \mathrm{~Hz}$ e $3 \mathrm{KHz}$ (B1), $3 \mathrm{KHz}$ e $4 \mathrm{KHz}$ (B2), $3 \mathrm{KHz}$, $4 \mathrm{KHz}$ e $6 \mathrm{KHz}$ (B3) e em $3 \mathrm{KHz}$ (B4) e por frequência dos instrumentos estudados foram em $3 \mathrm{KHz}, 4 \mathrm{KHz}$ e $6 \mathrm{KHz}$ (voz), $3 \mathrm{KHz}$ e $4 \mathrm{KHz}$ (guitarra), $3 \mathrm{KHz}, 4 \mathrm{KHz}$ e $6 \mathrm{KHz}$ (baixo) e $3 \mathrm{KHz}, 4 \mathrm{KHz}$ (bateria), havendo presença de entalhe nas frequências de $2 \mathrm{KHz}, 4 \mathrm{KHz}, 6 \mathrm{KHz}$ e $8 \mathrm{KHz}$ na audiometria tonal liminar, tais resultados vêm a somar com o trabalho realizado por Fiorini (1994), que constatou que às frequências de 3000,4000 e $6000 \mathrm{~Hz}$, quando rebaixadas podem revelar perda auditiva por exposição a níveis de pressão sonora elevada.

A presença do entalhe audiométrico, mesmo que em apenas uma frequência deveria ser encarada como um sinal de alerta, pois poderia sugerir uma tendência ao desencadeamento da perda auditiva pela exposição à níveis de pressão sonora elevados conforme o decorrer do tempo (FIORINI, 1994).

Já na audiometria de altas frequências, em todas as frequências apareceu ao menos um caso presença de entalhe.

Lüders et al. (2013) encontraram a presença de entalhe nas frequências de $12.500 \mathrm{~Hz}$ bilateralmente e na frequência de $14.000 \mathrm{~Hz}$ na orelha direita.

Otubo (2013) observou, em seus estudos, a presença de entalhe nas frequências de $11.200 \mathrm{~Hz}$, na orelha esquerda, $12.500 \mathrm{~Hz}$, na orelha direita, e $16.000 \mathrm{~Hz}$ em ambas as orelhas.

Nas altas frequências, foram observadas diferenças na orelha direita em 9.000 Hz e bilateralmente em 14.000 Hz e 16.000 Hz (GONÇALVES et al., 2013). 
Lüders et al. (2013) revelaram em seus estudos a piora dos limiares auditivos em estudantes de graduação de música, embora ainda dentro dos padrões de normalidade, mesmo que considerando que a auditiva induzida pela música ou pelo ruído ocorre após anos de exposição e progride lentamente conforme o passar do tempo.

A avaliação dos limiares de altas frequências de forma periódica pode ser útil na detecção precoce da deficiência auditiva em músicos (LÜDERS et al., 2013).

\subsubsection{Logoaudiometria}

Os resultados obtidos para o Limiar de Reconhecimento de Fala (LRF) mostram-se compatíveis dentro dos valores de normalidade, sendo iguais ou até 10 dB acima da média tritonal (500, 1000 e 200 Hz) na AT-AC (SANTOS; RUSSO, 1991). Os encontrados para o Índice Percentual de Reconhecimento de Fala (IPRF) dos participantes, também estiveram dentro dos valores de normalidade entre $88 \%$ e 100\% (GATES; CHAKERES, 1988).

De acordo com Menegotto e Costa (2015), apesar de sua variabilidade, especialmente no caso do IPRF, esses testes trazem informações preciosas sobre a condição auditiva de determinado paciente e apresentam uma excelente oportunidade para os profissionais compreenderem melhor as dificuldades auditivas dos indivíduos.

\subsubsection{Imitanciometria}

Foi encontrada a curva tipo A em quase $100 \%$ da população total estudada. Carvallo (2011) descreve como sendo curva do tipo A - curva normal caracterizada por um pico de máxima admitância à baixa pressão no MAE $(-100 \mathrm{a}+50$ decapascals daPa), ou seja, estavam dentro do padrão de normalidade.

Obtivemos reflexos presentes entre 95 e 105dB quando foram captadas respostas e reflexos ausentes em $4 \mathrm{KHz}$ (Ipsi e contralateral).

Pode-se concluir que músicos expostos a níveis de pressão sonora intensos apresentaram alteração temporária do limiar e alteração do reflexo acústico e, por esta razão, são profissionais de risco para perda auditiva ocupacional (PFEIFFER et al., 2007).

As medidas timpanométricas podem trazer maior contribuição ao diagnóstico de alterações de orelha media (PEREIRA; ANASTASIO, 2015). 


\subsubsection{Emissões Otoacústicas Evocadas (EOE)}

$\mathrm{Na}$ população adulta, as EOE são frequentemente utilizadas para realizar o diagnóstico diferencial entre perdas auditivas cocleares e retro- cocleares, além do monitoramento auditivo de indivíduos expostos a drogas ototóxicas, ao ruído ocupacional e à música (LEWIS, 2004). Diversos autores recomendaram o uso das EOE para avaliar e acompanhar a audição de músicos, por ser um instrumento mais sensível que a audiometria para detectar as alterações iniciais geradas pela exposição à música amplificada (KÄHÄRI et al.,2001; KÄHÄRI et al.,2003). As células ciliadas externas são as primeiras estruturas da orelha interna a serem lesadas por agentes externos, como no caso de níveis de pressão sonora elevados. Portanto, as EOE podem detectar sinais de danos cocleares iniciais, servindo como ferramenta de detecção precoce e monitoramento das alterações causadas por esses agentes, mesmo antes de ocorrer alterações nos limiares audiométricos na audiometria. Dessa forma, é possível determinar a localização da lesão e controlar a efetividade do uso de protetores auditivos (KIMBERLEY, 1999; LONSBURRYMARTIN, 2001; LOPES, 2002).

Obtivemos como resultados nas EOE por estímulo transiente ausência de resposta em $4 \mathrm{KHz}$ para todos os baixistas bilateralmente, EOE por produto de distorção: ausência de respostas em $6 \mathrm{KHz}$.

Clinicamente, o zumbido pode aparecer antes da perda auditiva e que as emissões otoacústicas evocadas são capazes de detectar alterações cocleares mínimas em indivíduos com audiometria normal (FREIRE, 2014).

\subsubsection{Workshop}

Os resultados deste estudo demonstraram a necessidade de atuação para a promoção da saúde por meio dos Programas de Preservação Auditiva, envolvendo medidas de controle do som intenso (coletiva e individualmente), além de ações educativas para músicos profissionais (GONÇALVES et al., 2013).

O II Congresso Internacional de Medicina para Músicos, ocorrido em setembro de 2005 na Espanha preocupou-se em afirmar que os músicos são profissionais com grande risco de adoecimento ocupacional, enfatizando ainda, que há uma falta de conscientização da classe sobre este risco, além de pouca procura 
por informações que possam preservar e gerenciar as condições de trabalho da classe (LÜDERS; GONÇALVES, 2013).

Além disso, alertam Frank e Mühlen (2007)que, geralmente, os músicos não procuram auxílio médico ao surgirem sinais de alerta, com receio de perda de espaço profissional e diminuição de ganho financeiro, o que é corroborado por Raymond, Romeo e Kumk (2012), que alertam para o fato de que, dada a natureza competitiva do trabalho, os músicos podem não buscar profissionais especializados por medo de que as demandas de tratamento ou de conhecimento público de uma lesão possam custar-Ihes suas posições. A natureza competitiva do ambiente de trabalho e pressões pela alta performance também podem estar relacionadas com as taxas elevadas de estresse e sintomas de depressão.

\subsubsection{Verificar a eficácia do PPPA/workshop}

Após o workshop, os músicos foram orientados a entrarem na página do website e, após a navegação, enviarem os questionários on line ${ }^{5}$ (Figura 17) com suas respostas e se o website havia ou não sido efetivo para os seguintes aspectos: linguagem, forma, cores, fonte e conteúdo. Contudo apenas um integrante de cada banda, iria responder e enviar o questionário para a pesquisadora, após entrarem em acordo.

\footnotetext{
${ }^{5}$ Disponível em:<

https://docs.google.com/forms/d/1Nhbu4I7I2EN02NsLolljw6BBQCI6I24pSEql1ouZHU/viewform>.
} 
Figura 17 - Questionário on line, referente a avaliação da efetividade do web site

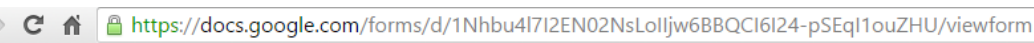

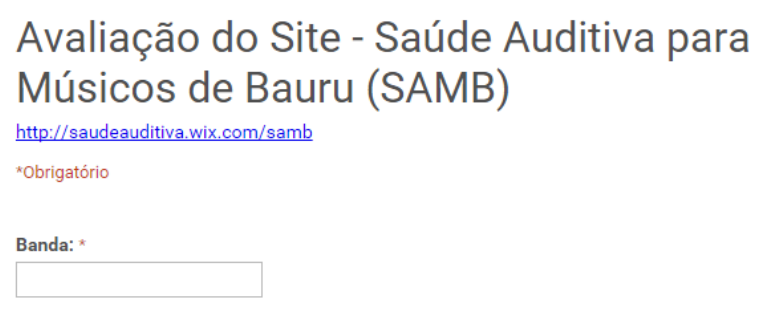

0 site foi efetivo para você quanto ao conteúdo, linguagem e forma de apresentação? * Conteúdo (assuntos abordados), linguagem (se a mesma foi de fácil compreensão ou não) e forma de Sim

Não

Se a resposta anterior foi "NÃO", qual aspecto poderia ser melhorado?

Conteúdo

Linguagem

Forma de apresentação

Deixe suas críticas e sugestões para o aperfeiçoamento do site:

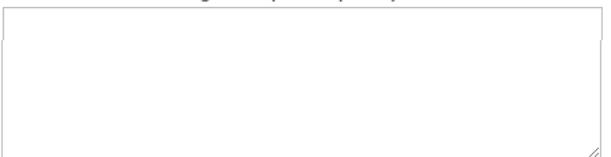

Enviar

Nunca envie senhas pelo Formulários Google.

Os resultados obtidos no período pré-oficina mostraram que grande parte dos participantes tinha apenas conhecimento dos aspectos isolados da profissão e não compreendia o trabalho do fonoaudiólogo no mundo da música, entendendo que este profissional trabalhe nesse meio somente se já houvesse uma perda auditiva. Quanto aos protetores, sabiam poucas informações a respeito; assim, pôde-se observar que nenhum dos participantes faz ou fez uso do equipamento com assiduidade.

Os músicos passaram a apresentar mudança de comportamento a partir do momento das devolutivas da avaliação audiológica, mostrando-se mais conscientes quanto ao risco de perda, higiene da orelha e uso de protetores auditivos, além de que a todo o momento faziam questionamentos referente ao assunto.

Após a oficina, os resultados foram positivos, já que passaram a compreender melhor a complexidade da profissão e visualizar que o fonoaudiólogo pode estar 
presente no âmbito musical desde a prevenção de perda auditiva até o momento de sua reabilitação. Entenderam a importância dos protetores auditivos e os prejuízos que as exposições a níveis elevados de pressão sonora podem causar à audição. $O$ Programa de Prevenção de Perdas Auditivas, ou Programa de Conservação Auditiva preconiza, que os aspectos educativos devem levar ao trabalhador, para seu próprio benefício, o quanto e de que maneira o ruído está afetando a sua audição (CÉZAR, 2012). Assim, tornaram-se mais conscientes dos hábitos nocivos que praticam não só para audição, mas também para a sua saúde em geral, incluindo-se a voz.

Dessa forma, os resultados da oficina mostraram-se satisfatórios, uma vez que o website foi utilizado como a ferramenta portadora das informações, considerando que pode ser acessada a qualquer momento em qualquer lugar, ou seja, as informações obtidas por meio da oficina estão disponíveis para os participantes acessarem a qualquer momento, assim como a disseminação dessas informações para outros profissionais da música não participantes do estudo. 
Conclusões 


\section{CONCLUSÕES}

Conclui-se a partir dos dados analisados que sejam tomadas medidas preventivas e a inserção dos músicos em um Programa de Preservação de Perdas Auditivas (PPPA) para esta população afim de proporcioná-los maiores condições de qualidade de vida e em seu trabalho, já que necessitam da sua audição para desempenhar com eficácia suas atividades e se manter no mercado de trabalho atuando como músico. 


\section{$\underline{\text { Referências }}$}


ALMEIDA, M. C. P. et al. Ocorrência de perda auditiva entre músicos. Resumo do Trabalho de conclusão do curso de Fonoaudiologia apresentado à UNESA/2008. Disponível <http://www.espacofono.com.br/artigos/ocorrenciadeperdaauditivaentremusicos>. Acesso em: 23 jan. 2015.

AMORIM, R.B.et al. Alterações auditivas da exposição ocupacional em músicos. Arq. Int. Otorrinolaringol./Intl. Arch. Otorhinolaryngol. São Paulo, v.12, n.3, p. 377-383, 2008.

ANDRADE A. I. A. et al. Avaliação auditiva em músicos de frevo e maracatu.RevistaBrasileira de Otorrinolaringologia, v. 68, n. 5, p.714-720, 2002.

ANDRADE, A. I. A. et al. Avaliação auditiva em músicos de frevo e maracatu. RevistaBrasileira de Otorrinolaringologia. v.5, p.714-720, São Paulo. Out. 2002.

ALCARÁS, P.A de Souza et al. Emissões otoacústicas evocadas em trabalhadores expostos a ruído: uma evisão. Int. Arch. Otorhinolaryngol. São Paulo - Brasil, v.16, n.4, p. 515-522, Oct/Nov/Dec. 2012.

ARAÚJO, R.; FEDICZKO, I. Impactos do $\mathrm{mp3}$ na música: reprodutibilidade, compartilhamento e regressão.Aurora, 12: 2011. Disponível em: <www.pucsp.br/revistaaurora $>$. Acesso em jun. 2015

ARDIC, F.N. et al.Higth-frequencyhearingandreflexlatency in patientswithpigmentdisord. American Journal of Otolaryngology. v.19, n.6, p. 365369, 1998.

AZEVEDO, L. L. Estudos dos limiares de audibilidade nas altas frequências em indivíduos de 12 a 15 anos com audição normal. 1997. Monografia (Especialização em Distúrbios da Comunicação Humana). São Paulo, Universidade Federal de São Paulo/ Escola Paulista de Medicina

BARRENAS, M.L. Haircelllossformacoustic trauma in chloroquine- treatedred, blackand albino guineapigs. Audiology, 36 (4), p. 187- 201, 1997.

BELTRAMI, C.H.B. Perda Auditiva Induzida pelo Ruído.Monografia (Especialização em Fonoaudiologia) -Escola Paulista de Medicina, Universidade Federal de São Paulo, São Paulo, 1992.

BERBEL, N. A. N. A metodologia da problematização e os ensinamentos de Paulo Freire: uma relação mais que perfeita.In: ___. (Org.). Metodologia da Problematização: fundamentos e aplicações. Londrina: Editora UEL, 1999.

A problematização e a aprendizagem baseada em problemas.Interface Comum. Saúde Educ. n. 2, p. 139-154, 1998.

BISTAFA, S. R. B. Acústica Aplicada ao Controle do Ruído. São Paulo: Edgard Blücher, 2006.

BRASIL. Academia Brasileira de Audiologia - ABA. Ruído é a terceira maior causa de poluição no planeta. Artigo publicado em 27/04/2010. Disponível em: <http://www.acital.com.br/noticias/ruido-e-a-terceira-maior-causa-de-poluicao-noplaneta>. Acesso em: 04 de fev. 2015. 
BRASIL. Ministério da Saúde.Saúde do Trabalhador Protocolos de Complexidade Diferenciada, Ministério da Saúde, 2006,p.1-40.

BRASIL. Ministério do Trabalho e Emprego. Portaria n. 19, de 9 de abril de 1998 da Secretaria de Segurança e Saúde do Trabalho. Disponível em: <http://portal.mte.gov.br/data/files/FF8080812BE914E6012BEEB7F30751E6/p_1998 0409_19.pdf>.

BRASIL. Ministério da Saúde. Ministério da Educação. Programa Nacional de Reorientação da Formação Profissional em Saúde - Pró- -Saúde: objetivos, implementação e desenvolvimento potencial / Ministério da Saúde, Ministério da Educação. Brasília: Ministério da Saúde, 2007. p. 86 (Série C. Projetos, Programas e Relatórios).

BRASIL. INSTITUTO BRASILEIRO DE GEOGRÁFIA E ESTATÍSTICA - IBGE (2010). Deficiência auditiva atinge 9,7 milhões de brasileiros. Março de 2012. Disponível em: <http://www.winaudio.com.br/produtos-e-servicos/noticias-emaudiologia/3704-deficiencia-auditiva-atinge-98-milhoes-de-brasileiros.html>. Acesso em: 10 Fev. 2014.

BORDENAVE, J.; PEREIRA, A. A estratégia de ensino aprendizagem. 26. ed. Petrópolis: Vozes; 2005.

BORDENAVE, J. E. D. Alguns fatores pedagógicos. In: SANTANA, J. P.;CASTRO, J. L. (Org.)Capacitaçãoem Desenvolvimento de Recursos Humanos - CADRHU. Natal: Ministério da Saúde/Organização Pan-Americana da Saúde/Editora da UFRN; 1999. p. 261-268.

CARVALHO, F. R. Perda Auditiva Induzida por Ruído. Disponível em: <http://www.portalocupacional.com.br/icontrole/images/arquivos/3feebd97c2.pdf>.

Acesso em: 27 jan. 2015.

CARVALHO, et al. Influência dos padrões timpanométricos na captação de emissões otoacústicas. Acta Awho, 19: 18-25, 2000.

PINTO-PORTO, C. A. B. et al. Metodologias Ativas de Ensino-Aprendizagem na formação do profissional de saúde: debates atuais. Ciência e Saúde Coletiva, 13(2): p. 2133-2144, 2008.

CÉZAR, M.R.V. Atuação do Fonoaudiólogo na Prevenção de Perda Auditiva Induzida por Ruído.2012. p. 32.Monografia (Especialização em Fonoaudiologia) Centro de Especialização em Fonoaudiologia Clínica. Recife/ PE. 2012.

CHASIN, M. Musiciansandtheprevention of hearingloss. San Diego: Singular PublishingGroup, 1996.

CHASIN, M.; BEHAR A. Hearingprotetion. SeminHear,24: p. 345- 54, 2003. $\begin{array}{lc}\text { CHESKY, } & \text { K. } \\ \text { musicandconservatoriesandhearinglossprevention.InternationalJournal }\end{array}$

of

of

Audiology. England, v. 50: p.S32-S37, 2011.

COELHO, C.C.B. SANCHEZ, T.G.; BENTO, R.F. Características do zumbido em pacientes atendidos em serviço de referência. Arq Otorrinolaringol, v.8, n.3, jul/set., 2004. 
COELHO, M. de Souza. B. et al. As emissões otoacústicas no diagnóstico diferencial das perdas auditivas induzidas por ruído, Revista CEFAC. nov./dez, v. 12, n. 6, p. 1050-1058, 2010.

CONLEE, J.W.; ABDUL-BAGI, K.J.; McCANDLESS, G.A. Differential susceptibity to noise-induced permanente threshold shift between albino andpigmentedguineapigs. Hear Res.n. 23, 1986, p.81- 91.

COMITÉ NACIONAL DE RUÍDO E CONSERVAÇÃO AUDIOLÓGICA. Perda auditiva induzida pelo ruído relacionado ao trabalho. AcustVibr. n. 13, p. 123-125., 1994

CRUZ, O. L. M. Os Danos da Poluição Sonora para o Corpo.Jornal da Cidade: caderno de saúde, 24 de fevereiro de 2008, p. 2, 24.

CURRIE, Q.; KENNEDY, J. Musicians and the risk of noise induced hearingloss. The measure online. Celebrating $C B C$ issue. Music industry association of Newfoundland \& Labrador, ago., 2002.

CYRINO, E.G; TORALLES-PEREIRA, M. L. Trabalhando com estratégias de ensinoaprendizado por descoberta na área da saúde: a problematização e a aprendizagem baseada em problemas. Caderno de Saúde Pública, Rio de Janeiro, v. 20, 3, p.780-788, 2004.

DIAS, A. et al. Associação entre perda auditiva induzida pelo ruído e zumbidos. Caderno de Saúde Pública.Rio de Janeiro, v.22, n.1, p.63-68, 2006.

EINHORN, K. The medical aspects of otologicdamagefromnoise in musicians. Chasin M. Hearingloss in musicians.San Dieg: Plural Publishing, 2009, p.31-40.

EL DIB et al.Prevalence of high frequencyhearingloss consistente withnoiseexposureamongpeopleworkingwithsound systems and general population in Brazil: a cross- sectionalstudy. BMC Public Health, v. 8, p. 151, may,2008.

FERRAZ, N.M. Ruído e saúde.Mundo Saúde. v. 20, n. 3. p.103-5,1996.

FELDMAN, S.; GRIMES, C.T. Hearingconservation in industry. Baltimore, 1985.

FERNANDES, J.C. et al. Avaliação do Risco de Perda Auditiva em Músicos. XI SIMPEP, 11, 2004, Bauru-SP. Anais.... USP: Bauru- SP, Brasil, 2004.

FERNANDES, J. C. et al. Medição do Nível de Ruído das Casas Noturnas de Bauru, XI Encontro Internacional de Audiologia,11, 1996, Bauru-SP.Anais...,Bauru-SP, Brasil: USP, p. 136, 1996.

FERREIRA, J. M. Perda auditiva induzida por ruído. Bom Senso e Consenso. São Paulo: Ed. VK,1998.

FIORINI, A.C. Efeitos não auditivos do ruído.In: BOECHAT, E. M., et al. (Org.). Tratado de audiologia. 2. ed. Santos-SP: Editora Gen, 2015, p. 201-204.

FIORINI, A. C.Conservação auditiva: estudo sobre o monitoramento audiométrico em trabalhadores de uma indústria metalúrgica. Dissertação (Mestrado em ). Pontifícia Universidade Católica, São Paulo, 1994.

FIORINI, A. C. Ruído: um problema de saúde pública. Jornal Quebrando o Silêncio, São Paulo. p 3-4. 1997. 
FRANK, A.; MÜHLEN, C. A. V. Queixas musculoesqueléticas em músicos: prevalência e fatores de risco. Revista Brasileira de Reumatologia. São Paulo. v. 47, n. 3, p. 188-90, 2007.

FRIZZO, A. C. M.;SCHARLAH, R. C., ANASTASIO, A. R. T. (Org.). Tratado de audiologia. 2. ed. São Paulo: Santos; 2015, p. 89- 94.

FREIRE, K. M. Saúde auditiva em músicos. Tratado das Especialidades em Fonoaudiologia. 2.ed.São Paulo:Editora GEN, 2014. p. 994-1004.

FUNDACENTRO. Norma de higiene ocupacional. Procedimento técnico: avaliação da exposição ocupacional ao ruído. NHO01. 2001.

GATTAZ, G; WAZEN, S.R.G. O Registro das Emissões acústicas Evocadas Produto de Distorção em Pacientes com Perda Auditivia Induzida pelo Ruído. Revista Brasileira de Otorrinolaringologia,v. 67, n. 2, p.213-218, 2001.

GATES, G.A; CHAKERES, D.W. Interpretation of diagnostic tests for acoustic neuroma. Otolaryngol Head Neck Surg. Rochester, 1988.

GERGES, S.N.Y. Ruído: fundamentos e controle. $2^{\mathrm{a}}$ Edição atualizada e ampliada, Florianópolis. NR Editora, 2000.

GERHARD, K.J; HEPLER, Junior EL. Acoustic-reflex activity and behavioral thresholds following exposure to noise. J Acoust Soc Am. 1983; 74(1):109-14.

GINSBERG, IA \& WHITE, TP. Considerações otológicas em audiologia. In: KATZ, J eds. Tratado de audiologia clínica. 3 ed. Editora Manole, 1989. p.14-38.

GLENVIEW, I.; M.D. DAWSON, W.J. Perda auditiva pela música - Causas, tratamento e prevenção. Trad. de Alexandre Nascimento. Artigo publicado em "thedoublereed", v. 30, n. 2, 2007 (reproduzido com licença de IDRS).

GOVERNO DO BRASIL. Ministério do Trabalho. Secretária de Segurança do Trabalho. D.O.U 06/07/1978. Portaria № 3214 de 08/06/1978.

GONÇALVES, C.G.de Oliveira et al. Limiares auditivos em músicos militares: convencionais e altas frequências. Revista CoDAS. v. 25, n. 2, p.181-187, 2013.

GONÇALVES, C. G. O. et al.Percepção e o impacto da música na audição de integrantes de banda militar.Revista da Sociedade Brasileira de Fonoaudiologia.São Paulo, v. 14, n. 4, p. 515-20, 2009.

GONÇALVES, C. G. O. et al.Limiares auditivos em músicos militares: convencionais e altas frequências.Revista CoDAS. São Paulo, v. 25, n. 2, p. 181-7, 2013.

GONÇALVES, C.G. Saúde do trabalhador: da estruturação à avaliação de programas de preservação auditiva.São Paulo: Roca, 2009.

GONÇALVES, C. G. O. Implantação de um programa de preservação auditiva em metalúrgica: descrição de uma estratégia. Distúrbios de Comunicação. 1999;16(1):43-51.

GRACIOLLI, L.S. Análise quali-quantitativa do uso de protetores auditivos especiais em músicos [tese]. Porto Alegre: Universidade Federal de Santa Maria; 2006. 
GREGO, M. Perigos nos Decibéis.Info Online, 12 de dezembro de 2006. Disponível em: <http://info.abril.com.br/aberto/infonews/122006/12122006-14.shl>. Acesso em: 27Jan.2007.

GUIDA, H. L. Efeitos psicossociais da perda auditiva induzida pelo ruído em exfuncionários da indústria.Acta ORL., v. 25, n. 1, p. 78-83, 2007.

HARGER, M. R. H. C.; BARBOSA-BRANCO, A. Efeitos auditivos decorrentes da exposição ocupacional ao ruído em trabalhadores de marmoraria no Distrito Federal. Associação Médica Brasileira. São Paulo, v.50, n.4, p.396-399, 2004.

HAUSLER, R. The effects of acousticoverstimulation.Umsch, v. 61. N. 1, p. 2129, 2004.

HENDERSON, D., HAMERNIK, R. P. Biologic bases of noise-inducedhearingloss. Occup Med.v. 10, p. 513-34,1995.

HUMES, L. E.Noise-inducedhearingloss as influencedbyotheragentsandby some physicalcharacteristics of the individual.Journal of theAcousticalSociety of America. v. 76, n.5, p. 1318-1323, 1984.

ISLEB, M. H. M. et al.A perda auditiva induzida pela música (PAIM) e a busca da promoção da saúde auditiva.In: MORATA, T. C.; ZUCKI, F. Saúde Auditiva avaliação de riscos e prevenção. São Paulo: Plexus Editora, 2010. p. 37-60.

JERGER, J.; MAUDIN, L. Studies in impedance audiometry; normal and sensorioneural ears. Arch Octolaryngol. 96:513-23, 1972.

KÄHÄRI, K.R; ZACHAU, G; EKLÖF, M; SANDDSJO, L.; MÜLLER, C. Assessment of hearingandhearingdisorders in rock/ jazz musicians. Int $\mathrm{J}$ Audiol2003;42:27988.

KÄHÄRI, K.R.; AXELSSON, A.; HELLSTROM, P.A.; ZACHAU, G.Hearingassessment of classicalorchestralmusicians.ScandAudiol. 2001;30(1):13-23.

KAHARIT, et al. Assessment of hearing and hearing disorders in rock/jazz musicians. Int J Audiol. 2003;42(5):279-88.

KAZKAYASI, M.; YETISER, S.; OZCELIK, S. Effect of Musical Training on Musical PerceptionandHearingSensitivity: Conventionaland HighFrequencyAudiometricComparison.J Otolaryngol. 2006, 35(5):343-8

KIMBERLEY, B. Applications of distortion- prduct emissions to na otological practice. Laryngoscope 1999; 109(12): 1908- 18.

KEPPLER, $\mathrm{H}$. et al. Short- term auditory effects of listening to na MP3 player. Arch Otolaryngol. Head Neck Surg, v. 136, n. 6, p. 538-548, June 2010.

KWITK A; FERREIRA P.G; FRANÇA M.T; ZANZINI C; STEGGIORIN S. Perdas auditivas ocupacionais: análise de variáveis e diagnóstico.RevBrasMedOtorrinolaringol. 1996; 3(3):151-64.

LACERDA, A. B. M. de; MOROTA, T. C.; FIORINI, A. C. Caracterização dos Níveis de Pressão Sonora em Academias de Ginástica e Queixas Apresentadas por Seus Professores. São Paulo, 2001. Disponível em <http://www.scielo.br/scielo.php?script=sci_arttext\&pid=S0034992001000500009\&ln $\mathrm{g}=\mathrm{pt \& nrm}=\mathrm{isso}>$. Acesso em: 20Fev.2006. 
LACERDA, A.B.M. de; et al. Hábitos auditivos e comportamento de adolescentes diante das atividades de lazer ruidosas. Rev. CEFAC. Mar-Abr, v.13, n.2, p.322329, 2011.

LOMSBURRY-MATIN, B.L; MARTIN, G.K. Otoacoustic emissions. Otolaryngology e Head and Neck Surgeru 2003; 11 (5): 361-6.

LOPES FILHO, O.; CARLOS, R.; REDONDO, M.C. Produto de Distorção das Emissões Otoacústicas. Revista Brasileira de Otorrinolaringologia, 61 (6): p. 485 494, 1995.

LOPES, A. GENOVESE, V.J. Doenças profissionais. São Paulo: Pancast. 1991.

LOPES, A. C.; GODOY, J. B. Considerações metodológicas para a investigação dos limiares de frequências ultra-altas em indivíduos expostos ao ruído ocupacional.Salusvita, v. 25, p. 149-160, 2006.

Lopes, A.C et al.Condições de saúde auditiva no trabalho: investigação dos efeitos auditivos em trabalhadores expostos ao ruído ocupacional. Arq int otorrinolaringol. 2009;13(1):49-54.

LOPES, A.C. Audiometria Tonal Liminar. Tratado de Audiologia, 2012. Cap.5. Pag.63-80.

LOPES, A.C; MUNHOZ, G.S; BOZZA, A. Audiometria tonal liminar e de Altas Frequências. In: Boéchat EM, Menezes. PD, Couto. CM, Frizzo. ACM, Scharlah. RC, Anastasio. ART,organizadores. Tratado de audiologia. $2^{\underline{a}}$ ed. São Paulo: Santos; 2015, p. 57-67.

LÜDERS, D.; GONÇALVES, C.G.DE OL.Trabalho e saúde na profissão de músico: reflexões sobre um artista trabalhador. Tuiuti: Ciência e Cultura, n. 47, p. 123-137, Curitiba, 2013.

LÜDERS D et al. Music students: conventionalhearingthresholdsandat high frequencies.BrazilianJournal of OTORHINOLARYNGOLOGY. 2013.

LÜDERS $D$ et al.Music students: conventionalhearingthresholdsandat high frequencies. Braz J Otorhinolaryngol. 2014;80(4):296-304

MAIA, J. R. F.; RUSSO, I. C. P., Estudo da Audição de Músicos de Rock andRoll.Pró-Fono Revista de Atualização Científica, volume 20, número 1, janeiro / março de 2008. Disponível em: <http://www.scielo.br/scielo.php?pid=S010456872008000100009\&script=sci_arttext>. Acesso em: 28Ago.2008.

MAIA, A. A. et al. Análise do perfil audiológico dos músicos da orquestra sinfônica de Minas Gerais (OSMG). Per Musi, v.15. Belo Horizonte: UFMG, p.6771, 2007.

MARTINS, J. P. F. et al. Avaliação da perda auditiva induzida por ruído em músicos de Tubarão-SC. Arquivos Catarinenses de Medicina. Florianópolis, v.37, n.4, p.69-74, 2008.

MARTINS, J. P. F. et al. Avaliação da perda auditiva induzida por ruído em músicos de Tubarão-SC. Arquivos Catarinenses de Medicina. Florianópolis, v.37, n.4, p.69-74, 2008.

MATOS, M.P. et al. Ruído risco e prevenção. 3ํed. São Paulo: Ed Hucitec; 1999.

McBride D, Gill F, Proops D, Harrington M, Gardiner K, Attwell, C. 
Noiseandclassicalmusician. BMJ. 1992;305(6868):1561-3. Exposição profissional à música: revisão 69 RevSocBrasFonoaudiol. 2007;12(1):63-9

MEDEIROS, L.B.RUÍDO: EFEITOS EXTRA-AUDITIVOS NO CORPO HUMANO. MONOGRAFIA DE CONCLUSÃO DO CURSO DE ESPECIALIZAÇÃO EM AUDIOLOGIA CLÍNICA. Porto Alegre, RS

1999.

MENDES, M. H.; MORATA, T. C. Exposição profissional à música: uma revisão.RevSocBrasFonoaudiol. 2007;12(1):63-9

MENDES, M.H; KOEMLER, L.A, ASSENCIO- FERREIRA, V.J. A prevalência de perdaauditiva induzida pelo ruído em músicos de banda instrumental.VerCEFAC. 2002;4(3):179-85.

MENDES, M. H.; MORATA, T. C.; MARQUES, J. M. Aceitação de protetores auditivos pelos componentes de banda instrumental e vocal. Revista Brasileira de Otorrinolaringologia. São Paulo, vol.73, n 6, p. 785-92, 2007.

MENEGOTTO, I. H.; COSTA, M. J.In: Boéchat EM, Menezes. PD, Couto. CM, Frizzo. ACM, Scharlah. RC, Anastasio. ART,organizadores. Tratado de audiologia. 2 ed. São Paulo: Santos; 2015, p. 67-75.

MELO, B.C.; SANT'ANA, G. A prática da Metodologia Ativa. Com. Ciências Saúde. 2012; 23(4):327-339.

MINISTÉRIO DA SAÚDE. Perda auditiva induzida por ruído (PAIR). Brasília: Editora do Ministério da Saúde, 2006.

MITRE, E. I. Conhecimentos essenciais para entender bem a inter-relação otorrinolaringologia e fonoaudiologia. São José dos Campos: Pulso Editorial, 2003.

MITRE, S.M. et al.Metodologias ativas de ensino-aprendizagemna formação profissional em saúde: debates atuaisCiênc. saúde coletiva vol.13 suppl.2 Rio de Janeiro Dec. 2008.

MINISTÉRIO DA SAÚDE. Perda auditiva induzida por ruído (Pair). Brasília: Editora do Ministério da Saúde, 2006.

MIRANDA, C.R.; DIAS, C.R. Perda auditiva induzida pelo ruído em trabalhadores de banda e trios elétricos de Salvador/ Ba. Ver Bras Saúde Ocup, v. 25, n. 93/94, p. 99- 118, Dez- 1998.

MIRANDA, C. R.; DIAS, C. R., Perda Auditiva Induzida pelo Ruído em Trabalhadores de Banda e Trios Elétricos de Salvador / BA.Revista Brasileira de Otorrinolaringologia, setembro de 2008. Disponível em: $<$ http://audiolist.org/forum/kb.php?mode=article\&k=100>. Acesso em: 18Ago.2008.

MONTEIRO, V.M.; SAMELLI, A.G. Estudo da audição de ritmistas de uma escola de samba de São Paulo. Rev Soc Bras Fonoaudiol, v.15, n. 1, p.14-8, 2010.

MORATA, T.C. Young people: theirnoiseandmusicexossuresandtherisk of hearingloss.Int. J. Audiol. 2007; 46(3):111-2.

NAMUUR, F.A.B.M, FUKUDAY, ONISHI ET, TOLEDO RN. Avaliação auditiva em músicos da Orquestra Sinfônica Municipal de São Paulo.RevBrasOtorrinolaringol. 1999;65(5):390-5. 
NEVES, R. R. R. A importância que metalúrgicos e músicos atribuem à audição e sua preservação. São Paulo: Pontifícia Universidade Católica, 2007. Dissertação (Mestrado em Fonoaudiologia).

NIQUETTE, P. Hearingprotetion for musicans. Review mar. 2006.

ORGANIZAÇÃO MUNDIAL DA SAÚDE - OMS. Deficiência auditiva atinge $\mathbf{9 , 7}$ milhões de brasileiros. Março de 2012. Disponível em: $<$ http://www.winaudio.com.br/produtos-e-servicos/noticias-em-audiologia/3704-

deficiencia-auditiva-atinge-98-milhoes-de-brasileiros.html>. Acesso em: 10 Fev. 2014 ORGANIZAÇÃO MUNDIAL DA SAÚDE - OMS. Música alta pode levar um bilhão de jovens à surdez; saiba como se proteger. Março de 2015. Disponível em: http://g1.globo.com/ciencia-e-saude/noticia/2015/03/musica-alta-pode-levar-umbilhao-de-jovens-a-surdez-saiba-como-se-proteger.html. Acesso em: 07 Marc. 2015.

OLIVEIRA, L. F. A emergência do significado em música. Tese de Doutorado. Instituto de Artes, Universidade Estadual de Campinas, Campinas, 2010.

OLIVEIRA, JAA. Fisiologia clínica da audição - cóclea ativa. In: Nudelman AL (org.), Perda Auditiva Induzida pelo Ruído. Porto Alegre: Bagaggem, 1997, p. 101-142.

OWENS, D.T. SoundPressurelevelsexperiencedbythe high schoolbanddirector. MedProblPerform Art. 2004;19(3):109-15.

OLSEN, S.E. Psychologicalaspects os adolescentes' persptionsandhabits in noisyenvironments.2004. Tese (Doutorado) - Departamento de Psicologia, GöteborUniversity, Götebor.

OTUBO, K. A; LOPES, A. C; LAURIS, J.R. Uma análise do perfil audiológico de estudantes de música.Per musi no 27 Belo Horizonte Jan/ June2013;27:141-51.

PALÁCIOS, JOG; MARQUEZER,EC.Efeitos nocivos ao sistema auditivo provocado por escutas em aparelhos de sons portáteis e computadores em altos níveis de pressão sonora. Disponível em http://www.dcc.unesc.net/sulcomp/artigos/Workshop/21996.pdf. Acesso em 10/12/2006.

Perda auditiva atinge $16 \%$ da população. Abril/ 2013. Disponível em: $<$ http://www.cruzeirodosul.inf.br/materia/464243/perda-auditiva-atinge-16-dapopulacao>. Acesso em: 10Fev.2014.

PANELLI, M. Avaliação da audição em adolescentes expostos a música amplificada. Bauru;(Dissertação de Mestrado, Faculdade de Odontologia de Bauru, Universidade de São Paulo) 2014.

PANELLI, M. ; FERREIRA, N. S. ; SANTOS, A. A. et al. ASSOCIAÇÃO A EXPOSIÇÃO DE NÍVEIS DE PRESSÃO SONORA ELEVADO DE MÚSIÇA E A FUNÇÃO COCLEAR. In: 28 Encontro Internacional de Audiologia, 2013.Anais -, 2013. p. 65-65.

PALÁCIOS, J. O. G.; MARQUEZER, E. C., Efeitos nocivos ao sistema auditivo provocado por escutas em aparelhos de sons portáteis e computadores em altos níveis de pressão sonora. Disponível em <http://www.dcc.unesc.net/sulcomp/artigos/Workshop/21996.pdf>. Acesso em 10 Dez. 2006.

PALIN, S.L. Does classicalmusicdamagethehearing of musicians? A 
review of theliterature.OccupMed (Lond). 1994;44(3):130-6.

PEREIRA, E.F, et al. Percepção de qualidade do sono e da qualidade de vida de musicos de orquestra. RevPsiq Clín. 2010;37(2):48-51

PFEIFFER, M.; ROCHA, R. L.O.; OLIVEIRA, F. R.; FROTA, S. Intercorrência audiológica em músicos após um show de rock. Revista CEFAC, São Paulo, v.9, n.3, 417-22, jul-set, 2007.

PINTO, A. S. et al. O ruído urbano e a saúde auditiva. Lato \& Senso. Amazônia, v.3, n.5, p.90-93, 2002.

PIZZARRO, G.; PIZARRO, G.U. Diagnóstico clínico pela audiometria ocupacional. Acta AWHO. 2000; 19(1):32-8.

PROTETORES AUDITIVOS. Disponível em: http://www.audicare.com.br/audicareears/protetoresauditivos.aspx Acesso em: 06 de outubro 2014.

QUARANTA, A.; SALLUSTIO, V.; QUARANTA, N., 2001. Noiseinducedhearingloss: Summaryand perspectives. In: Noiseinducedhearingloss: basicmechanism, preventionandcontrol (Henderson, D., Prasher, D., Kopke, R., Salvi, R., \&Hamernik, R., eds.), pp. 539-557, London: NoiseResearch Network Publications.

RAYMOND, D. M.; ROMEO, J. H.; KUMKE, K. V. A. Pilotstudy of occupationalinjuryandillnessexperiencedbyclassicalmusicians. Workplace Health andSafety. United States, vol. 60, $\mathrm{n}^{\circ}$ 1, p. 19-24, 2012.

REGAZZI, R.D. Ruído no interior de casas noturnas. Rio de Janeiro, 1996; disponível em: <www.isegnet.com.br/colunistas/coluna_regazzi2.htm>. Acesso em: 20 Dez. 2007.

REQUIÃO, L. P. S. “Eis aí a Lapa...": processos e relações de trabalho do músico nas casas de shows da Lapa. 2008. Dissertação de Mestrado. Faculdade de Educação, Universidade Federal Fluminense. Niterói, 2008.

REQUIÃO, L. P.; RODRIGUES, J. Trabalho, economia e cultura no capitalismo: as novas relações de trabalho do músico no meio fonográfico. Revista Educação Skepsis. São Paulo, vol. 1, n², p. 321-96, 2011.

ROYSTER, L.H.; ROYSTER, J.D.; THOMAS, W.G. Representativehearinglevelsbyraceand sex in North Caroline industry.JournalAcoustSoc Am. 1980; 68: 551-66.

RUSSO, I. C. P., Santos, T. M. M., Busgaib , B. B., Osterne , F. J. V. Um estudo comparativo sobre os efeitos da exposição à música em músicos de trios elétricos. Revista Brasileira de Otorrinolaringologia. São Paulo, vol. 61, n 1, p. 477 84, 1995.

RUSSO, I.C.P. \& SANTOS, T.M.M. A prática de audiologia clínica. São

Paulo, Cortez, 1993. 253p.

SÁ, L. C. B et al.Avaliação dos limiares de audibilidade das altas frequências em indivíduos entre 18 e 29 anos sem queixas otológicas. Rev. Bras. Otorrinolaringol. 2007; 73:215-25. 
SAMELLI, A.G.; SCHOCHAT, E. (2000). Perda Auditiva Induzida por Nível de Pressão Sonora Elevado em um Grupo de Músico Profissionais de Rock-AndRoll. Acta Awho, 19 (3): p.136 143.

SANT'ANA, N.C. LOPES, A.C. Análise do nível de conhecimento de jovens sobre os riscos da música amplificada na saúde auditiva. In: $17^{\circ}$ Simpósio Internacional de Iniciação Cientifica da Universidade de São Paulo, 17., 2009, Ribeirão Preto. Anais. Sã Paulo: USP, 2009.

SANCHEZ, T. G. Quem disse que zumbido não tem cura?.São Paulo: H Máxima Produtora e Editora Gráfica;2007.

SANCHEZ, T. G. Grupo de Apoio a Portadores de Zumbido. Disponível em <http://www.cidadeverde.com/noticia.asp?ID=39522>. Acesso em: 07 Jan. 2007.

SANTONI, C. B. Músicos de pop-rock: efeitos da música amplificada e avaliação da satisfação no uso de protetores auditivos.2008. f. Dissertação (Mestrado em Fonoaudiologia) - Pontifícia Universidade Católica de São Paulo-PUC, São Paulo, 2008.

SANTONI, C.B.; FIORINI, A.C.Músicos de pop-rock: avaliação da satisfação com protetores auditivos. Braz J Otorhinolaryngol, v. 76, n. 4, p.454-461, 2010.

SANTUCCI, M. Musicians can protect their hearing. Med Problem Perform Art. 1990/ 5(4)? 136-8. ISO (1990). International Standard ISO 1999 second edition: Acoustics determination of noise exposure and estimation of noise-induced hearing impairment.

SANTOS, U. et al. Ruído: riscos e prevenção.São Paulo, Hucitec, 1996.

SANTOS, T. M. N.; RUSSO, I. C. P. A prática da audiologia clínica. 6. ed. São Paulo: Cortez, 2007.

SAMELLI, A. G.; SCHOCHAT, E. Perda auditiva induzida por nível de pressão sonora elevado em um grupo de músicos profissionais de rock androll. Acta Awho. São Paulo, v.19, n.3, p.136 -143, 2000.

SAMELLI, A. G.; SCHOCHAT, E. Perda auditiva induzida por nível de pressão sonora elevado em um grupo de músicos profissionais de rock androll. Acta Awho. São Paulo, v.19, n.3, p.136 -143, 2000.

SEARCHFIELD, G. D. ; JERRAM, C.; WISE, K. The impact of hearingloss on tinnitusseverity. The Australian and New Zealand J Audiol. v.29, n. 67-76, 2007.

SCHOCHAT, E.; RABELO, C.M; SANFINS, M. D. Processamento auditvo central: testes tonais de padrão de frequências e duração em indivíduos normais de 7 a 16 anos de idade. Pró Fono, v. 12, n. 2, p. 1-7, 2000.

SILVA, L. F. Ruído, ultra-som e infra-som.In: MENDES, R.Patologia do trabalho. 2. ed. Rio de Janeiro: Atheneu, 2003, p.517-550,

Estudo sobre a exposição combinada entre ruído e vibração de corpo inteiro e os efeitos na audição de trabalhadores.2002.[Tese] - Faculdade de Saúde Pública, Universidade de São Paulo, São Paulo-SP, 2002.

SOUZA, M.T.A reabilitação auditiva em motoristas de ônibus urbano, portadores de perda auditiva induzida por ruído (PAIR): proposta metodológica. 2002. f. [Tese de Doutorado ] - Faculdade de Saúde Pública, Universidade de São Paulo-USP, . São Paulo-SP, 2002. 
SOUZA, S.; BORGES, L. O. A profissão de músico conforme apresentada em Jornais Paraibanos. Psicologia \& Sociedade, v. 22, n.1, p. 157-168, 2010.

SUMERA, M.A. Avaliação audiológica, metabólica e de qualidade de vida no indivíduo jovem com zumbido usuário de estéreo pessoal. 2015. f. Dissertação (Mestrado em Fonoaudiologia ) -Faculdade de Filosofia e Ciências,Universidade Estadual Paulista "Júlio de Mesquita Filho"- UNESP, Marília-SP, 2015.

THOMAS, G. B.; WILLIAMS, C. E. ; HOGER, N. G. Some non Auditory correlates of thehearingthresholdlevels of anaviationnoise - exposedpopulation. Aviation, Space and Environmental Medicine, v. 52, n 9 , p. 531-536, 1981.

TOPPILA, E.; LAITINEN, H., Finnish institute of occupational health e KUISMA, K., Finnish National Opera. Hearing loss among classical music players. Podium 109. Helsinki, Finlândia. Risk assessment and management. P. 56-65.Disponível em: <http://www.aiha.org/abs04/ po109.htm>.

UGALDE , A. C. L. et al. Hipoacusia por ruído: um problema de salud y de conciencia pública.RevFac Med., v. 43, n. 2, p. 41-2, 2000.

VERBEEK, et al. Efeitos das intervenções para prevenção de perdas auditivas ocupacionais induzidas por ruído: uma revisão sistemática Cochrane.In: BOÉCHAT,E. M. et al. (Org.) Tratado de audiologia. 2. ed. São Paulo: Santos, 2015, p. 211-223.

VINSON, J.K. A proposed study: the hearing effects of playing in a high school marching band. Stephen F. Austin State University. 2004.

VOGUEL, I.; BRUG, J.; PLOEG, C.P.B.V., et al. Discothequesandtherisk of hearinglossamongyouth: riskylisteningbehaviorand its psychosocial correlates. Health educationresearch, v.25, p.737-747, 2010.

WADE, A. B. Musicians' HearingLoss: DefiningtheProblem e DesigningSolutions. 2010. Tese de Doutorado. UniversityCollege, UniversityHonorsProgram, Texas StateUniversity, San Marcos, 2010.

WARD, D. W. General auditory effects of noise.OtolaryngologicClinics of North America,v. 12, p. 473-492, 1979.

WEVER, E.G; LAWRENCE, M. Physiologicalacoustics. Princeton: Princeton University Press, 1954.

ZANOTTO, M; ROSE, T. Problematizar a Própria Realidade: análise de uma experiência de formação contínua. Revista de Educação e Pesquisa. v. 29, n. 1, p. 45-54, 2003.

ZOCOLI, A.M.F. MORATA, T.C . Adolescência, música e ruído ambiental. In: MORATA, T.C.; ZUCKI, F. Saúde auditiva: avaliação de riscos e prevenção. São Paulo: Plexus Editora, 2010. 
Anexos 
ANEXO 1

\section{FACULDADE DE ODONTOLOGIA DE BAURU- USP}

\section{PARECER CONSUBSTANCIADO DO CEP}

\section{DADOS DO PROJETO DE PESQUISA}

Título da Pesquisa: Decibel festival: a arte em ouvir

Pesquisador: Graziella Simeão Munhoz

Área Temática:

Versão:

CAAE: 30315914.7 .0000 .5417

Instituição Proponente: Universidade de Sao Paulo

Patrocinador Principal: Universidade de Sao Paulo

\section{DADOS DO PARECER}

Número do Parecer: 640.183

Data da Relatoria: 30/04/2014

Apresentação do Projeto:

A Pesquisa "Decibel festival: a arte em ouvir" de autoria de Graziella Simeão Munhoz sob a orientação do(a) Prof. ${ }^{\circledR}$ Dra. Andrea Cintra Lopes será conduzido pelo Departamento de Fonoaudiologia da Faculdade de Odontologia de Bauru, Universidade de São Paulo, Campus de

Bauru, após aprovação do Comitê de Ética em Pesquisa desta Faculdade.

O Decibel Festival é um festival de música de estilo pop e/ou rock,

proposto pelo Departamento de Fonoaudiologia da FOB/USP, nas dependências desta instituição.

$\mathrm{Na}$ quinta- feira, no período da manhã os participantes serão acolhidos e apresentados uns aos outros e aos profissionais que os orientarão durante o fim de semana, será proposta uma atividade de integração, que deverá ser definida posteriormente. Em seguida os integrantes serão distribuídos e encaminhados à Clínica de Fonoaudiologia da FOB/USP para avaliações específicas de audição.

a.) Avaliações audiológica dos integrantes das bandas:

b) Educação em saúde. Realizado por meio da entrega dos folders, esclarecimentos de dúvidas e Workshops:

Na sexta- feira e sábado no período da manhã serão realizados os workshops para as 10 bandas selecionadas, realizados nas dependências da

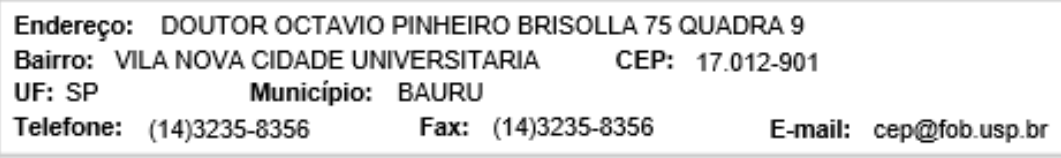




\section{FACULDADE DE ODONTOLOGIA DE BAURU- USP}

Continuação do Parecer: 640.183

Faculdade de Odontologia de Bauru. Estes workshops serão ministrados por engenheiros de som, fonoaudiólogos e músicos.

Os workshops objetivam a conscientização e o aperfeiçoamento dos

músicos participantes. $\mathrm{O}$ curso de Fonoaudiologia contribuirá com orientações e

esclarecimentos a respeito da saúde auditiva.

Nestes workshops os participantes serão divididos em grupos, menores

de, no máximo, 15 pessoas, sendo utilizadas metodologias ativas para abordar

conteúdos educacionais que tenham como objetivo tornar os participantes

conscientes sobre atitudes preventivas de distúrbios auditivos:

Preservação da Audição: serão abordados conteúdos a respeito da

perda auditiva induzida por niveis de pressão sonora elevados,

importância da realização de avaliações audiológicas de rotina,

importância do repouso auditivo durante 24 horas após exposição a

NPS elevados e utilizar equipamentos de proteção individual -

"protetores auditivos".

Para avaliação da efetividade dos workshops, serão aplicados questionários antes e depois dos workshops: o primeiro será para avaliar o que os músicos sabem sobre Fonoaudiologia, o que conhecem da profissão, como acreditam que este profissional trabalha, se fizeram algum acompanhamento fonoaudiológico, se conhecem sobre protetores auditivos, já o segundo, será

aplicado após as oficinas e tem o intuito de qualificar as informações expostas pelos instrutores de cada oficina, podendo observar no questionário, se houve mudança de comportamento em relação à Fonoaudiologia

\section{Objetivo da Pesquisa:}

Investigar a audição dos integrantes de músicos selecionados no Decibel

Festival.

\section{Avaliação dos Riscos e Benefícios:}

O que pode ocorrer é um pequeno desconforto, causado pela colocação dos fones e sondas dos equipamentos de avaliação auditiva, e/ou durante a realização dos exames.

Benefícios:

O conhecimento da sua condição de saúde auditiva e aprenderá a fazer o uso adequado da música amplificada (alta) e algumas medidas preventivas para reduzir a exposição ao ruído durante os ensaios musicais da banda.

Endereço: DOUTOR OCTAVIO PINHEIRO BRISOLLA 75 QUADRA 9

Bairro: VILA NOVA CIDADE UNIVERSITARIA CEP: $17.012-901$

UF: SP Municipio: BAURU

Telefone: (14)3235-8356 Fax: (14)3235-8356 E-mail: cep@fob.usp.br 


\section{FACULDADE DE ODONTOLOGIA DE BAURU- USP}

Continuaçâo do Parecer: 840.183

Comentários e Considerações sobre a Pesquisa:

Não há nenhum impedimento do ponto de vista ético para a realização da pesquisa

Consideraçōes sobre os Termos de apresentação obrigatória:

Os termos de apresentação obrigatório foram devidamente apresentados.

Recomendações:

Acrescentar no TCLE o item referente a indenização do participante da pesquisa

Conclusôes ou Pendências e Lista de Inadequações:

O parecer é favorável pela aprovação.

Situação do Parecer:

Aprovado

Necessita Apreciação da CONEP:

Não

Consideraçöes Finais a critério do CEP:

Esse projeto foi considerado APROVADO na reunião ordinária do CEP de 30.4.2014, de acordo com a Resolução CNS 466/12. Ao término da pesquisa o CEP-FOB/USP exige a apresentação de relatório final. Os relatórios parciais deverão estar de acordo com o cronograma e/ou parecer emitido pelo CEP. Alterações na metodologia, título, inclusão ou exclusão de autores, cronograma e quaisquer outras mudanças que sejam significativas deverão ser previamente comunicadas a este CEP sob risco de não aprovação do relatório final. Quando da apresentação deste, deverão ser incluídos todos os TCLEs e/ou termos de doação assinados e rubricados.

BAURU, 08 de Maio de 2014

Assinador por:

Izabel Regina Fischer Rubira Bullen

(Coordenador)

Endereço: DOUTOR OCTAVIO PINHEIRO BRISOLLA 75 QUADRA 9

Bairro: VILA NOVA CIDADE UNIVERSITARIA CEP: $17.012-901$

UF: SP Município: BAURU

Telefone: (14)3235-8356 Fax: (14)3235-8356 E-mail: cep@fob.usp.br 
ANEXO 2

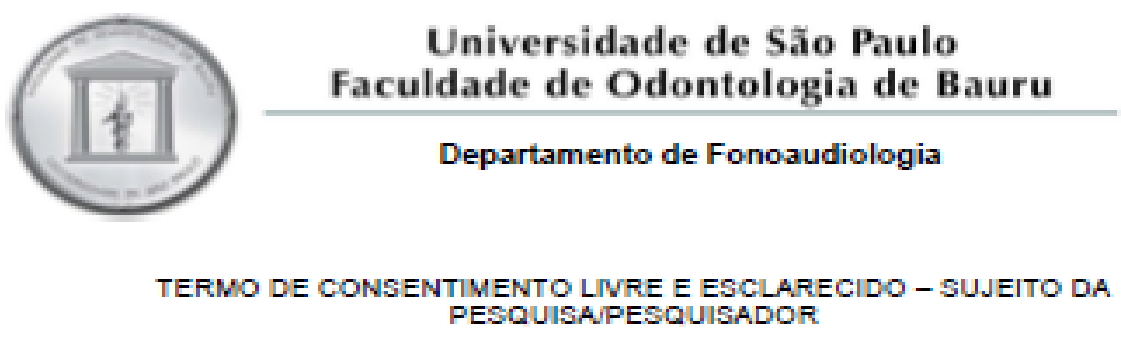

Queremos convidar voce a participar de um estudo que sera realizado com os integrantes das bandas musicals selecionadas para particlpar da pesquisa thulada "Proposta de Programa de Prevenç5̆o de Perdas Auditvas para Musicos" que conslste em submeter os músicos, componentes e bandas, ao programa de prevençalo de perdiss audituas (PPPA) e verifcar sua efettvidade. Iremos avallar a capacidade de ouvir, destes integrantes musicais que estälo expostos a elevadas Intensidades de ruido. Tambem Iremos entregar um questionario contendo cerca de 16 questodes mistas quanto a formato (dlscursivo e muitpla escoina) para conhecer sobre as caracteristicas da banda musical a que voce pertence.

Este estudo sera realzado na cirnica de Fonozudloiogia da Faculdade de Odontoioga de Bauru, atraves de aiguns testes de audiçálo, que conseguem detectar mesmo aterap̧es minimas. Os testes que serác usados sto os seguintes: - exame visual da parte Interna da orelna usando um equpamento delcado; exame das condlçöes internas da orelha usando fones auriculares - o participante năo precisa dar nenhuma resposta; - exame das condçbles de audiçäo, usando fones auriculares - o participante Ira Informar quando perceber o menor estimulo auditivo; - exame das condlobles de audiçăo, usando fones aunculares- o participante devera repetir as palavras Indicadas; - exame das condiçbes de parte do slstema audtlvo, usando fones aurtculares - o partipante nJ̆o precisa dar nenhuma resposta. Eles zjudam a diagnosticar a presença de aiteraçbes audituas. Os procedlmentos de avalaçấ serfa realizados em um únlco da, ou seja, em uma única vinda a Faculdade de fonoaudlologla, ja para o workshop terấo que vir em cutro da, ambos com horarto marcado, por mim, Grazlella Simeto Munhoz. fonoaudiologa e pesquisadora responsavel. A pesquisadora responsavel tambem ira ate o local de ensaio da banda para realzar a medida do nivel de pressăo sonora durante o ensalo, a qual tal procedimento de avallaçăo amblental sera previamente agendado com os componentes da banda.

Por $\mathrm{nm}$ voce participara de workshocs realzado pela pesquisadora que abordarăo sobre $\infty 6$ culdados a serem tomados com a saude auditiva e sobre a importancla do uso dos fones auriculares e o repouso auditva. Sera utilzada Inguagem simples para que a comunlcaç5o seja efetva, alem conter Imagens llustrativas e de facl compreensalo.

Se apos esses exames, encontramos alguma aiteraçăo em sua oreha, explicaremos o dagnostico audloioglco a voce, que sera encaminhado para a cilnica de audlologla da Unidade Basica de Saude. A Diretoria Regional de Saude (DRS), entăo encaminhara voce a clinica de fonoaudiologla para receber o tratamento, pago pelo SUS. Todos esses exames năo causam nenhum mal a sua saude e 06 riscos que voce podera correr, sấ $\propto 6$ mesmos que um paciente teria na mesma situaçăo, em que sua audlçăo fosse avallada $O$ que pode ocorrer e um pequeno descorforto, causado pela colocaç5o dos fones e sondas dos equlpamentos de avallaç5̆o auditiva, elou durante a realizaçấo dos exames. Ja os beneflcios, voce ficara conhecendo sua condiçăo de saude audtiva e aprendera a fazer o uso adequado da musica amplifcada (aita) e algumas medias preventivas para reduzir a exposiç5o ao ruido durante 06 ensalos musicals da banda. As infomaçbes que resultarem desse estudo serấo confindenclals e seu nome sera mantido em sigla Contudo, elas poderăo ser dvulgadas em discussấo com outros profissionals, ou alnda, usadas para lustrar apresentaçbes e publicaçbes clentincas. A pesquisadora assegura que voce tera o direlto a respostas de qualquer pergunta ou esciarecimento de qualquer dúvida soore as procedimentos e outros assurtos relacionados com o estudo, atraves de seu contato a Al. Octavio Pinheiro Brisola, 9-75 (Departamento de Fonoaudlologla, FOB/USP) pelo telefone (14) 3235-8232 ou pelo e-malt:

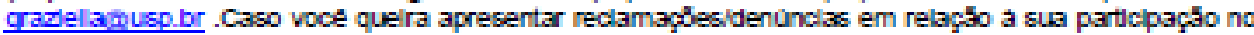
estudo, podera entrar em contato com o Comite de tetica em Pesquisa em Seres Humanos, da FOBUSP.

N. Dr. Octavio Pinheiro Brisolla, 9-75-Bouru-SP - CEP 17012-101- C.P. 73

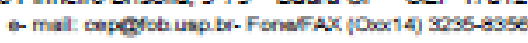
hollew flob usp b 


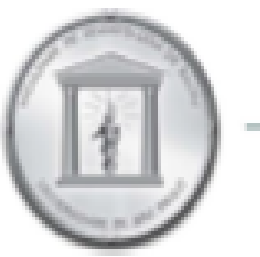

\section{Universidade de São Paulo Faculdade de Odontologia de Bauru}

Departamento de Fonoaudiologia

pelo mesmo endereço acima, na sala do predlo da Pos-Graduaç50, pelo telefone (14)3235-8356 ou pelo e-mall: cepagfob usp.br

\section{CONSENTIMENTO LIVRE:}

Pelo presente instrumento que atende as exigenclas legals, 0 Sr. (a) de Identdade __apos leltura minuclosa das Informaçbes constantes neste TEFMO DE CONSENTIMENTO UIVRE E ESCLARECIDO, devidamente explcada pelos profissionals en seus minimos detahes, dente dos serviços e procedmentos a0s quals serd submetido, năo restando qualsquer duvidas a respelto do lldo e explcado, fima seu CONSENTIMENTO LIVRE E ESCLARECIDO concordando em partclpar da pesqusa proposta. Flca claro que o sujelto da pesqulsa, pode a qualquer momento retirar seu CONSENTIMENTO LIVRE E ESCLARECIDO e delxar de participar desta pesqulsa e clente de que todas 36 informaçbes prestadas tornar-6e-ấ conflidenclais e guardadas por força de siglo profssional (Avt. 90 do Codlgo de ttica Odortoioglca, ou Art. $13^{\circ}$ do Codigo de Ética Fonoaudologico Inserir aqul o codgo de ttica do siglo profissional de sua protssto). Por fim, cono pesqulsador (a) responsaivel pela pesquisa, comprometo-me a cumprir todas as evigendas contidas no item IV.3 e IV.4 (se pertinente) da resoluçato do CNSIMS nْ 456 de dezembro de 2012, publcada em 13 de junho de 2013.

Por estammos de acordo com o presente termo o firmamos em duas vias (uma via para 0 sujelto da pesqulsa e outra para o pesquisador) que serb́o rubricadas em todas as suas paginas e assinadas ao seu temnino.

Bauru, SP, de de

Assinatura do Sujeto da Pesquisa

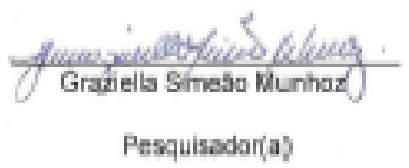

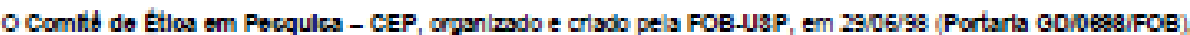
previsto no tem VII da Resoluçalo CNS $n^{\circ}$ 456/12 do Conseho Nacional de Saude do Mnisterio da Salde ipublicads

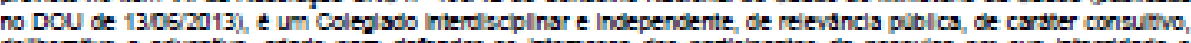
delberotvo e educatio, criado para detender os interezoes dos participantes da pesquisa em sua integridsde e

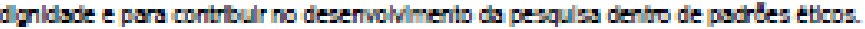

Qualquer denunda elou reciamaçlo sobre sua partcipaçbo na pesquisa podert ser reportada a este cep: Herdrie o loosal da tunolansmenter.

Comith de Étca em Feaculas

Faculdade de Codontalogis de Bsun-USP - Predlo da Pog-Gradusço (oloco E - pavimento superiori, de segunda a extaleira, no hordrio das 14 he as 17 horac, em diss uttes.

Nameda Dr. Octavio Pinheiro Brcolls, 9-75

Mla Untverattris - Bsiru - SP - CEP 17012-901

Teictone FNX[14]3235-8356

e-mal: cenolobuenter

A. Dr. Octavio Pinheiro Brisolla, 9-75 - Bauru-GP - CEP 17012-101 - C.P. 73

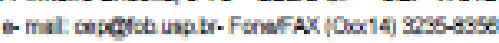

the lliter fob usp b 


\section{ANEXO 3}

QUESTIONÁRIO SOBRE A CARACTERÍSTICA DA BANDA MUSICAL

Data:

RG:

01. Identificação

Nome:

Data de nascimento:

Nome da banda:

02.Sua banda é composta por quantos integrantes?

( ) 2 ( ) 3 ( ) 4 ( ) 5 ( )6 ( ) 7 ( ) 8 ( ) 9 ( ) 10

03. Quantos integrantes da banda são alunos do ensino médio?

( )0 ( )1 ( ) 2 ( ) 3 ( ) 4 ( ) 5 ( ) 6 ( ) 7 ( ) 8 ( ) 9

( ) 10

04. Quem são os integrantes da banda e qual a idade de cada um? (Incluindo você).

$01-$

$02-$

03-

$04-$

$05-$

06-

$07-$

$08-$

09-

$10-$

05. Há quantos anos você trabalha com música? 
06. Há quanto tempo trabalham juntos na banda?

07. Quantas horas semanais vocês costumam ensaiar?

( ) até 1 hora ( ) até 5 horas ( ) até 10 horas ( ) até 15 horas

( ) até 20 horas ( ) até 25 horas ( ) até 30 horas ( ) até 35 horas

( ) até 40 horas ( ) mais de 40 horas.

08. Quantos shows costumam realizar por semana?

09. Onde costumam realizar os ensaios musicais?

( ) na residência de algum integrante (sem tratamento acústico)

( ) em estúdio

( ) ao ar livre

( ) outros:

10. Onde costumam fazer as apresentações?

( ) em lugares fechados

( ) em lugares fechados com acústica adequada

( ) em lugares ao ar livre

( ) outros:

11. Você tem queixa auditiva?

( ) não ( ) sim

Qual?

Quando? Antes da apresentação ( ) durante a apresentação ( ) após a apresentação ( )

12. Você tem queixa não auditiva após as apresentações?

( ) não ( ) sim 
O que sente? Por quanto tempo?

13. Você faz uso de Equipamento de Proteção Individual -EPI?

( ) sempre ( ) as vezes ( ) frequentemente ( ) nunca.

Qual?

14. Que instrumento cada integrante toca? (Incluindo você)

15. Há histórico de deficiência auditiva na família? ( ) não ( ) sim Por que?

16. Você trabalha apenas com música?

( ) $\operatorname{sim}($ )não O que faz? 


\section{ANEXO 4}

QUESTIONÁRIO MUDANÇA DE COMPORTAMENTO (Pré/ Pós oficina)

Nome:

Data de Nascimento:

Banda musical:

01.0 que você sabe sobre Fonoaudiologia?

02. Como você acredita que o Fonoaudiólogo trabalha com os profissionais da música?

03. Você já passou por algum acompanhamento Fonoaudiológico? Se sim, qual (is) e por que?

( ) não ( ) sim

04. O que você sabe sobre protetores auditivos?

05. Você faz uso de protetores auditivos? Se sim qual e por que? 
06. Após a oficina o que você aprendeu e irá tentar colocar em prática em sua vida diária? (Essa questão deverá ser respondida somente no questionário após a oficina).

07. Deixe aqui suas sugestões/ críticas:

08. Teve alguma importância para você ter participado da pesquisa?

( ) sim ( ) não

Por que? 
ANEXO 5

UNIVERSIDADE DE SAO PAULO FACULDADE DE ODONTOLOGIA DE BAURU

CLINICA DE FONOAUDIOLOOLA

FORMULÁRIO DE AVALCCAO AUDIOLOOICA EU MÚ3ICOS

PESQUISA DE MESTRADO GRAZIELLA \&. MUNHOZ

Nome: RG: \begin{tabular}{|l|l|l|l|l|}
\hline & & & & \\
\hline
\end{tabular}

Avallaç30 $n^{\circ} \sqcup$

Fonoaudlologo responsalvel (osshatura e canimbo)

Banda:

Data.

Audiometro:

AUDIOMETRIA

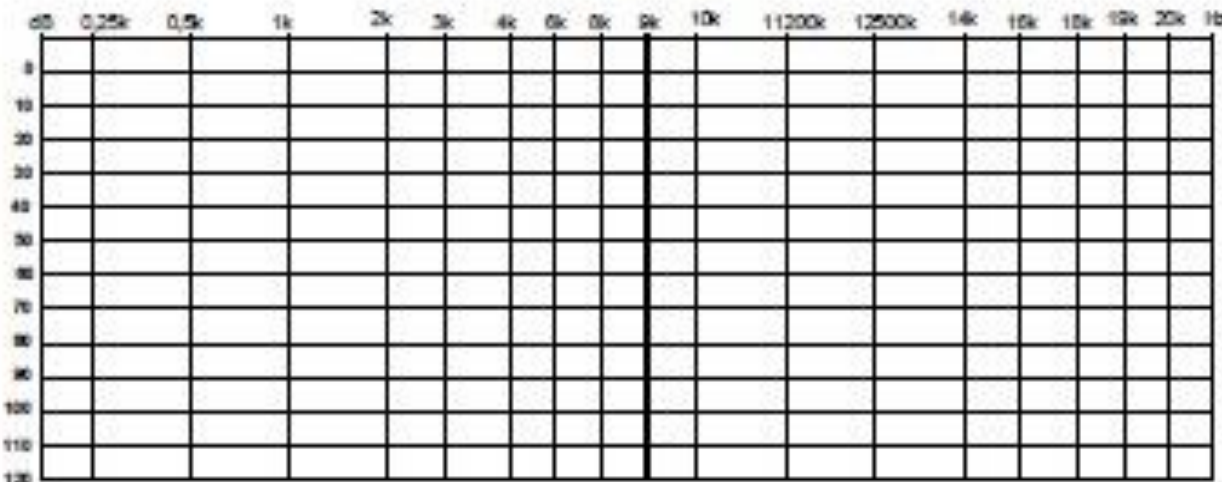

Oralha Direlta

Oretha Esquerda

Mascaramento: VA

v.O

Msecaramento: V.A

V.O

\section{LOGOAUDIOMETRIA}

\begin{tabular}{|c|c|c|}
\hline & Oreilha Direlta & Orelha Esquerda \\
\hline \multirow{5}{*}{ IRF } & $d B$ & $d B$ \\
\hline & $\%$ & $\%$ \\
\hline & $\%$ & $\%$ \\
\hline & $\%$ & Fig. \\
\hline & Masc. & Masc. \\
\hline & SRT _ _ dE & _da \\
\hline & Masc & Masc. \\
\hline & LDV ___ dE & LDV __ $d \theta$ \\
\hline & Masec & Masc. \\
\hline
\end{tabular}

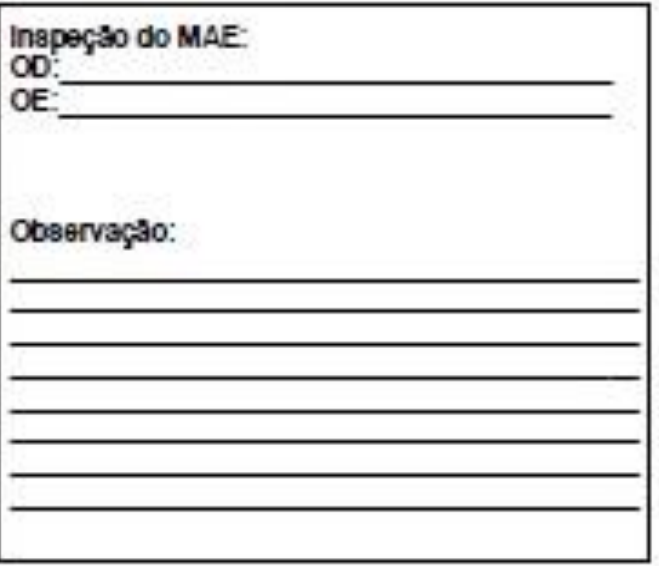


IMIT ANCIOMETRIA

Invtanciometro:

TIMPANOMETRIA

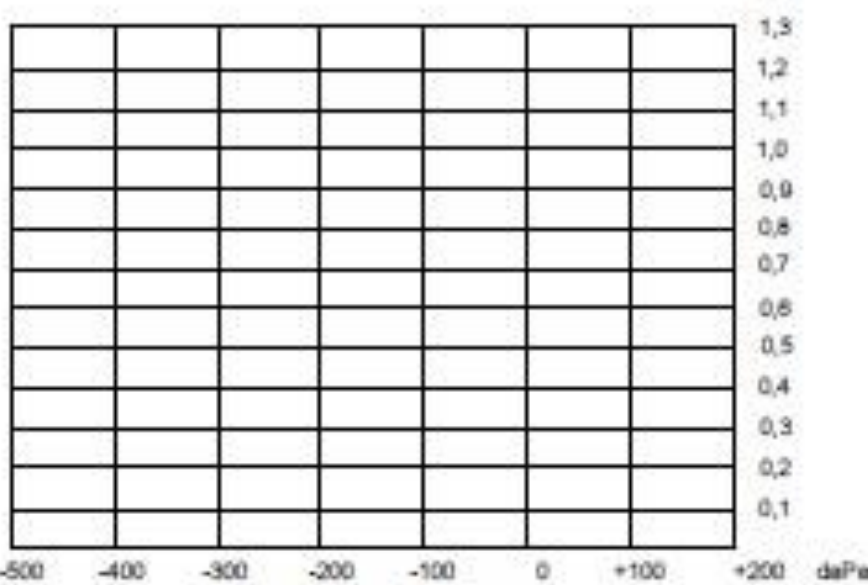

COMPLIANCIA ESTATICA

\begin{tabular}{|l|l|l|}
\hline & Oreha Direlta & Creha Esquerda \\
\hline Pressao da Orena Meda (dapa) & & \\
\hline Maxdmo de Rel axcmento $(\mathrm{m})$ & & \\
\hline +200dapa $(\mathrm{m})$ & & \\
\hline Volume equivalente da Oreha Meda $(\mathrm{m})$ & & \\
\hline
\end{tabular}

REFLEXO ESTAPEDIANO ACUSTICO

\begin{tabular}{|c|c|c|c|c|c|c|c|c|}
\hline \multirow{2}{*}{$\mathrm{Hz}$} & \multicolumn{3}{|c|}{ 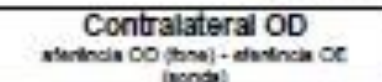 } & \multirow[t]{2}{*}{\begin{tabular}{|c|} 
TDT \\
OD
\end{tabular}} & \multicolumn{3}{|c|}{ 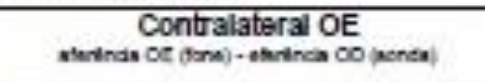 } & \multirow[t]{2}{*}{\begin{tabular}{|l} 
TDT \\
OE
\end{tabular}} \\
\hline & Lmar & Fetero & Drerença & & tumar & Rerexo & Drerença & \\
\hline 500 & & & & & & & & \\
\hline 7000 & & & & & & & & \\
\hline 2000 & & & & & & & & \\
\hline 4000 & & & & & & & & \\
\hline
\end{tabular}

REFLEXO IPSILATERAL

\begin{tabular}{|l|l|l|l|l|}
\hline & $500 \mathrm{~Hz}$ & $1000 \mathrm{~Hz}$ & $2000 \mathrm{~Hz}$ & $400 \mathrm{HHz}$ \\
\hline$O D$ & & & & \\
\hline$O E$ & & & & \\
\hline
\end{tabular}

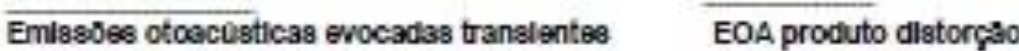

\begin{tabular}{|l|c|c|c|c|c|}
\hline \multicolumn{2}{|c|}{} & IKHZ & 2KHz & 3KHZZ & 4KHz \\
\hline \multirow{2}{*}{$O D$} & $\% / 2$ & & & & \\
\hline & $d B$ & & & & \\
\hline \multirow{2}{*}{$O E$} & $\% / 2$ & & & & \\
\hline & $d B$ & & & & \\
\hline
\end{tabular}

\begin{tabular}{|l|l|l|l|l|l|l|}
\hline \multicolumn{2}{|c|}{} & $1 \mathrm{KHz}$ & $2 \mathrm{KHz}$ & $3 \mathrm{KHZ}$ & $4 \mathrm{KHZ}$ & $6 \mathrm{KHZ}$ \\
\hline$O D$ & $d \mathrm{~B}$ & & & & & \\
\hline$O E$ & $d B$ & & & & & \\
\hline
\end{tabular}




\section{ANEXO 6}

\section{Carta de esclarecimento}

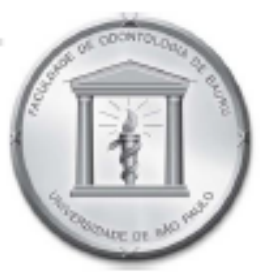

Universidade de São Paulo Faculdade de Odontologia de Bauru

Departamento de Fonoaudiologia

Bauru, 27 de Outubro de 2015.

Informamos ao Comitê de Ética em Pesquisa, que a partir das sugestões da banca de examinação, realizada durante o exame de qualificação, houve a modificação do título e objetivos do estudo, uma vez que o recurso financeiro disponível para o evento "Decibel Festival" não será mais disponibilizado pela Universidade.

Considerando que houve uma redução do custo do projeto em função da não liberação do recurso, este estudo irá submeter os músicos ao Programa de Prevenção de Perdas Auditivas (PPPA) e não mais realizar o festival.

Estamos à disposição a quaisquer outros esclarecimentos.

Att,
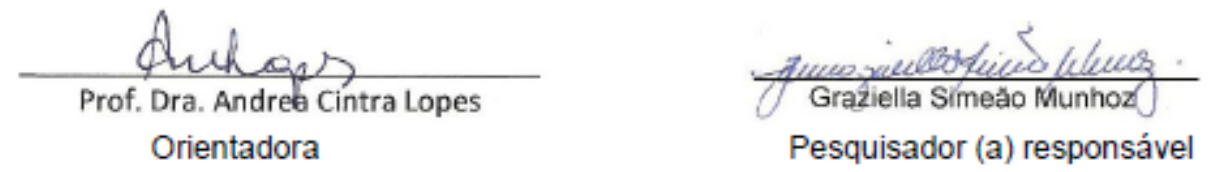